\title{
jpen
}

AUTARQUIA ASSOCIADA À UNIVERSIDADE DE SÃO PAULO

\section{INSTALAÇÃO E CARACTERIZAÇÃO BÁSICA DE UM LABORATÓRIO PARA TESTES DE MONITORES PORTÁTEIS COM RADIAÇÃO DE NÊUTRONS}

Tallyson Sarmento Alvarenga

Dissertação apresentada como parte dos requisitos para obtenção do Grau de Mestre em Ciências na Área de Tecnologia Nuclear - Aplicações

Orientadora:

Profa. Dra. Linda V. E. Caldas 


\title{
INSTITUTO DE PESQUISAS ENERGÉTICAS E NUCLEARES
}

Autarquia associada à Universidade de São Paulo

\section{INSTALAÇÃO E CARACTERIZAÇÃO BÁSICA DE UM LABORATÓRIO PARA TESTES DE MONITORES PORTÁTEIS COM RADIAÇÃO DE NÊUTRONS}

\author{
TALLYSON SARMENTO ALVARENGA
}

\author{
Dissertação apresentada como parte dos \\ requisitos para obtenção do Grau de \\ Mestre em Ciências na Área de Tecnologia \\ Nuclear - Aplicações \\ Orientadora: \\ Profa. Dra. Linda V. E. Caldas
}

Versão Corrigida

Versão Original disponível no IPEN

São Paulo

2014 
A Deus, aos meus pais, ao meu irmão e à minha noiva Layane, com carinho e amor. 


\section{AGRADECIMENTOS}

Em primeiro lugar queria agradecer a Deus por sua infinita bondade e misericórdia e por me conceder a graça de finalizar esse trabalho, tornando o impossível possível.

Aos meus pais, Ruyterbram e Cústodia, pelo amor incondicional, pelo apoio, por me terem dado educação, valores e por muitas vezes renunciaram aos seus sonhos para que eu pudesse realizar o meu. Obrigado por nunca terem desistido de mim.

Ao meu irmão, Francisco (Kiko), que sempre se fez presente na minha vida me apoiando e se dedicando ao máximo para o bem-estar da família. Obrigado pela amizade.

À minha noiva, Layane Karla, por ser tão importante na minha vida, sempre me apoiando e me fazendo acreditar que tudo é possível e por compreender a minha ausência durante a realização desse trabalho. Obrigado pelo seu amor.

Agradeço à minha orientadora Dra. Linda V. E. Caldas, pela dedicação, compreensão, pela confiança, e principalmente pela paciência, que resultaram na concretização desse trabalho. Sou grato pela amizade, pela preocupação, por todo carinho e pelos valiosos conselhos. Com ela adquiri muito mais do que conhecimentos acadêmicos, aprendi a cultivar a generosidade e a humildade. Obrigado pelo privilégio de fazer parte de um seleto grupo no qual tive a oportunidade de conviver e aprender com uma pessoa tão especial.

Aos meus tios e tias, especialmente tia Socorro, tia Sibelia, tia Rita e a tia Elba, obrigado pela acolhida e receptividade, pelo carinho e pelo apoio que foram fundamentais para tornar os meus dias em São Paulo tão agradáveis.

Aos meus primos e primas, especialmente Camila, Nágila, Jordelly e Sofia, obrigado por todo amor e carinho.

À minha querida sobrinha, Maria Eduarda. Obrigado pelo carinho.

Ao MSc. Matias Puga Sanches, pelas opiniões, ajuda e pelos conhecimentos compartilhados que foram fundamentais na concretização deste trabalho. 
Ao Eng. Wagner Nieto, muito obrigado pela dedicação e colaboração na elaboração dos projetos que foram importantes para conclusão deste trabalho.

Ao Dr. Claudio Federico, que sempre teve boa vontade em ajudar a sanar as dúvidas que tive durante o trabalho.

Ao Laboratório de Metrologia de Nêutrons do IRD por ter calibrado os detectores usados como referência neste trabalho, e aos seus pesquisadores Dra. Karla Patrão, Dr. Walsan Wagner e Dr. Evaldo Fonseca, obrigado pelo apoio.

Ao Dr. Jair Mengatti, pelo apoio financeiro e pela boa vontade de ajudar.

Ao Dr. Lucio Pereira Neves e à Dra. Ana Paula Perini, que me ajudaram na simulação de Monte Carlo com código MCNP5, pela amizade, apoio e pelas palavras de incentivo.

À Dra. Patrícia de Lara Antonio, ao MSc. Mateus Hilário de Lima, à MSc. Isabela Mattos e ao MSc. Felipe Cintra, que sempre estiveram dispostos a me ajudar esclarecendo dúvidas e pelas conversas agradáveis e por muitos momentos de descontração. Obrigado pela amizade.

Ao Dr. Tufic Madi, pelas orientações em relação à instrumentação, amizade e apoio. Seus ensinamentos e conselhos foram importantes na concretização deste trabalho.

À Dra. Maria da Penha Albuquerque Potiens e ao Dr. Vitor Vivolo, por sugestões importantes ao trabalho.

Ao meu amigo Kelvin Oliveira, pela amizade e por se dispor a me ajudar a chegar ao IPEN.

À empresa MPE, pela colaboração na instalação da parte elétrica do laboratório.

Aos amigos e colegas do IPEN, MSc. Fernanda Nonato, Dra. Maíra Yoshizumi, MSc. Daniella Groppo, MSc. Eduardo Corrêa, Dr. Gustavo Villa, Bel. Cristiane Honda, MSc. Lucas Rodrigues, Bel. Willian Damatto, Dr. Jonas Silva, Lic. Natalia Fiorini da Silva e Bel. Maysa Costa de Castro.

Ao Sr. Claudinei Cescon e ao Sr. Marcos Xavier, pelas importantes sugestões 
oferecidas, que foram importantes para concretização deste trabalho.

À Sra. Donata Zanin, porque esteve sempre disposta a me ajudar, principalmente nas questões burocráticas que surgiram no decorrer desse trabalho.

Ao Instituto de Pesquisas Energéticas e Nucleares, Comissão Nacional de Energia Nuclear, pela infraestrutura oferecida e pela oportunidade de desenvolver este trabalho.

Agradeço à CAPES (Coordenação de Aperfeiçoamento de Pessoal de Nível Superior) pela concessão da bolsa durante todo o período de realização deste projeto de Mestrado.

À Fundação de Apoio à Pesquisa do Estado de São Paulo e ao Conselho Nacional de Desenvolvimento Científico e Tecnológico, no Projeto INCT em Metrologia das Radiações na Medicina, pelos auxílios a viagens para participação de congressos científicos.

Ao Instituto de Física, Universidade de São Paulo, pelo empréstimo do material necessário para o projeto.

A todos os irmãos da Assembleia de Deus Butantã, pelo amor, preocupação e cuidado, principalmente à Sra. Maria Bezerra, que me acolheu em sua casa com todo o carinho. 


\section{EPÍGRAFE}

"Porque o Senhor dá a sabedoria; da sua boca é que vem o conhecimento e o entendimento".

Provérbios 2:6 


\section{Instalação e caracterização básica de um laboratório para testes de monitores portáteis com radiação de nêutrons}

\section{Tallyson Sarmento Alvarenga}

\section{RESUMO}

Foi realizada a implantação de um laboratório para testes de detectores com radiação de nêutrons. Uma sala foi reformada e adaptada para ser o Laboratório de Testes com Nêutrons (LTN) no subsolo do prédio do Laboratório de Calibração de Instrumentos do IPEN. Foi criada uma sala de controle do sistema de exposição e posicionamento da fonte e para o operador responsável pelos procedimentos de testes dos instrumentos. Foi desenvolvida uma blindagem adequada para a fonte de ${ }^{241} \mathrm{Am}(\mathrm{Be})$, previamente calibrada no Laboratório Nacional de Metrologia das Radiações Ionizantes (LNMRI), num sistema padrão primário. Um arranjo de irradiação automatizado foi implantado, possibilitando a variação da distância fonte-detector por meio de um comando à distância por um painel eletrônico localizado na sala de controle. Os resultados obtidos do levantamento radiométrico permitiram avaliar as condições existentes no LTN e a sua classificação. Foi realizado um estudo de estabilidade a curto e a médio prazo da resposta de vários detectores de nêutrons, que apresentaram resultados dentro do limite recomendado pela norma internacional. A influência da radiação espalhada foi determinada por duas técnicas: Método de Monte Carlo e método experimental, com a utilização de um cone de sombra e um detector de radiação de nêutrons portátil calibrado no LNMRI. Alguns monitores portáteis foram testados no arranjo estabelecido. Dos resultados obtidos por meio da simulação foi possível concluir que a estrutura do LTN está em concordância com os resultados obtidos em outros laboratórios que oferecem o mesmo serviço. 


\title{
Installation and basic characterization of a laboratory for testing of portable monitors with neutron radiation
}

\section{Tallyson Sarmento Alvarenga}

\begin{abstract}
A laboratory for testing of detectors with neutron radiation was established. A room was renovated and adapted for the Testing Laboratory with Neutrons (LTN). A control room was created for the exposure and positioning of the source system and for localization of the operator responsible for the testing procedures of the instruments. An adequate shielding was developed for the ${ }^{241} \mathrm{Am}(\mathrm{Be})$ source, previously calibrated at the National Metrology Laboratory of lonizing Radiation (LNMRI), using a primary standard system. The set-up of the automated irradiation was established for the variation of the source-detector distance through a remote control by an electronic panel located in the control room. A radiometric survey was undertaken to evaluate the conditions at LTN and its classification. A study of the short and medium-term stability of the response of various detectors was realized, and the results were within the international recommended limits. The influence of the scattered radiation was determined by two techniques: Monte Carlo method and experimentally using a shadow cone and a portable radiation detector calibrated at LNMRI. Some portable monitors were tested at the established set-up. From the results obtained through the simulation, it was shown that the LTN structure is in agreement with the results obtained in other laboratories that offer the same service.
\end{abstract}




\section{Sumário}

Lista de Figuras $\quad$ xi

Lista de Tabelas $\quad$ xvi

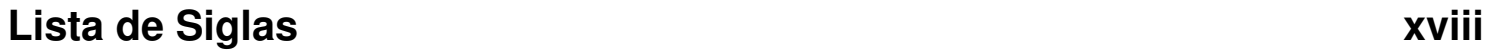

1 Introdução 1

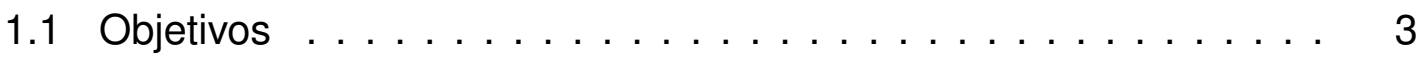

2 Fundamentos Teóricos 4

2.1 Os nêutrons . . . . . . . . . . . . . . . . . . . . . 4

2.2 Fontes de nêutrons $\ldots \ldots \ldots \ldots \ldots$

2.3 Interação dos nêutrons com a matéria . . . . . . . . . . . . . 7

2.4 Sistema de detecção de nêutrons . . . . . . . . . . . . . . . 8

2.4.1 Detectores semicondutores . . . . . . . . . . . . 8

2.4.2 Detectores proporcionais a gás . . . . . . . . . . . 9

2.4.3 Detectores auto-alimentados . . . . . . . . . . . . . 9

2.4 .4 Detectores cintiladores . . . . . . . . . . . . . 10

2.5 Grandezas e unidades . . . . . . . . . . . . . . . . . . . . . . 10

2.5.1 Grandezas físicas . . . . . . . . . . . . . . . . . . . 11

2.5 .2 Grandezas operacionais . . . . . . . . . . . . . . . . . . . 12

2.5.3 Grandezas de radioproteção . . . . . . . . . . . . . . . . . . 15

2.6 Métodos de avaliação da radiação espalhada de nêutrons . . . . . 16

2.6.1 Método semi-empírico . . . . . . . . . . . . . . . . 17 
2.6.2 Método do ajuste polinomial . . . . . . . . . . . . . 17

2.6.3 Método do cone de sombra . . . . . . . . . . . . . . 18

2.7 Método de Monte Carlo . . . . . . . . . . . . . . . . . . . . . . . . . 19

2.8 Calibração de detectores de radiação . . . . . . . . . . . . . . . . . 20

2.9 Testes de estabilidade $\ldots \ldots \ldots \ldots$. . . . . . . . . . . . . 21

3 Materiais e Métodos 23

3.1 Sistema de radiação de nêutrons . . . . . . . . . . . . . . . . 23

3.2 Material para confecção da blindagem da fonte de nêutrons . . . . 24

3.3 Cone de sombra . . . . . . . . . . . . . . . . . . . . . . . 24

3.4 Detectores de radiação de nêutrons . . . . . . . . . . . . . . . . . 25

3.4.1 Detectores de radiação de nêutrons, marca Camberra, modelo Dineutron, séries 133, 292, 293, 294 e 361 . . . . 25

3.4.2 Detectores de radiação de nêutrons, marca Ludlum, modelo 12-4, séries 227914 e 305363 . . . . . . . . . . . 25

3.4.3 Detectores de radiação de nêutrons, marca Ludlum, modelo $2241-4$, séries 274063 e $274064 \ldots \ldots$

3.4.4 Detectores de radiação de nêutrons, marca Thermo, modelo ASP-2, séries 02514 e $02517 \ldots$. . . . . . . 26

3.4.5 Monitor de radiação gama Geiger - Müller, marca Automess, modelo 6150 AD5, série 10739 . . . . . . . . . 27

3.4.6 Monitor de radiação de nêutrons e gama Identifinder, marca Thermo Scientific, modelo NGH, série 3574-468 . . . . . . . 28

3.5 Código de simulação Monte Carlo . . . . . . . . . . . . . . . . . . . . 29

4 Resultados e Discussão $\quad 30$

4.1 Adequação e reforma do Laboratório de Testes com Nêutrons . . . 30

4.2 Blindagem para a fonte de nêutrons . . . . . . . . . . . . . 33

4.3 Arranjo de irradiação . . . . . . . . . . . . . . . . . . . . . 35

4.4 Sistema de posicionamento da fonte de nêutrons . . . . . . . . . . 37 
4.5 Sistema de monitoração da medição e da distância fonte-detector 39

4.6 Construção do suporte para o cone de sombra . . . . . . . . . . . . 40

4.7 Levantamento radiométrico . . . . . . . . . . . . . . . . . . . 42

4.8 Determinação de parâmetros do LTN utilizando simulação de Monte Carlo . . . . . . . . . . . . . . . . . . . . . . . . . . . . . . . . . 44

4.8.1 Avaliação das doses de radiação em pontos específicos do

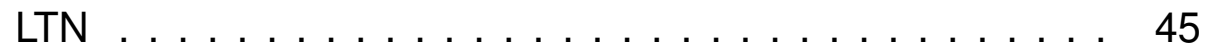

4.8.2 Avaliação da radiação espalhada nos pontos utilizados para testes de instrumentos . . . . . . . . . . . . . 48

4.9 Determinação preliminar da radiação espalhada com o método de cone de sombra . . . . . . . . . . . . . . . . 51

4.10 Estudo da estabilidade a curto prazo da resposta dos detectores . 53

4.11 Estudo da estabilidade a médio prazo da resposta dos detectores 64

4.12 Mapeamento do campo de radiação . . . . . . . . . . . . . . . . . 67

4.13 Testes dos detectores de radiação de nêutrons . . . . . . . . . . . . 75

5 Conclusões $\quad 77$

$\begin{array}{ll}\text { Referências Bibliográficas } & 79\end{array}$ 


\section{Lista de Figuras}

2.1 Esquema do cone de sombra (KHABAZ e HAKIMABAD, 2011). . 18

2.2 Método de calibração por substituição (IAEA, 2000). . . . . . . 20

2.3 Método de calibração para campos conhecidos (IAEA, 2000). . . 21

3.1 Dimensões da fonte de nêutrons de ${ }^{241} \mathrm{Am}(\mathrm{Be})$ do LTN (AMERSHAM, 1986) . . . . . . . . . . . . . . . . . . 24

3.2 Cone de sombra utilizado neste trabalho. . . . . . . . . . . . . 24

3.3 Monitor de área Camberra, modelo Dineutron. . . . . . . . . . . 25

3.4 Monitor de área Ludlum, modelo 12-4. . . . . . . . . . . . . 26

3.5 Monitor de área Ludlum, modelo $2241-4 \ldots \ldots \ldots \ldots$. . . . 26

3.6 Monitor de área Thermo, modelo ASP-2 . . . . . . . . . . . . 27

3.7 Monitor de radiação gama Geiger-Müller, marca Automess, modelo 6150 AD5 . . . . . . . . . . . . . . . . . . . 28

3.8 Monitor de área nêutron-gama Identifinder NGH. . . . . . . . 28

4.1 Planta baixa do Bunker do LCl. A área destacada em vermelho é o Laboratório de Testes com Nêutrons. . . . . . . . . . . . . . . 31

4.2 Planta baixa do Laboratório de Testes com Nêutrons. . . . . . . . 31

4.3 Laboratório de testes. . . . . . . . . . . . . . . . . . 32

4.4 Sala de controle. . . . . . . . . . . . . . . . 33

4.5 Fixação do tubo guia (a); Acomodação dos blocos (b); Derretimento da parafina (c); Preenchimento do tambor com parafina liquida (d); Bloco único de parafina (e). . . . . . . . . . 35 
4.6 Configuração final do arranjo de irradiação do LTN. . . . . . . . . . 36

4.7 Visão frontal do arranjo de irradiação do LTN. . . . . . . . . . . . . . 37

4.8 Visão lateral do arranjo de irradiação do LTN. . . . . . . . . . . . . . 37

4.9 Configuração do sistema de posicionamento da fonte do LTN. . . . 38

4.10 Sistema de posicionamento da fonte no LTN. . . . . . . . . . . . . 38

4.11 Manivela de acionamento para exposição da fonte de ${ }^{241} \mathrm{Am}(\mathrm{Be})$, localizada na sala de controle. . . . . . . . . . . . . . 39

4.12 Sistema de monitoração das leituras dos detectores, com destaque para a câmera de vídeo. . . . . . . . . . . . . . . . . . 40

4.13 Sistema de monitoração das distâncias fonte - detector, com destaque para a câmera de vídeo. . . . . . . . . . . . . . . . . . 40

4.14 Projeto com a utilização do software Solid Edge do suporte para o cone de sombra. . . . . . . . . . . . . . . . . . . . . . . 41

4.15 Suporte final para o cone de sombra. . . . . . . . . . . . . . . . . 41

4.16 Planta baixa do LTN, identificando os pontos de medição onde foi realizado o levantamento radiométrico. O ponto de medição D está localizado na parte superior da blindagem da fonte, e não pode ser visto na figura.

4.17 Geometria do LTN utilizada na simulação com o código de Monte Carlo MCNP5. Os pontos de medição são mostrados na figura: 1 a 6 .

4.18 Corte lateral da geometria do LTN utilizada na simulação com o código de Monte Carlo MCNP5.

4.19 Corte axial da geometria do LTN utilizado na simulação com o código de Monte Carlo MCNP5.

4.20 Geometria do LTN utilizada na simulação com o código de Monte Carlo MCNP5. Os oitos pontos de medição são mostrados na figura. 49 
4.21 Influência da radiação espalhada na resposta do detector Thermo, modelo ASP-2 (02514). (ロ) Medições sem o cone de sombra e (•) medições com o cone de sombra com subtração das medições sem o cone de sombra.

4.22 Resposta do detector de nêutrons Thermo ASP-2 (02514) em função da distância fonte - detector

4.23 Resposta do detector de nêutrons Thermo ASP-2 (02517) em função da distância fonte - detector.

4.24 Resposta do detector de nêutrons Ludlum 2241-4 (274063) em função da distância fonte - detector. . . . . . . . . . . . . . . . . . 59

4.25 Resposta do detector de nêutrons Ludlum 2241-4 (270465) em função da distância fonte - detector.

4.26 Resposta do detector de nêutrons Ludlum 12-4 (227914) em função da distância fonte - detector. . . . . . . . . . . . . . . .

4.27 Resposta do detector de nêutrons Ludlum 12-4 (305363) em função da distância fonte - detector. A incerteza máxima foi de 0,7\%, não visível na curva.

4.28 Resposta do detector de nêutrons Camberra Dineutron (361) em função da distância fonte - detector. . . . . . . . . . . . . . . . . .

4.29 Resposta do detector de nêutrons Camberra Dineutron (292) em função da distância fonte - detector. . . . . . . . . . . . . . . . . 62

4.30 Resposta do detector de nêutrons Camberra Dineutron (293) em função da distância fonte - detector.

4.31 Resposta do detector de nêutrons Camberra Dineutron (133) em função da distância fonte - detector.

4.32 Resposta do detector nêutrons-gama Thermo Identifinder (3574-468) em função da distância fonte - detector. A incerteza máxima foi de $1,6 \%$, não visível na curva. . . . . . . . . . . . 63 
4.34 Reprodutibilidade da resposta do detector Thermo ASP-2 (02517). 65

4.35 Reprodutibilidade da resposta do detector Ludlum 2241-4 (270463). 65

4.36 Reprodutibilidade da resposta do detector Ludlum 2241-4 (270465). 66

4.37 Reprodutibilidade da resposta do detector Cambera Dineutron (294). 66

4.38 Resposta do detector Camberra Dineutron (133) em função da distância fonte-detector. A incerteza máxima foi de 5,0\%, não visível na curva. . . . . . . . . . . . . . . . . . . 68

4.39 Resposta do detector Camberra Dineutron (294) em função da distância fonte-detector. . . . . . . . . . . . . . . . 68

4.40 Resposta do detector Camberra Dineutron (361) em função da distância fonte-detector. A incerteza máxima foi de 2,8\%, não visível na curva.

4.41 Resposta do detector Ludlum12-4(305363) em função da distância fonte-detector. A incerteza máxima foi de 7,8\%, não visível na curva. 69

4.42 Resposta do detector Ludlum12-4 (227914) em função da distância fonte-detector. A incerteza máxima foi de 7,8\%, não visível na curva. . . . . . . . . . . . . . . . . . . . . 70

4.43 Resposta do detector Camberra Ludlum 2241-4 (214063) em função da distância fonte-detector. A incerteza máxima foi de 3,5\%, não visível na curva.

4.44 Resposta do detector Camberra Ludlum 2241-4 (214065) em função da distância fonte-detector. A incerteza máxima foi de 3,2\%, não visível na curva.

4.45 Resposta do detector Thermo Identifinder (3574-468) em função da distância fonte-detector. A incerteza máxima foi de $0,5 \%$, não visível na curva.

4.46 Mapeamento do campo de radiação com o detector de referência Thermo ASP-2( 02514). 
4.47 Mapeamento do campo de radiação com o detector de referência Thermo ASP-2 (02517). . . . . . . . . . . . . . . . . . . . . 72

4.48 Mapeamento do campo de radiação de nêutrons, utilizando os dois sistemas de referência Thermo ASP-2 (02514) e (02517). . . . . . 74 


\section{Lista de Tabelas}

2.1 Propriedades das principais fontes ( $\alpha, n)$ (ZAMBONI, 2007). E $\alpha$ é a energia da radiação alfa. . . . . . . . . . . . . 6

2.2 Propriedades das principais fontes ( $\gamma$,n) (ZAMBONI, 2007). E $\gamma$ é a energia da radiação gama. . . . . . . . . . . . 6

2.3 Reações utilizadas para produção de nêutrons monoenergéticos. Q é o fator de intensidade da emissão de nêutrons (TURNER, 2007). 7

2.4 Valores do coeficiente de conversão da fluência de nêutrons para equivalente de dose ambiente dos nêutrons $h(E)$ (ICRP, 1996). . . 14

2.5 Fatores de ponderação da radiação para os diversos tipos de radiação e energias recomendadas pela ICRP 60 (ICRP, 2007). . . 15

2.6 Fatores de ponderação para diversos tipos de órgãos e tecidos recomendados pela ICRP 60 (ICRP, 1991). . . . . . . . . 16

4.1 Propriedades dos materiais moderadores (NCRP, 1971) . . . . . 33

4.2 Níveis de radiação do LTN em 16/07/2013, com a fonte de ${ }^{241} \mathrm{Am}(\mathrm{Be})$ na blindagem e exposta. . . . . . . . . . . . 43

4.3 Taxas de equivalente de dose $\dot{H}^{*}(10)$, simulados (para nêutrons) obtidos em diversos pontos no LTN. . . . . . . . . . . . . . 47

4.4 Influência da radiação espalhada na determinação da $\dot{H}^{\star}(10)$ e do fluxo de nêutrons nos oito Pontos de medição. . . . . . . . . . 50

4.5 Influência da radiação espalhada nas leituras do detector nos cinco pontos de medição. . . . . . . . . . . . . . . . . . 52 
4.6 Estabilidade a curto prazo dos detectores de nêutrons a $50 \mathrm{~cm}$ de distância em relação à fonte. . . . . . . . . . . . . . . . . . . . 55

4.7 Estabilidade a curto prazo dos detectores de nêutrons a $75 \mathrm{~cm}$ de distância em relação à fonte. . . . . . . . . . . . . . . . . . 56

4.8 Estabilidade a curto prazo dos detectores de nêutrons a $100 \mathrm{~cm}$ de distância em relação à fonte. . . . . . . . . . . . . . . . . . . . 57

4.9 Coeficientes de correlação obtidos das curvas de resposta dos detectores de nêutrons em função da distância fonte-detector. . . . 73

4.10 Mapeamento do campo de radiação utilizando os detectores de referência Thermo ASP-2. . . . . . . . . . . . . . . . . . . . . . 74

4.11 Condições de testes dos detectores de radiação de nêutrons. . . . 75

4.12 Testes dos detectores de nêutrons. . . . . . . . . . . . . . . . 76 


\title{
Lista de Siglas
}

\author{
ALARA As Low As Reasonably Achievable \\ BNCT Terapia de captura de nêutrons por boro \\ CNEN Comissão Nacional de Energia Nuclear \\ GMR Gerência de Metrologia das Radiações \\ IPEN Instituto de Pesquisas Energéticas e Nucleares \\ IRD Instituto de Radioproteção e Dosimetria \\ ISO International Organization for Standardization
}

ICRU International Commission on Radiation Units and Measurements

ICRP International Commission on Radiation Protection

IAEA International Atomic Energy Agency

LNMRI Laboratório Nacional de Metrologia das Radiações lonizantes

LCI Laboratório de Calibração de Instrumentos

LTN Laboratório de Testes com Nêutrons

MMC Método de Monte Carlo

MCNP Código de Monte Carlo N-Particle

VIM Vocabulário Internacional de Metrologia 


\section{Capítulo 1}

\section{Introdução}

Em virtude da neutralidade de sua carga, os nêutrons são partículas indiretamente ionizantes que podem ser produzidos naturalmente na atmosfera, neste caso chamados raios cósmicos, e também podem ser produzidos por fissão espontânea, em aceleradores de partículas, em reatores nucleares e no reprocessamento de combustíveis nucleares (BAILEY, 2000). As fontes de radiação de nêutrons são utilizadas em três áreas: industrial, científica e médica (ALBERTS et al., 1996). Na indústria, o uso da radiação de nêutrons destaca-se pela geração de energia nuclear e em prospecção de petróleo. Na área médica, os nêutrons são usados em terapia de captura de nêutrons por boro (BNCT). No campo científico, os nêutrons estão presentes nos estudos de fissão e fusão.

No passado, a monitoração das radiações de nêutrons era muito limitada e somente os trabalhadores de reatores e aceleradores precisavam ser monitorados. Atualmente, com o aumento do uso de técnicas na indústria, área médica e em pesquisas científicas, que utilizam radiação de nêutrons,

é crescente o número de trabalhadores potencialmente expostos a este tipo de radiação, ampliando assim o número de trabalhadores que necessitam de monitoração individual. A utilização de um sistema de detecção de nêutrons possibilita a monitoração periódica da área da exposição ocupacional a fim de avaliar as condições de segurança dos trabalhadores e das instalações.

A medição confiável da radiação de nêutrons é uma tarefa complexa devido 
ao grande intervalo de energia, à dependência energética e à dependência angular dos monitores, e consequentemente as respostas são imperfeitas na maioria dos instrumentos de medição de radiação de nêutrons disponíveis comercialmente. Para que os instrumentos tenham suas medições confiáveis, eles precisam ser calibrados periodicamente (GRESSIER et al., 2004).

A calibração consiste num conjunto de operações que estabelece a relação entre os valores indicados por um instrumento de medição, ou valores representados por uma medição materializada, e os valores correspondentes das grandezas estabelecidas por padrões, que têm por objetivo assegurar a confiabilidade e a qualidade de um instrumento de medição, certificando-se que as incertezas, exigidas pelas normas, sejam as menores possíveis (ISO, 2000; McDONALD et al., 1993).

De acordo com a norma NE 3.02 da CNEN (CNEN, 2011), é obrigatória a calibração dos instrumentos de medição por uma instituição autorizada, que esteja em conformidade com as normas específicas, garantindo assim que 0 detector esteja trabalhando devidamente.

O Laboratório de Calibração de Instrumentos do IPEN (LCI) dispõe de vários arranjos experimentais com fontes radioativas e equipamentos emissores de radiação ionizante para a calibração de uma variedade de equipamentos seguindo as recomendações da Agência Internacional de Energia Atômica (IAEA, 2000). Os laboratórios já possuem estabelecidos os serviços de calibração de detectores com radiações $X$, gama, beta e alfa, utilizando fontes ou detectores rastreados por sistemas padrões primários ou secundários.

No Brasil, atualmente só há um laboratório de calibração de detectores de radiação de nêutrons, sendo responsável pela guarda e manutenção do padrão brasileiro de fluência de nêutrons, localizado no Laboratório Nacional de Metrologia das Radiações Ionizantes (LNMRI), Rio de Janeiro, no Instituto de Radioproteção e Dosimetria, Comissão Nacional de Energia Nuclear, com uma demanda muito grande de serviços com esse tipo de radiação. 
Assim, considerando que no IPEN existem mais de 30 equipamentos detectores de radiação de nêutrons, utilizados pelos trabalhadores dos dois reatores nucleares e dos dois cíclotrons, além de várias fontes radioativas que necessitam ser calibradas periodicamente, e com o intuito de descentralizar a oferta de calibração, surgiu a necessidade da montagem de um segundo laboratório de calibração com nêutrons, no IPEN, a ser utilizado inicialmente para testes de detectores portáteis com radiação de nêutrons. Este laboratório pretende no futuro atender à demanda interna e externa de calibração de detectores de radiação de nêutrons utilizando uma fonte de ${ }^{241} \mathrm{Am}(\mathrm{Be})$.

A instalação para irradiação com nêutrons foi projetada levando-se em conta as recomendações e as instruções da International Organization for Standardization (ISO), estabelecidas nas normas ISO 8529 Parte1 (ISO, 2001) e ISO 8529 Parte 2 (ISO, 2000), atendendo aos padrões de segurança de um laboratório para calibração de instrumentos.

\subsection{Objetivos}

Os objetivos principais deste trabalho são: estabelecer uma infraestrutura que permita inicialmente a realização de testes de monitores portáteis com radiação de nêutrons, dentro dos seus programas de controle de qualidade, e no futuro a calibração de detectores de radiação utilizando uma fonte de ${ }^{241} \mathrm{Am}(\mathrm{Be})$; caracterizar o feixe de radiação; elaborar e executar os testes dos instrumentos detectores de radiação de nêutrons, com o intuito de garantir a confiabilidade das medições e assim aumentar a oferta de serviços do Laboratório de Calibração de Instrumentos do IPEN . 


\section{Capítulo 2}

\section{Fundamentos Teóricos}

Neste capítulo são apresentados os conceitos principais utilizados no desenvolvimento deste trabalho.

\subsection{Os nêutrons}

A radiação de nêutrons foi identificada pela primeira vez por Chadwick em 1932 num experimento no qual incidiu um feixe de partículas alfa em uma amostra de berílio $(\mathrm{Be})$. Foi possível perceber a emissão de partículas que não possuíam carga, mas que em contato com outras matérias conseguiam arrancar prótons (ZAMBONI, 2007). A sua massa inercial é 1,0087 u.m.a, cerca de $0,1 \%$ mais pesado que o próton, que possui 1,0073 u.m.a. $O$ nêutron só adquire a estabilidade quando está ligado a um núcleo livre; neste caso, tem meia-vida de 10,235 min decaindo em um próton, um elétron e um antineutrino (BYRNE, 2011).

Em virtude da neutralidade de sua carga, os nêutrons são partículas indiretamente ionizantes, que cruzam as camadas eletrônicas sem qualquer interferência com a barreira coulombiana, e interagem diretamente com o núcleo.

Podem penetrar profundamente o material alvo sem sofrer interações. Quando interagem diretamente com os núcleos da substância que está sendo atravessada, os nêutrons desaparecem e podem originar as radiações 
secundárias, como a radiação gama (ZAMBONI, 2007). Em consequência disso, a interação de nêutrons com a matéria é fortemente dependente da energia do nêutron e do próprio material alvo. A radiação de nêutrons na maioria das vezes é acompanhada de radiação gama.

A classificação dos nêutrons é feita de acordo com os intervalos de energia:

- Térmicos: Energia $\leq 0,4 \mathrm{eV}$

- Intermediários: 0,4 $<$ Energia $<1 \mathrm{MeV}$

- Rápidos: $1 \mathrm{MeV} \leq$ Energia $<10 \mathrm{MeV}$

Os nêutrons térmicos encontram-se em equilíbrio com os núcleos do meio onde interagem. A energia de $0,4 \mathrm{eV}$ corresponde à energia de corte do Cádmio mediante a reação de captura (nêutron, gama).

Os nêutrons intermediários são consequência das colisões elásticas dos nêutrons rápidos em materiais de baixo número atômico, sendo que a sua distribuição é proporcional ao inverso da sua velocidade.

Os nêutrons rápidos possuem energia suficiente para interagir com a grande maioria dos núcleos por meio de limiares, cuja energia é superior a várias dezenas de keV.

\subsection{Fontes de nêutrons}

A produção de nêutrons ocorre a partir dos processos de reações nucleares e de fissão espontânea, sendo que no processo de reações nucleares eles podem ser do tipo $(\alpha, \mathrm{n})$ ou $(\gamma, \mathrm{n})$. A fonte do tipo $(\alpha, \mathrm{n})$ é produzida em virtude da combinação de um emissor alfa com um elemento de baixo número atômico, em geral Berílio, resultando na emissão de nêutrons. Na Tabela (2.1) tem-se as características das principais fontes $(\alpha, \mathrm{n})$ (ZAMBONI, 2007). 
Tabela 2.1: Propriedades das principais fontes $(\alpha, \mathrm{n})$ (ZAMBONI, 2007). E $\alpha$ é a energia da radiação alfa.

\begin{tabular}{|c|c|c|c|}
\hline Fonte & $\begin{array}{c}\mathrm{E} \alpha \\
(\mathrm{MeV})\end{array}$ & Meia-vida & $\begin{array}{c}\text { Produção (n/ } \alpha) \\
\left(\mathrm{cm}^{2} \mathbf{g}^{-1}\right)\end{array}$ \\
\hline${ }^{210} \mathrm{Po}+\mathrm{Be}$ & 5,3 & 134,4 dias & $0,7 \times 10^{-4}$ \\
\hline${ }^{22} \mathrm{Ra}+\mathrm{Be}$ & 4,$78 ; 4,59$ & $1,622 \times 10^{3}$ anos & $1,8 \times 10^{-4}$ \\
\hline${ }^{239} \mathrm{Pu}+\mathrm{Be}$ & 5,15 & $2,44 \times 10^{4}$ anos & $0,6 \times 10^{-4}$ \\
\hline${ }^{241} \mathrm{Am}+\mathrm{Be}$ & 5,48 & $4,60 \times 10^{2}$ anos & $0,7 \times 10^{-4}$ \\
\hline${ }^{242} \mathrm{Cm}+\mathrm{Be}$ & 6,11 & 163 dias & $1,1 \times 10^{-4}$ \\
\hline${ }^{241} \mathrm{Am}+\mathrm{B}$ & 5,48 & $2,44 \times 10^{4}$ anos & $1,0 \times 10^{-5}$ \\
\hline${ }^{241} \mathrm{Am}+\mathrm{F}$ & 5,48 & $2,44 \times 10^{4}$ anos & $4,0 \times 10^{-6}$ \\
\hline
\end{tabular}

As fontes do tipo $(\gamma, \mathrm{n})$ são obtidas empregando o mesmo princípio, mudando apenas o nuclídeo que é um emissor beta ou gama de alta energia. Os feixes produzidos por essas fontes produzem energia inferior a $1 \mathrm{MeV}$ cuja atividade especifica é muito inferior às do tipo $(\alpha, \mathrm{n})$. A Tabela 2.2 mostra as características das principais fontes $(\gamma, \mathrm{n})$ (ZAMBONI, 2007).

Tabela 2.2: Propriedades das principais fontes ( $\gamma, \mathrm{n})$ (ZAMBONI, 2007). E $\gamma$ é a energia da radiação gama.

\begin{tabular}{cccc}
\hline Fonte & $\begin{array}{c}\mathbf{E} \gamma \\
(\mathbf{M e V})\end{array}$ & Meia-vida & $\begin{array}{c}\text { Produção } \mathbf{( n} / \boldsymbol{\beta}) \\
\left(\mathbf{c m}^{2} \mathbf{g}^{-\mathbf{1}} \mathbf{)}\right.\end{array}$ \\
\hline${ }^{24} \mathrm{Na}+\mathrm{Be}$ & 2,76 & $15,1 \mathrm{~h}$ & $0,7 \times 10^{-4}$ \\
${ }^{24} \mathrm{Na}+\mathrm{D}_{2} \mathrm{O}$ & 2,76 & $15,1 \mathrm{~h}$ & $1,8 \times 10^{-4}$ \\
${ }^{72} \mathrm{Ga}+\mathrm{D}_{2} \mathrm{O}$ & 2,51 & $14,3 \mathrm{~h}$ & $0,6 \times 10^{-4}$ \\
${ }^{124} \mathrm{Sb}+\mathrm{Be}$ & 1,69 & 60,9 dias & $0,7 \times 10^{-4}$ \\
${ }^{140} \mathrm{La}+\mathrm{Be}$ & 2,51 & $40,2 \mathrm{~h}$ & $1,1 \times 10^{-4}$ \\
\hline
\end{tabular}

As fontes produzidas por fissão são provenientes do decaimento por fissão dos nuclídeos pesados, emitindo nêutrons rápidos. Um dos elementos mais comuns utilizados neste tipo de fontes é o ${ }^{252} \mathrm{Cf}$, com meia-vida de 2,65 anos.

Os nêutrons podem ser produzidos em aceleradores de partículas, que geralmente são usados para produzir nêutrons monoenergéticos ou quase monoenergéticos. Neste caso, o elemento alvo é bombardeado por partículas aceleradas que possuem carga elétrica que pode variar dependendo do tipo 
do material alvo, provocando reações nucleares que resultam na emissão de nêutrons (ZAMBONI, 2007). Na Tabela 2.3 são listadas algumas reações importantes que são usadas para se obter nêutrons monoenergéticos.

Tabela 2.3: Reações utilizadas para produção de nêutrons monoenergéticos. Q é o fator de intensidade da emissão de nêutrons (TURNER, 2007).

\begin{tabular}{cc}
\hline Reações & Valor de $\mathbf{Q}(\mathbf{M e V})$ \\
\hline${ }^{3} \mathrm{H}(\mathrm{d}, \mathrm{n})^{4} \mathrm{He}$ & 17,6 \\
${ }^{2} \mathrm{H}(\mathrm{d}, \mathrm{n})^{3} \mathrm{He}$ & 3,27 \\
${ }^{12} \mathrm{C}(\mathrm{d}, \mathrm{n})^{13} \mathrm{~N}$ & $-0,281$ \\
${ }^{3} \mathrm{H}(\mathrm{p}, \mathrm{n})^{3} \mathrm{He}$ & $-0,764$ \\
${ }^{7} \mathrm{Li}(\mathrm{p}, \mathrm{n})^{7} \mathrm{Be}$ & $-1,65$ \\
\hline
\end{tabular}

Os nêutrons produzidos em reatores nucleares apresentam uma distribuição energética bastante ampla podendo variar desde alguns keV até mais de $10 \mathrm{MeV}$. Em geral, estes feixes de nêutrons são contaminados por radiação gama (ZAMBONI, 2007).

\subsection{Interação dos nêutrons com a matéria}

A interação dos nêutrons com a matéria consiste num processo bastante diferente se comparado com as partículas carregadas e a radiação eletromagnética. Os nêutrons não possuem carga, não interagem com a matéria por meio da força coulombiana; essas características fazem com que o nêutron seja bastante penetrante, ou seja, a interação dos nêutrons com a matéria ocorre diretamente com os núcleos dos átomos (LAMARSH, 1983). Os nêutrons podem interagir das seguintes formas:

1. Espalhamento inelástico (n,n'): após a colisão, a energia cinética não se conserva e parte dessa energia é utilizada como energia de excitação do núcleo alvo, assim reduzindo a energia do nêutron incidente. A desexcitação do núcleo ocasiona a emissão de radiação gama; 
2. Espalhamento elástico $(n, n)$ : nesta interação o núcleo permanece em seu estado fundamental e a energia do nêutron não se altera;

3. Reação de fissão: ocorre após a colisão dos nêutrons com um núcleo pesado, que se divide, gerando de dois a três novos nêutrons e radiação gama;

4. Captura radioativa $(n, \gamma)$ : neste processo o nêutron incidente é capturado pelo núcleo alvo, que fica em estado excitado. Depois tende a se desexcitar, ocasionando vários fenômenos, em função da energia do nêutron incidente e do produto final.

\subsection{Sistema de detecção de nêutrons}

Os detectores de nêutrons são utilizados com o objetivo de determinar e monitorar a taxa de equivalente de dose em áreas onde pessoas são ocupacionalmente expostas à radiação de nêutrons. Os sensores mais utilizados para detecção de nêutrons são: câmaras de ionização, câmaras de fissão, cintiladores líquidos acoplados a fotomultiplicadoras, detectores proporcionais gasosos e detectores semicondutores (MADI FILHO, 1999).

Os detectores de radiação de nêutrons mais utilizados na radioproteção são os semicondutores, gasosos, cintiladores e auto-alimentados (DANTAS, 2013).

\subsubsection{Detectores semicondutores}

Os detectores semicondutores são mais utilizados na indústria e na pesquisa cientifica devido à sua elevada resolução espacial, são compactos no tamanho, apresentam um tempo adequado de resposta e permitem a determinação da energia das partículas carregadas. Estes detectores utilizam semicondutores como material responsável pela captação da radiação e conversão em energia elétrica detectável (DANTAS, 2013). 
A propriedade de um semicondutor baseia-se na teoria de bandas de energia. Os materiais normalmente utilizados são silício ou germânio, que são materiais cristalinos cujos níveis de energia mais externos exibem uma estrutura de bandas, capazes de originar os pares elétron-buracos. Os principais problemas na utilização de detectores semicondutores é que geralmente necessitam ser resfriados a temperaturas baixas, e a sua sensibilidade aos efeitos da radiação é elevada, limitando a sua vida útil.

\subsubsection{Detectores proporcionais a gás}

Os detectores gasosos são os mais utilizados na detecção de radiação de nêutrons, devido à sua facilidade de manuseio e operação. $O$ detector proporcional a gás consiste de uma câmara preenchida por um determinado tipo de gás, com um filamento na parte central que funciona como anodo; e a sua parede funciona como catodo à qual se aplica uma tensão elétrica (ZAMBONI, 2007).

Quando a radiação ionizante incide no volume sensível do detector proporcional, os íons resultantes desta interação provocam a ionização do gás que preenche $\mathrm{o}$ detector. $\mathrm{O}$ movimento dessas cargas formadas produzirá no coletor um pulso ou uma corrente elétrica detectável (MADI FILHO, 1999).

\subsubsection{Detectores auto-alimentados}

O detector auto-alimentado é composto de materiais que possuem alta secção de choque para nêutrons; sua aplicação limita-se a reatores nucleares.

Quando os nêutrons incidem no detector, o material emite radiação gama ou partículas beta. A corrente gerada pelas partículas beta é proporcional à taxa de reação de nêutrons no material; por esse motivo, a sua medição é feita de maneira direta, não necessitando de uma fotomultiplicadora para a geração dos sinais para o detector. A radiação gama emitida pelo material interage por efeito Compton, fotoelétrico ou formação de pares. A corrente dos elétrons secundários 
é usada como sinal do detector (KNOLL, 2010).

\subsubsection{Detectores cintiladores}

O detector de cintilação é composto por um cintilador, uma superfície fotocatódica e uma fotomultiplicadora. Esse tipo de detector é largamente utilizado na detecção e na medição das radiações $X$, alfa, beta, gama e de nêutrons.

Os materiais cintiladores são responsáveis por transformar a energia cedida pelas radiações ionizantes em luz. Os materiais conversores mais utilizados são o brometo de lantânio, iodeto de sódio, sulfeto de zinco e cintiladores plásticos.

No detector de cintilação a energia depositada pela radiação no detector produz excitações, que ao retornar ao estado estável, produz radiação na faixa de frequência da luz visível, ou seja, radiação fluorescente. Esta radiação é absorvida por meio do efeito fotoelétrico na parede fotocatódica, resultando na produção de elétrons livres que são multiplicados na fotomultiplicadora até obterem a intensidade suficiente para produzirem um pulso, que é proporcional à energia da radiação incidente.

\subsection{Grandezas e unidades}

Em física, grandeza é tudo aquilo que envolve medições, portanto, medir significa comparar quantitativamente uma grandeza física com uma unidade por meio de uma escala já estabelecida. Unidade é uma quantidade usada para expressar a magnitude de uma grandeza e é definida por convenção.

A International Commission on Radiation Units and Measurements (ICRU) e a International Commission on Radiological Protection (ICRP) são as duas instituições internacionais responsáveis pela organização e a padronização das grandezas usadas na caracterização dos campos de radiação e da radioatividade, quantificação dos efeitos e descrição da interação da radiação com a matéria. 
Nos relatórios da ICRU são definidos os tipos de grandezas físicas básicas e operacionais e a ICRP regula as grandezas limitantes de radioproteção. As grandezas relacionadas à radiação utilizadas neste trabalho são as seguintes:

\subsubsection{Grandezas físicas}

Grandezas físicas são grandezas definidas pela ICRU, utilizadas na metrologia e na dosimetria das radiações para caracterizar o campo de radiação em qualquer ponto. As grandezas físicas básicas para dosimetria de nêutrons são a atividade, fluência, taxa de fluência ou fluxo, dose absorvida, kerma e distribuição espectral (ICRP, 1998).

\section{Atividade (A)}

Atividade é a grandeza utilizada para expressar a atividade de um material radioativo e o número de desintegrações por unidade de tempo (t) (ICRP, 2001). É expressa por:

$$
A=\frac{d N}{d t}
$$

onde $d N$ é o número de transformações nucleares em um intervalo de tempo $(d t)$. A unidade desta grandeza é o becquerel $(\mathrm{Bq})$, equivalente a uma desintegração por segundo. A unidade antiga é o Curie $(\mathrm{Ci})$, onde $1 \mathrm{Ci}=3,7 \times 10^{10} \mathrm{GBq}$.

\section{Fluência ( $\Phi$ )}

A fluência é a razão entre o número de partículas incidentes $(d N)$ sobre uma esfera e a sua secção de área (da) (ICRP, 1998). É expressa em m².

$$
\Phi=\frac{d N}{d a}
$$

Taxa de Fluência ou Fluxo ( $\dot{\Phi})$

É a variação da fluência num intervalo de tempo. É expressa por $\mathrm{m}^{-2} \mathrm{~s}^{-1}$ 


$$
\dot{\Phi}=\frac{\Phi}{d t}
$$

\section{Dose Absorvida (D)}

Dose absorvida é a grandeza utilizada para expressar a energia absorvida em um órgão ou tecido dividida pela massa daquele órgão (ICRP, 1998), dada pela expressão:

$$
D=\frac{d \epsilon}{d m}
$$

onde $D$ é a dose absorvida e $d \epsilon$ é a energia total absorvida pela matéria em um elemento de massa $d m$. A unidade da dose absorvida é o gray (Gy).

\section{Kerma (K)}

O kerma é definido como a soma de todas as energias cinéticas iniciais das partículas carregadas liberadas pelas partículas sem carga, dEtr, por unidade de massa dm (ICRU, 1998). De acordo com o Sistema Internacional de Unidades (SI), a unidade da grandeza kerma é o gray (Gy).

$$
K=\frac{d E_{t r}}{d m}
$$

\subsubsection{Grandezas operacionais}

As grandezas operacionais têm o objetivo de fornecer uma estimativa razoável das grandezas de radioproteção na maioria das situações de trabalho. As grandezas operacionais são equivalente de dose direcional, equivalente de dose pessoal e equivalente de dose ambiente. 


\section{Equivalente de Dose Direcional $\left[H^{\prime},(d, \omega)\right]$}

O equivalente de dose direcional é o valor produzido em um ponto em uma profundidade (d) na esfera de referência ICRU em uma direção específica $(\omega)$. A unidade utilizada é o J.kg-1 , denominada sievert (Sv) (ZAMBONI, 2007).

\section{Equivalente de Dose Pessoal [Hp(d)]}

O equivalente de dose pessoal, $\mathrm{Hp}(\mathrm{d})$, é o equivalente de dose produzido em um ponto especifico a uma profundidade (d) do corpo humano. Esta grandeza é utilizada para monitoração individual externa. A sua unidade é o sievert (Sv).

\section{Equivalente de Dose Ambiente $\left[H^{*}(d)\right]$}

O equivalente de dose ambiente, para um ponto qualquer de um campo de radiação, é definido como a dose produzida em um ponto situado a uma profundidade (d) no interior da esfera de referência ICRU, com $30 \mathrm{~cm}$ de diâmetro e composição de material equivalente ao tecido humano. Esta grandeza é utilizada para monitoração de área em ambientes de trabalho. A unidade é J. $\mathrm{kg}^{-1}$, denominada sievert (Sv).

A relação entre o equivalente de dose ambiente e a fluência é obtida por meio do coeficiente de conversão, que provém da razão entre o equivalente de dose ambiente $\mathrm{H}^{*}(10)$ e a fluência $(\Phi)$ em um determinado ponto de radiação dentro do campo não perturbado pelo objeto irradiado.

Os relatórios da ICRU apresentam os coeficientes de conversão $h(E)$ em unidades de $\mathrm{pSv} . \mathrm{cm}^{2}$ para nêutrons monoenergéticos utilizados para calcular a equivalente de dose ambiente $\mathrm{H}^{\star}(10)$. A Tabela 2.4 apresenta alguns destes valores. 
Tabela 2.4: Valores do coeficiente de conversão da fluência de nêutrons para equivalente de dose ambiente dos nêutrons $h(E)$ (ICRP, 1996).

\begin{tabular}{|c|c|}
\hline $\begin{array}{c}\text { Energia } \\
(\mathrm{MeV})\end{array}$ & $\begin{array}{c}h(E) \\
\left(p S v . c^{2}\right)\end{array}$ \\
\hline $1,00 \times 10^{-9}$ & 6,6 \\
\hline $1,00 \times 10^{-8}$ & 9,0 \\
\hline $2,53 \times 10^{-8}$ & 10,6 \\
\hline $1,00 \times 10^{-7}$ & 12,9 \\
\hline $5,00 \times 10^{-7}$ & 13,6 \\
\hline $1,00 \times 10^{-6}$ & 13,3 \\
\hline $2,00 \times 10^{-6}$ & 12,9 \\
\hline $1,00 \times 10^{-5}$ & 11,3 \\
\hline $2,00 \times 10^{-5}$ & 10,6 \\
\hline $5,00 \times 10^{-5}$ & 9,9 \\
\hline $1,00 \times 10^{-4}$ & 9,4 \\
\hline $5,00 \times 10^{-4}$ & 8,3 \\
\hline $1,00 \times 10^{-3}$ & 7,9 \\
\hline $2,00 \times 10^{-3}$ & 7,7 \\
\hline $1,00 \times 10^{-2}$ & 10,5 \\
\hline $3,00 \times 10^{-2}$ & 23,7 \\
\hline $7,00 \times 10^{-1}$ & 375,0 \\
\hline $9,00 \times 10^{-1}$ & 400,0 \\
\hline $1,00 \times 10^{-0}$ & 416,0 \\
\hline $1,20 \times 10^{-0}$ & 425,0 \\
\hline $2,01 \times 10^{+2}$ & 260,0 \\
\hline
\end{tabular}




\subsubsection{Grandezas de radioproteção}

As grandezas de radioproteção são utilizadas especificamente em proteção radiológica. Foram definidas pela ICRU e pelo ICRP, com o intuito de avaliar os riscos biológicos ocasionados após uma exposição à radiação ionizante.

\section{Dose Equivalente $\left(\mathrm{H}_{\mathrm{T}}\right)$}

A dose equivalente num tecido ou órgão é dada por:

$$
H_{\mathrm{T}}=\sum_{R} D_{\mathrm{T} \cdot \mathrm{R}} \cdot w_{\mathrm{R}}
$$

onde $\mathrm{H}_{\mathrm{T}}$ é a dose equivalente num tecido ou órgão, $\mathrm{D}_{T . R}$ é a dose absorvida no tecido ou órgão e $w_{R}$ é o fator de ponderação da radiação. Na Tabela 2.5 são apresentados os fatores de ponderação da radiação $w_{R}$.

Tabela 2.5: Fatores de ponderação da radiação para os diversos tipos de radiação e energias recomendadas pela ICRP 60 (ICRP, 2007).

\section{Tipo de radiação}

Fator de ponderação

da

\begin{tabular}{cc} 
& radiação, $\mathbf{w}_{\mathbf{R}}$ \\
\hline Fótons, todas as energias & 1 \\
Elétrons e múons, todas as energias & 1 \\
Prótons $>2 \mathrm{MeV}$ & 5 \\
Partículas alfa, fragmentos de fissão, íons pesados & 20 \\
$<10 \mathrm{keV}$ & 5 \\
Nêutrons & $>10 \mathrm{keV}$ até $100 \mathrm{keV}$ \\
& $>100 \mathrm{keV}$ até $2 \mathrm{MeV}$ \\
$>2 \mathrm{MeV}$ até $20 \mathrm{MeV}$ & 20 \\
$>20 \mathrm{MeV}$ & 10 \\
\end{tabular}

\section{Dose Efetiva (E)}

A dose efetiva (E) é a soma das doses equivalentes nos tecidos ou órgãos do corpo, multiplicados pelo fator de ponderação de cada tecido, sendo expressa por: 


$$
E=\sum_{R} w_{\top} \cdot H_{\top}
$$

onde $H_{\mathrm{T}}$ é a dose equivalente em um tecido ou órgão e $w_{\mathrm{T}}$ é o fator de poderação correspondente a um tecido ou órgão. A unidade desta grandeza é a sievert (Sv). Na Tabela 2.6 são apresentados os fatores de ponderação $\left(w_{T}\right)$ recomendados pela ICRP 60 (ICRP, 1991).

Tabela 2.6: Fatores de ponderação para diversos tipos de órgãos e tecidos recomendados pela ICRP 60 (ICRP, 1991).

\begin{tabular}{cc}
\hline Órgão ou tecido & Fator de ponderação $w_{\mathbf{T}}$ \\
\hline Gônadas & 2,0 \\
Medula óssea (vermelha) & 0,12 \\
Cólon & 0,12 \\
Pulmão & 0,12 \\
Estômago & 0,12 \\
Bexiga & 0,05 \\
Mama & 0,05 \\
Fígado & 0,05 \\
Esôfago & 0,05 \\
Tireóide & 0,05 \\
Pele & 0,01 \\
Superfície óssea & 0,01 \\
\hline
\end{tabular}

\subsection{Métodos de avaliação da radiação espalhada de nêutrons}

Nas situações práticas envolvendo os testes de detectores de radiação de nêutrons, um dos problemas principais está relacionado à radiação espalhada, que pode variar dependendo das diferentes dimensões dos laboratórios usados nos procedimentos de testes dos monitores portáteis. Um laboratório de teste pequeno resulta numa grande possibilidade de aumento na quantidade de nêutrons refletidos nas paredes, piso e teto (ISO, 2000), e consequentemente influenciando a leitura do instrumento a ser testado neste laboratório e 
ocasionando um erro sistemático na leitura dos dispositivos para medição de nêutrons.

A norma ISO 8529-1 (ISO, 2000) recomenda três métodos para a determinação da radiação espalhada. Eles são denominados: método semi-empírico, método de ajuste polinomial e método do cone de sombra.

\subsubsection{Método semi-empírico}

A resposta dos instrumentos de medição é corrigida por fatores de espalhamento $(\mathrm{Ar})$ e pelo fator de correção geométrico para a fonte utilizada. A leitura do detector de radiação de nêutrons está relacionada com a fluência por:

$$
\frac{M_{\mathrm{T}}(d)}{\Phi_{\mathrm{D}}(d) \cdot F_{1}(d) \cdot(1+A \cdot d)}=R_{\Phi_{\mathrm{D}}}(d) \cdot\left[1+S \cdot d^{2}\right]
$$

onde $M_{\top}(d)$ é a leitura total do dispositivo em função da distância $d, \Phi_{\mathrm{D}}(d)$ é a fluência direta de nêutrons à distância $d, F_{1}(d)$ é o fator de correção geométrico, $R_{\Phi_{\mathrm{D}}}(d)$ é a resposta do dispositivo à fluência direta dos nêutrons a uma distância $d, S$ representa a fração da contribuição do espalhamento correspondente ao laboratório de testes e $(1+A \cdot d)$ é a correção total (espalhamento menos atenuação) (ISO, 2000).

As medições devem ser realizadas em várias distâncias com relação à fonte e os dados devem ser corrigidos pelos fatores de espalhamento do ar e das paredes, teto e piso. Assim, estes valores numéricos podem ser utilizados para calibrações futuras de monitores do mesmo tipo, se as condições permanecerem inalteradas (FRATIN, 1993).

\subsubsection{Método do ajuste polinomial}

Neste método, a determinação dos fatores de espalhamento do ar e do laboratório são considerados como variáveis de ajuste, podendo ser utilizados para vários tipos de detectores ou fontes grandes em laboratórios de baixo 
espalhamento. O procedimento de calibração por este tipo de ajuste apresenta uma desvantagem devido à necessidade da realização de um número maior de medições para se fazer o ajuste por polinômios, com o risco da ocultação das leituras não lineares a serem obtidos. Portanto, recomenda-se a realização de testes de estabilidade e linearidade da resposta do instrumento (VILELA, 1996).

\subsubsection{Método do cone de sombra}

Para aplicação deste método, a norma ISO 10647 (ISO, 1996), recomenda a utilização de um cone constituído de dois tipos de materiais, sendo que a parte dianteira é composta de $20 \mathrm{~cm}$ de ferro maciço e a parte traseira possui $30 \mathrm{~cm}$ de polietileno borado. Na Figura 2.1 é apresentado um diagrama do cone de sombra.

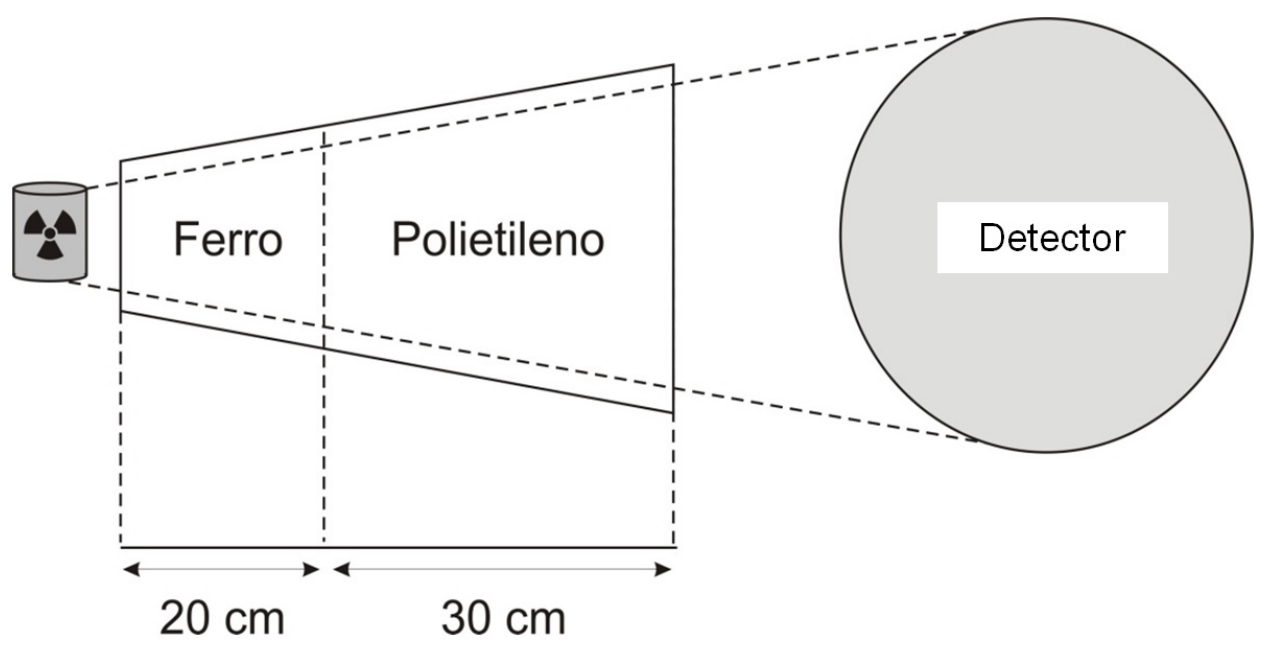

Figura 2.1: Esquema do cone de sombra (KHABAZ e HAKIMABAD, 2011).

O cone deve ser posicionado entre a fonte e o detector, com o objetivo de evitar a passagem do feixe primário da fonte de nêutrons. Deste modo, a resposta obtida pelo detector $\left(\mathrm{M}_{\mathrm{D}}\right)$ será leitura do detector no ponto $d$ do campo de nêutrons, corrigida proveniente apenas da radiação espalhada causada pelo arranjo de posicionamento, pelo ar, paredes e piso do laboratório. A leitura corrigida será fornecida pela diferença das medições realizadas sem o cone $\left(M_{T}\right)$, e com o cone $\left(M_{S}\right)(I S O, 2000)$ : 


$$
M_{\mathrm{D}}(d)=\left(M_{\mathrm{\top}}(d)-M_{\mathrm{S}}(d)\right) \cdot F_{\mathrm{A}}(d)
$$

onde $\left(\mathrm{F}_{\mathrm{A}}(\mathrm{d})\right)$ é o fator de correção de atenuação do ar no ponto $d$.

O cone de sombra deve ser projetado de forma que seu ângulo não seja maior do que duas vezes o ângulo sólido do detector (ISO, 1996). Neste método torna-se difícil a realização das medições em várias distâncias, pois isso levaria à necessidade de construção de vários cones.

\subsection{Método de Monte Carlo}

O método de Monte Carlo é um método estatístico, no qual se utiliza uma sequência de números aleatórios, com a finalidade de solucionar problemas físicos e matemáticos, para os quais a solução por métodos diretos é muito difícil.

O método de Monte Carlo é uma ferramenta matemática utilizada por profissionais de diversos segmentos da ciência e da engenharia, com o objetivo de simular problemas que podem ser representados por processos estocásticos. Observa-se que, com o passar do tempo, houve um rápido crescimento da utilização deste método na área de transporte e interação da radiação com a matéria. Isto se deve ao rápido avanço tecnológico dos computadores, resultando no aumento da velocidade de processamento e da capacidade de armazenamento das informações (ZAMBONI, 2007).

A aplicação do Método de Monte Carlo ao transporte de radiação consiste na escolha aleatória da trajetória de uma partícula de um conjunto de todas as possibilidades envolvidas. Os comportamentos dessas partículas são descritos em termos de grandezas macroscópicas, tais como fluxo ou densidade de partículas. Dentre os vários pacotes de simulação de Monte Carlo optou-se pela utilização do código MCNP (Monte Carlo N-Particle) versão 5, por permitir a simulação de fótons, elétrons e nêutrons e a sua base de dados de secção de choque é constantemente atualizada (BRIESMEISTER, 1993). 


\subsection{Calibração de detectores de radiação}

O conceito de calibração é definido no Vocabulário Internacional de Metrologia (VIM ) como: "conjunto de operações que estabelece, sob condições especificas, uma relação entre os valores indicados por um instrumento ou sistema de medição e os valores representados por uma medição materializada ou os materiais correspondentes das grandezas estabelecidas por padrões" (INMETRO, 2012).

A calibração dos detectores tem o propósito de garantir que o instrumento de medição esteja funcionando conforme as normas ou regulamentos. Assim, a calibração é uma operação imprescindível para a garantia da rastreabilidade e da qualidade das medições, possibilitando um uso consciente do equipamento. Os métodos básicos utilizados nos procedimentos de calibração são: método de substituição e o uso de campos de radiação conhecidos (IAEA, 2000).

No método de substituição, primeiramente um detector de referência é posicionado no campo de radiação e são tomadas as medições; posteriormente, o detector a ser calibrado substitui o detector de referência, ocupando precisamente a mesma posição no feixe de radiação e a calibração é feita a partir da comparação das medições feitas pelos dois detectores. Este método é representado na Figura 2.2.

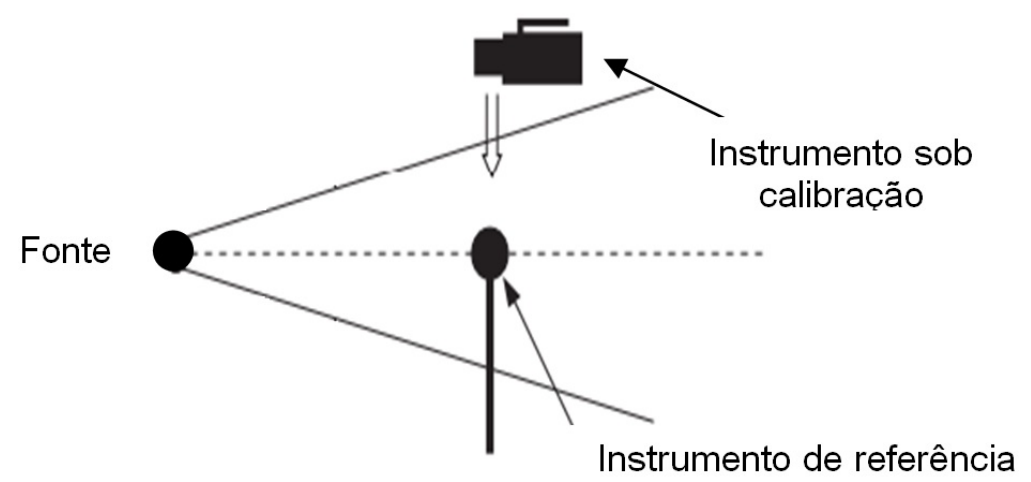

Figura 2.2: Método de calibração por substituição (IAEA, 2000).

No método de campos conhecidos, o campo de radiação pode ser determinado pelo conhecimento das características de uma fonte padrão ou pelo 
mapeamento prévio do campo com um sistema padrão secundário. O detector a ser calibrado é posicionado no campo de radiação e são tomadas as medições, que são comparadas com o valor previamente conhecido da intensidade da fonte de radiação em termos da grandeza em questão (IAEA, 2000). Na Figura 2.3 está representado o método de calibração para campos conhecidos.

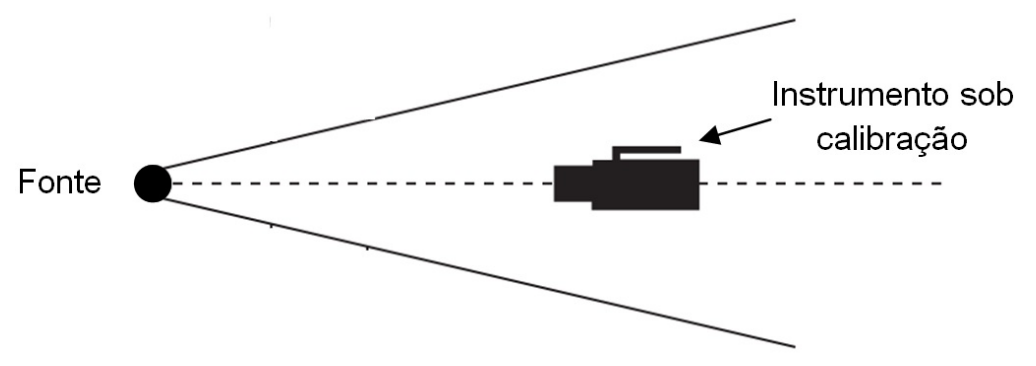

Figura 2.3: Método de calibração para campos conhecidos (IAEA, 2000).

Nos programas de controle de qualidade de detectores portáteis, recomenda-se testá-los periodicamente; este procedimento consiste em se verificar, por comparação com um padrão, a exatidão das indicações de um instrumento. No caso da calibração, em geral ainda são realizados ajustes no instrumento, além de ser um procedimento muito mais completo, só efetuado em laboratórios credenciados ou autorizados por autoridade competente.

\subsection{Testes de estabilidade}

Os testes de estabilidade têm o objetivo de avaliar as respostas medidas com um detector de radiação. Existem dois tipos de testes de estabilidade: estabilidade a curto prazo (teste de repetitividade) e estabilidade a longo ou médio prazo (teste de reprodutibilidade).

De acordo com a definição fornecida pelo Vocabulário Internacional de Metrologia (VIM ) repetitividade é o "grau de concordância entre os resultados das medições sucessivas utilizando o mesmo procedimento de medição, os mesmos operadores, as mesmas condições de operação e o mesmo local" e reprodutibilidade é o "grau de concordância entre os resultados das medições de um mesmo detector efetuados sob as mesmas condições e no mesmo local". 
Os testes de estabilidade têm o objetivo de avaliar a frequência das respostas medidas com um detector de radiação (INMETRO, 2012).

No caso do teste de repetitividade de resposta (estabilidade a curto prazo), são tomadas medições consecutivas e no teste de reprodutibilidade são considerados os valores médios do teste de repetitividade ao longo do tempo (estabilidade a longo ou médio prazo). 


\section{Capítulo 3}

\section{Materiais e Métodos}

Neste capitulo são apresentados a fonte de nêutrons, os equipamentos e os materiais utilizados na montagem do Laboratório de Testes com Nêutrons (LTN).

\subsection{Sistema de radiação de nêutrons}

Foi utilizada uma fonte de ${ }^{241} \mathrm{Am}(\mathrm{Be})$, modelo AMNK128-AMN200, fabricada pela Amersham, com atividade de $3,7 \times 10^{10} \mathrm{~Bq}(1 \mathrm{Ci})$ e taxa de emissão de nêutrons de $2,46 \times 10^{6} \mathrm{n} / \mathrm{s}$. Foi calibrada em 17/06/2011 no Sistema Absoluto de Padronização Primária do Instituto de Radioproteção e Dosimetria, IRD/CNEN. Essa fonte é a mais utilizada comercialmente, devido à sua meia - vida ser longa, de 432,6 anos, o que evita a necessidade de sua calibração periódica, e por ser recomendada pela norma ISO 8529-1 (ISO, 2001). A Figura 3.1 mostra as dimensões da fonte de ${ }^{241} \mathrm{Am}(\mathrm{Be})$ utilizada neste trabalho. 


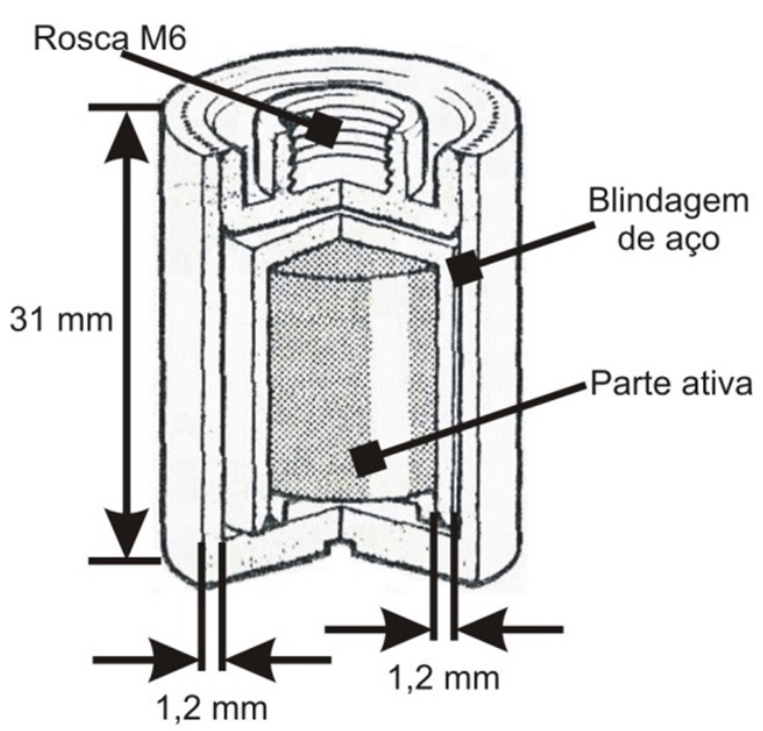

Figura 3.1: Dimensões da fonte de nêutrons de ${ }^{241} \operatorname{Am}(B e)$ do LTN (AMERSHAM, 1986).

\subsection{Material para confecção da blindagem da fonte de nêutrons}

Para a confecção da blindagem da fonte de nêutrons foi utilizada parafina composta por ácido bórico.

\subsection{Cone de sombra}

Para as medições da radiação espalhada foi utilizado o método do cone de sombra (emprestado do Laboratório de Dosimetria do Instituto de Física/USP). Este cone possui $40 \mathrm{~cm}$ de comprimento, com $20 \mathrm{~cm}$ de ferro e $20 \mathrm{~cm}$ de parafina borada. O cone de sombra pode ser visualizado na Figura 3.2.

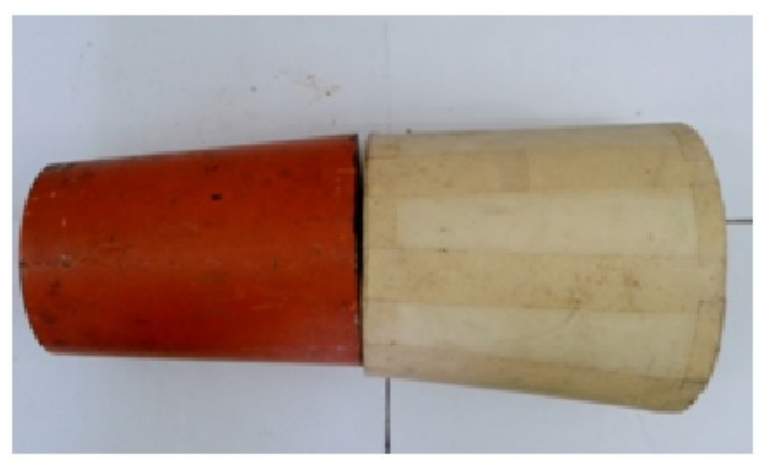

Figura 3.2: Cone de sombra utilizado neste trabalho. 


\subsection{Detectores de radiação de nêutrons}

Os seguintes detectores de radiação de nêutrons e gama portáteis foram utilizados neste trabalho:

\subsubsection{Detectores de radiação de nêutrons, marca Camberra, modelo Dineutron, séries 133, 292, 293, 294 e 361}

Cada um destes equipamentos possui dois detectores de ${ }^{3} \mathrm{He}$ com esferas moderadoras de tamanhos variados (Figura 3.3). As características principais destes detectores são:

- Resposta energética: 0,025 eV a $15 \mathrm{MeV}$;

- Intervalo de taxa de equivalente de dose ambiente: 0,01 a $99 \mathrm{mSv} / \mathrm{h}$;

- Visor digital.

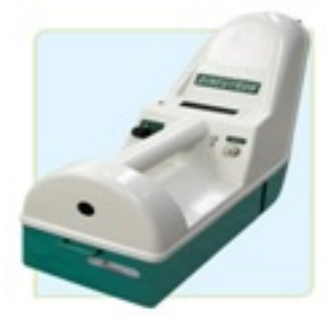

Figura 3.3: Monitor de área Camberra, modelo Dineutron.

\subsubsection{Detectores de radiação de nêutrons, marca Ludlum, modelo 12-4, séries 227914 e 305363}

Cada um destes equipamentos possui um detector proporcional a gás com $\mathrm{BF}_{3}$ e um moderador esférico de polietileno, com $22,9 \mathrm{~cm}$ de diâmetro (Figura 3.4). As características principais destes equipamentos são:

- Resposta energética: de 0,025 eV a $12 \mathrm{MeV}$;

- Intervalo de taxa de equivalente de dose ambiente: 0 a $100 \mathrm{mSv} / \mathrm{h}$.

- Visor analógico. 


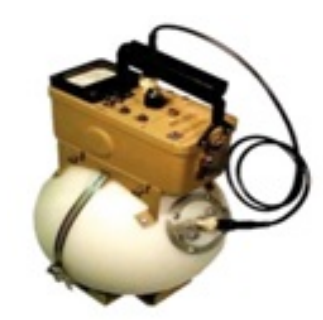

Figura 3.4: Monitor de área Ludlum, modelo 12-4.

\subsubsection{Detectores de radiação de nêutrons, marca Ludlum, modelo 2241-4, séries 274063 e 274064}

Estes equipamentos possuem um detector proporcional a gás com ${ }^{3} \mathrm{He} e$ moderador esférico de polietileno, com 22,9 cm de diâmetro (Figura 3.5). As características principais destes detectores são:

- Resposta energética: de 0,025 eV a 12 MeV;

- Intervalo de taxa de equivalente de dose ambiente: 0 a $100 \mathrm{mSv} / \mathrm{h}$;

- Visor digital.

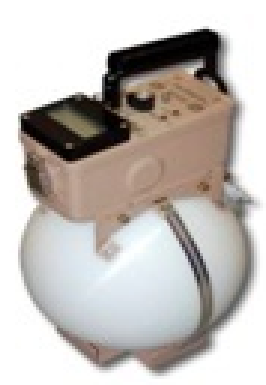

Figura 3.5: Monitor de área Ludlum, modelo 2241-4.

\subsubsection{Detectores de radiação de nêutrons, marca Thermo, modelo ASP-2, séries 02514 e 02517}

Cada um destes equipamentos possui um detector proporcional a gás com BF3 e um moderador de polietileno esférico com $22,9 \mathrm{~cm}$ de diâmetro (Figura 3.6). Suas características principais são:

- Resposta energética: de 0,025 eV a 10 MeV; 
- Intervalo de taxa de equivalente de dose ambiente: 0 a $100 \mathrm{mSv} / \mathrm{h}$;

- Visores analógico e digital.

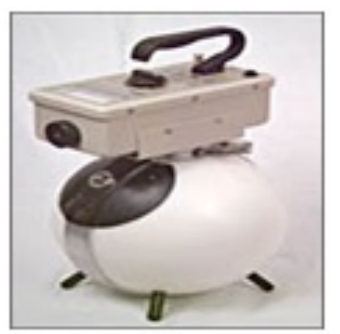

Figura 3.6: Monitor de área Thermo, modelo ASP-2.

Estes equipamentos possuem Certificados de Calibração $N^{\circ}$ 0528-2013 e 0530-2013, do Laboratório Nacional de Metrologia das Radiações Ionizantes (LNMRI) e foram utilizados como sistemas de referência neste trabalho.

\subsubsection{Monitor de radiação gama Geiger - Müller, marca Automess, modelo 6150 AD5, série 10739}

Este detector possui um detector Geiger-Müller na parte interna (Figura 3.7). Suas principais características são:

- Resposta energética: de 45 keV a 3 MeV;

- Intervalo de taxa de equivalente de dose ambiente: 0,01 mR/h a $99,99 \mathrm{mR} / \mathrm{h}$;

- Visor digital.

Este equipamento possui Certificado de Calibração IPEN № 0473/2012. 


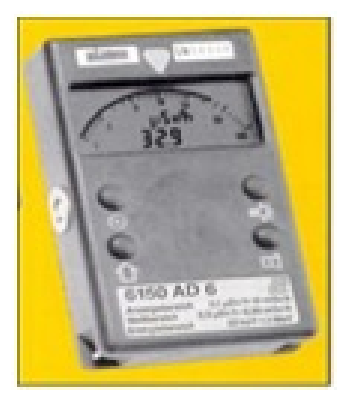

Figura 3.7: Monitor de radiação gama Geiger-Müller, marca Automess, modelo 6150 AD5.

\subsubsection{Monitor de radiação de nêutrons e gama Identifinder, marca Thermo Scientific, modelo NGH, série 3574-468}

Este monitor possui um detector Geiger-Müller para medição da radiação gama e um detector cintilador para medição da radiação de nêutrons (Figura 3.8). Suas principais características são:

- Resposta energética: de 20 keV a 3 MeV;

- Intervalo de taxa de equivalente de dose ambiente: $0,000 \mu \mathrm{Sv} / \mathrm{h}-10,00 \mathrm{mSv} / \mathrm{h}$;

- Visor digital.

Este equipamento possui Certificado de Calibração IRD N423/2014.

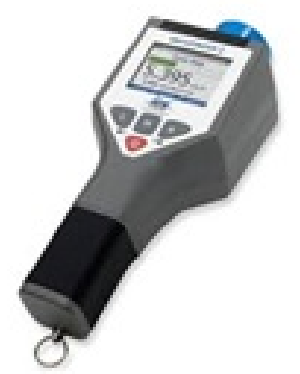

Figura 3.8: Monitor de área nêutron-gama Identifinder NGH. 


\subsection{Código de simulação Monte Carlo}

O código de Monte Carlo MCNP5 (X-5 Monte Carlo Team, 2008) foi desenvolvido e é mantido pelo Laboratório de Los Alamos (EUA); é um código multipropósito que pode ser utilizado para transporte de fótons e elétrons ou transporte acoplado de nêutrons. Uma das vantagens principais desse código reside no fato de que arranjos geométricos complexos podem ser descritos. 


\section{Capítulo 4}

\section{Resultados e Discussão}

Neste capítulo são apresentados os resultados obtidos na adequação e reforma do LTN, elaboração da blindagem para fonte de nêutrons, elaboração do arranjo de irradiação, elaboração do sistema de posicionamento da fonte de nêutrons, implantação do sistema de monitoração, construção do suporte do cone de sombra, levantamento radiométrico, estudo da estabilidade de resposta dos detectores, mapeamento do campo de radiação e a avaliação do LTN utilizando simulação de Monte Carlo.

\subsection{Adequação e reforma do Laboratório de Testes com Nêutrons}

A instalação fica no prédio do Bunker (local semi-enterrado), que possui diversas salas com fontes de radiação gama que fazem parte do Laboratório de Calibração de Instrumentos, da Gerência de Metrologia das Radiações (GMR). A sala que irá abrigar o Laboratório de Testes com Nêutrons (LTN) possui dimensões de 6,88 m $\times 5,46 \mathrm{~m}$ e paredes de concreto com espessura de $15 \mathrm{~cm}$. A sala possui uma altura de $2,8 \mathrm{~m}$, sendo o teto de concreto, com $15 \mathrm{~cm}$ de espessura, e o piso de granito, com $5 \mathrm{~cm}$ de espessura (Figura 4.1). 


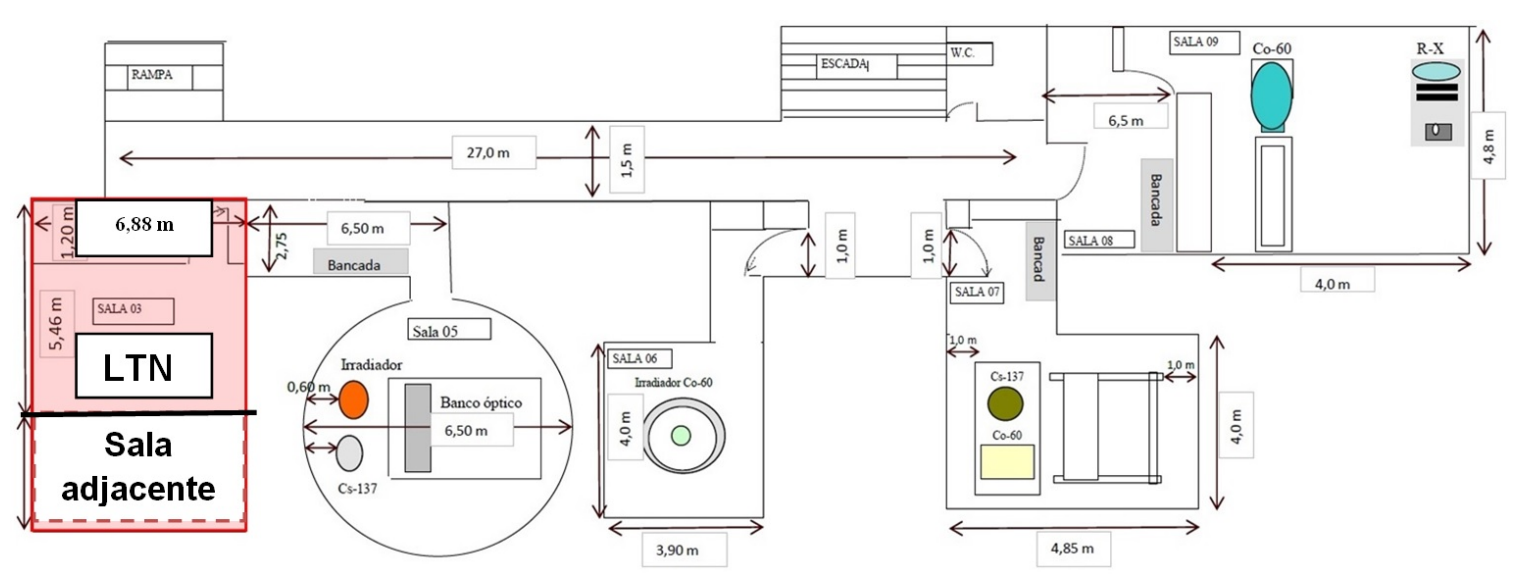

Figura 4.1: Planta baixa do Bunker do LCI. A área destacada em vermelho é o Laboratório de Testes com Nêutrons.

No projeto da reforma da sala onde está sendo instalado o Laboratório de Testes com Nêutrons, foi colocada uma parede de drywall, permitindo criar uma sala de controle onde ficará o painel de controle do arranjo, o sistema de controle da fonte e o técnico responsável pelos testes dos detectores de nêutrons, atendendo assim às normas de radioproteção (CNEN, 2011). A planta baixa do LTN pode ser visualizada na Figura 4.2.

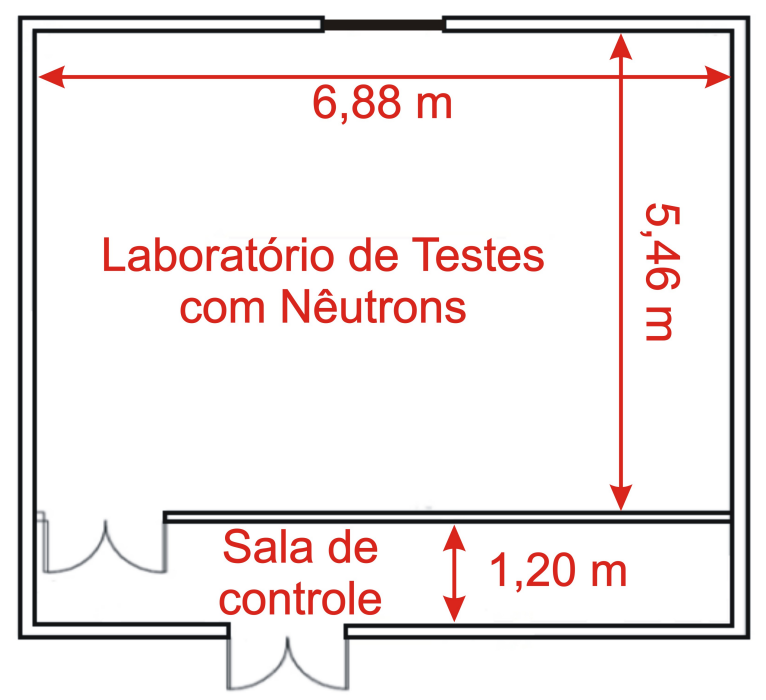

Figura 4.2: Planta baixa do Laboratório de Testes com Nêutrons.

As seguintes adequações foram realizadas:

- o portão da entrada da sala foi substituído por uma porta;

- as paredes de concreto foram revestidas com drywall com $2,5 \mathrm{~cm}$ de espessura, com o objetivo de diminuir o espalhamento da radiação; 
- as luminárias existentes foram substituídas;

- foi instalado um sistema de exaustão de ar;

- foi instalado um sistema de refrigeração (ar condicionado);

- foram instaladas tomadas para viabilizar o uso de diferentes equipamentos utilizados nos testes dos monitores portáteis de nêutrons;

- o piso de granito foi polido devido ao desgaste pelo uso, com aplicação de resina impermeabilizante;

- foi construída uma parede divisória de drywall com $5 \mathrm{~cm}$ de espessura entre a área do laboratório e a sala de controle,

- foi instalado um visor de Lucite na parede que divide a sala de controle e o laboratório;

- foram instalados dois pontos de rede para viabilizar o acesso à internet.

As Figuras 4.3 e 4.4 mostram o laboratório de testes e a sala de controle, ainda vazios.

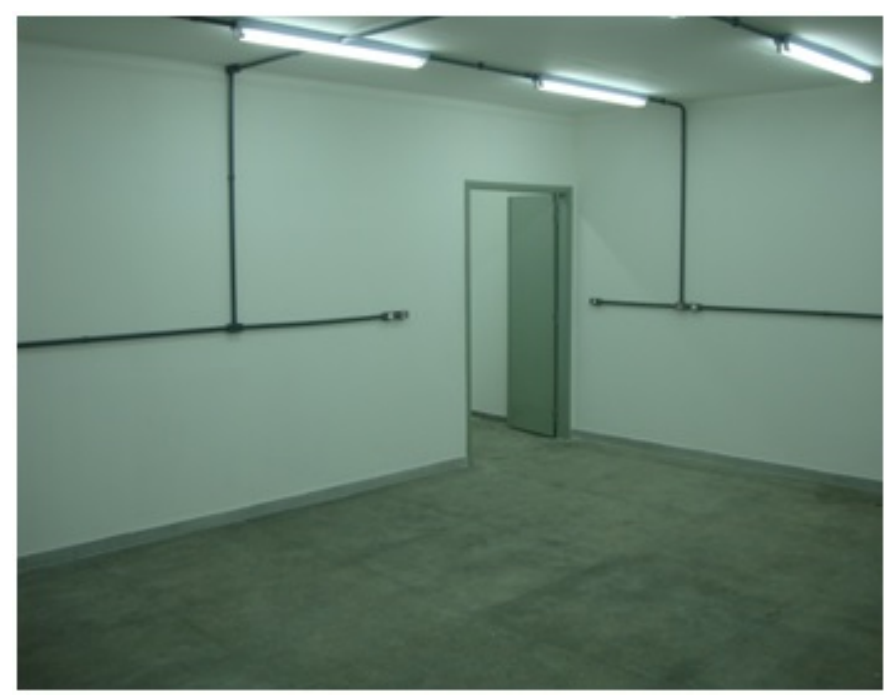

Figura 4.3: Laboratório de testes. 


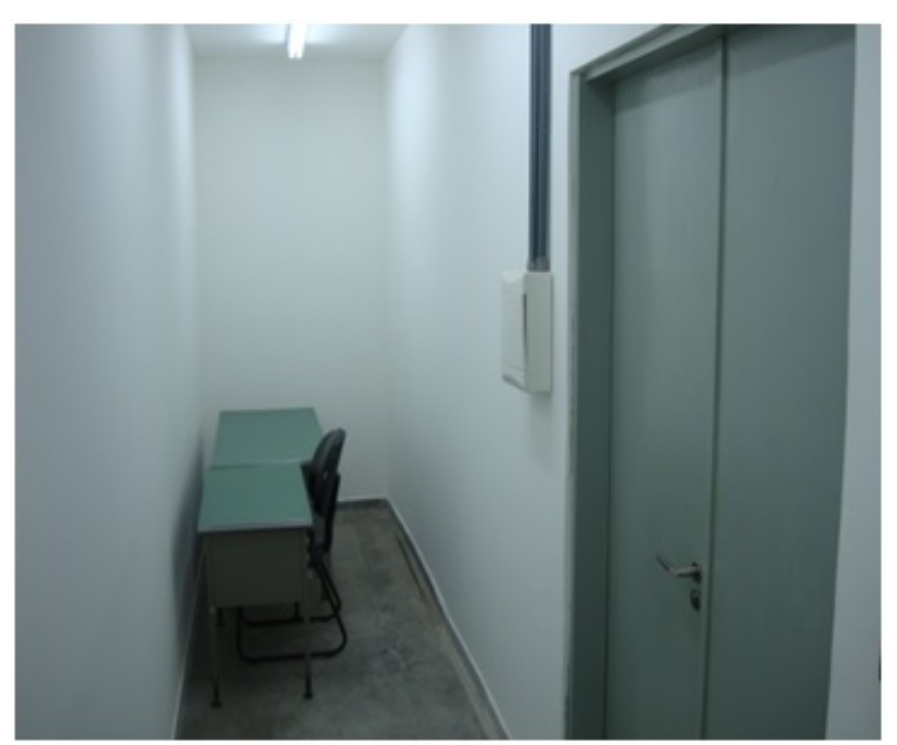

Figura 4.4: Sala de controle.

\subsection{Blindagem para a fonte de nêutrons}

Para utilização da fonte de ${ }^{241} \mathrm{Am}(\mathrm{Be})$ neste trabalho, foi necessário desenvolver uma blindagem para seu armazenamento adequado. A blindagem para radiação de nêutrons atua moderando os nêutrons rápidos, absorvendo os nêutrons térmicos e absorvendo os feixes de radiação gama, provenientes da fonte de ${ }^{241} \mathrm{Am}(\mathrm{Be})$. Os elementos mais eficazes utilizados para moderar e absorver os nêutrons são os materiais hidrogenados como água, polietileno, parafina e boro (MURRAY, 2004). Na Tabela 4.1 mostra as propriedades dos principais materiais utilizados para moderar nêutrons.

Tabela 4.1: Propriedades dos materiais moderadores (NCRP, 1971).

\begin{tabular}{ccc}
\hline Material & $\begin{array}{c}\text { Seção de choque } \\
\left(\mathbf{c m}^{-\mathbf{1}}\right)\end{array}$ & $\begin{array}{c}\text { Densidade } \\
(\mathbf{g . c m} \mathbf{- 3})\end{array}$ \\
Água & 0,103 & 1 \\
Polietileno & 0,121 & 0,94 \\
Concreto & 0,089 & 2,35 \\
Parafina & 1,80 & 0,98 \\
\hline
\end{tabular}

Na elaboração da blindagem para a fonte de ${ }^{241} \mathrm{Am}(\mathrm{Be})$, as dimensões foram determinadas por meio de cálculos. Foi utilizada a parafina borada como material atenuador e absorvedor devido à sua eficiência e ao baixo custo. 
Determinou-se que a blindagem deveria ter $30 \mathrm{~cm}$ de raio e $60 \mathrm{~cm}$ de altura, sendo essas dimensões suficientes para blindar a radiação gama oriunda da emissão do ${ }^{241} \mathrm{Am}(\mathrm{Be})$, a radiação gama produzida na interação dos nêutrons com o material de encapsulamento da fonte, a radiação gama secundária proveniente da interação dos nêutrons com a parafina borada e os nêutrons produzidos pela fonte de ${ }^{241} \mathrm{Am}(\mathrm{Be})$.

Os materiais utilizados no processo de construção da blindagem foram:

- um tambor de papelão de $60 \mathrm{~cm}$ de altura e $60 \mathrm{~cm}$ de diâmetro;

- um tubo guia em PVC com dimensões de $60 \mathrm{~cm}$ de altura e 91,2 mm de diâmetro;

- 56 litros de parafina borada;

- fios de níquel.

No processo de construção da blindagem, um dos cuidados principais foi em relação ao posicionamento do tubo guia para a fonte radioativa no centro da blindagem. Para o alinhamento do tubo guia foram utilizados os fios de níquel para sua fixação.

$\mathrm{Na}$ etapa do preenchimento do tambor com parafina borada, optou-se pela utilização de blocos pequenos, em forma de paralelepípedos, divididos por camadas. O espaço vazio entre os blocos foi preenchido com parafina borada derretida. Assim, após o resfriamento, a massa tornou-se homogênea, seguindo o procedimento sugerido por (OLIVEIRA, 2011).

$\mathrm{Na}$ Figura 4.5, a sequência de fotos mostra o procedimento adotado para construção da blindagem para a fonte de ${ }^{241} \mathrm{Am}(\mathrm{Be})$, a ser utilizada no Laboratório de Testes com Nêutrons. 


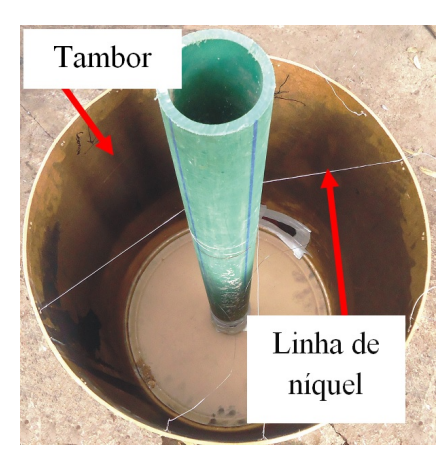

(a)

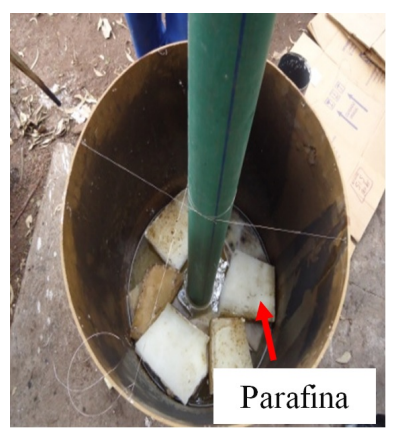

(b)

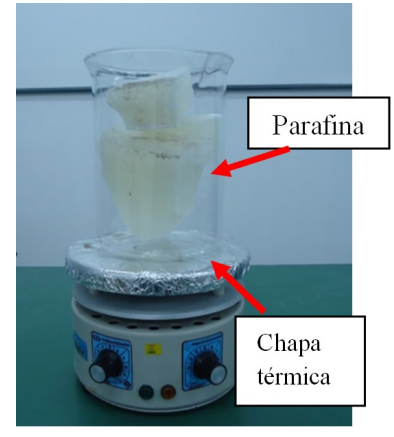

(c)

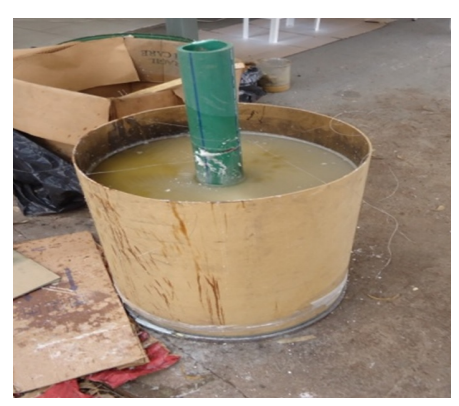

(d)

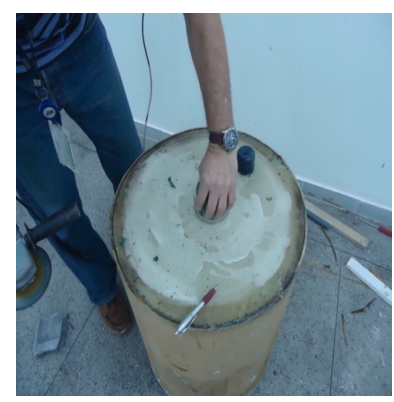

(e)

Figura 4.5: Fixação do tubo guia (a); Acomodação dos blocos (b); Derretimento da parafina (c); Preenchimento do tambor com parafina liquida (d); Bloco único de parafina (e).

\subsection{Arranjo de irradiação}

A estrutura do arranjo experimental do Laboratório de Testes com Nêutrons foi confeccionada em alumínio, para diminuir o espalhamento da radiação. Este equipamento possui duas bases deslizantes, fixadas sobre estruturas de aço carbono com regulagem manual de altura. $O$ arranjo encontra-se representado na Figura 4.6. O projeto do arranjo foi idealizado pelo Eng. Wagner Nieto (Oficina Mecânica/Centro de Radiofarmácia/IPEN) e confeccionado pela empresa APF — Usinagem e Montagem Ltda. 


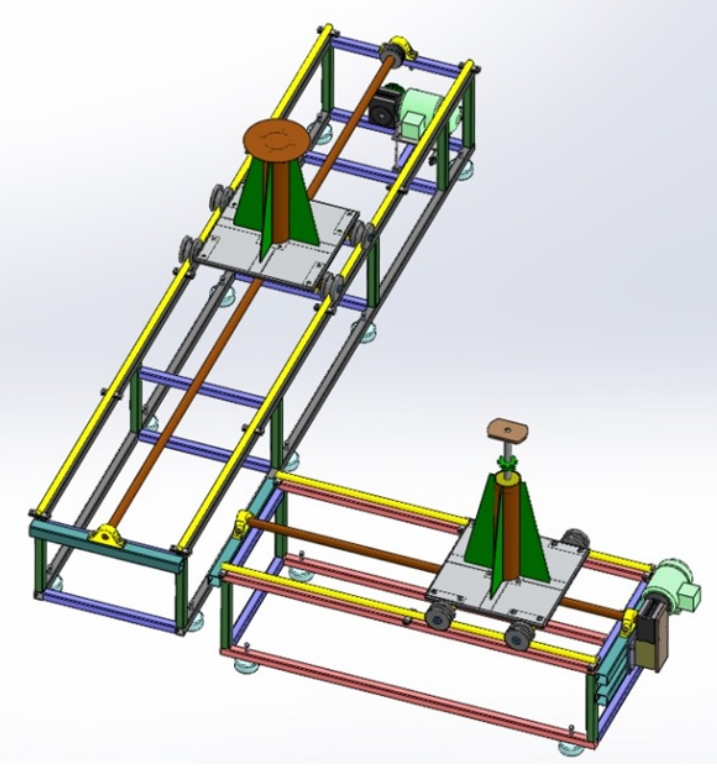

Figura 4.6: Configuração final do arranjo de irradiação do LTN.

As bases metálicas serão utilizadas para variação da distância entre 0 detector e a fonte de ${ }^{241} \mathrm{Am}(\mathrm{Be})$, possibilitando assim a realização dos testes dos monitores portáteis e dosímetros pessoais no LTN. Para movimentação das duas bases foram utilizados motores com redutores de velocidade, acoplados a um fuso trapezoidal de movimento linear com paradas programadas por um comando à distância por um painel eletrônico. Nas Figuras 4.7 e 4.8 são apresentadas as perspectivas frontal e lateral da estrutura do arranjo de irradiação do LTN. 


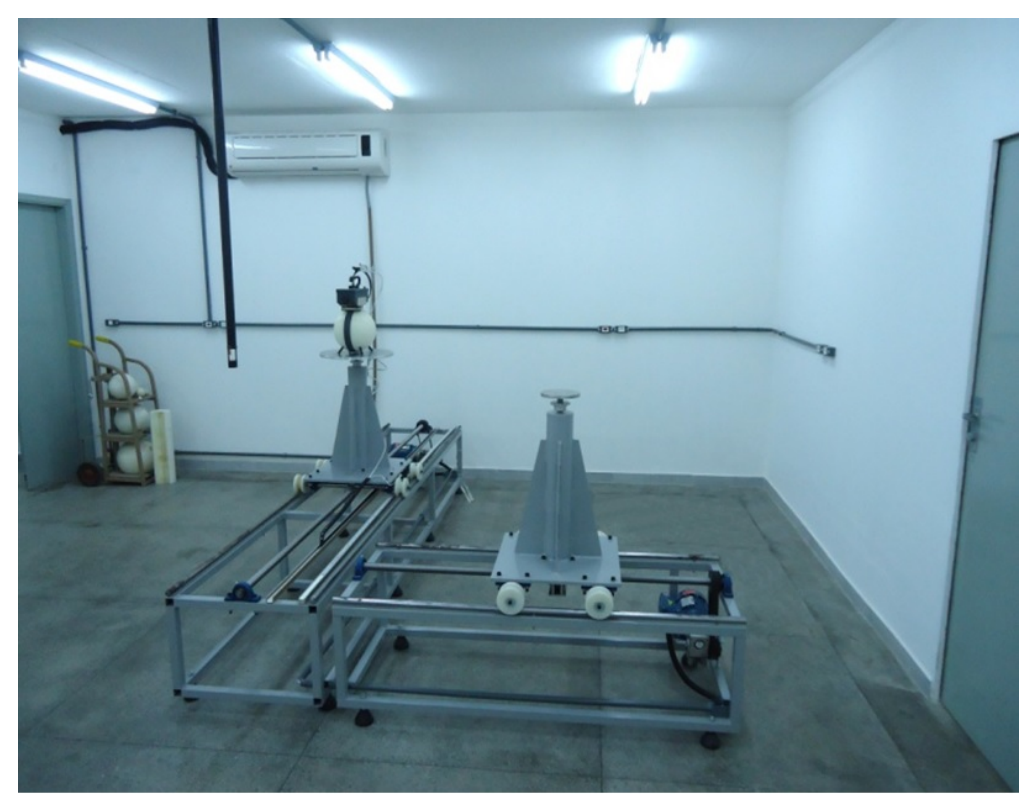

Figura 4.7: Visão frontal do arranjo de irradiação do LTN.

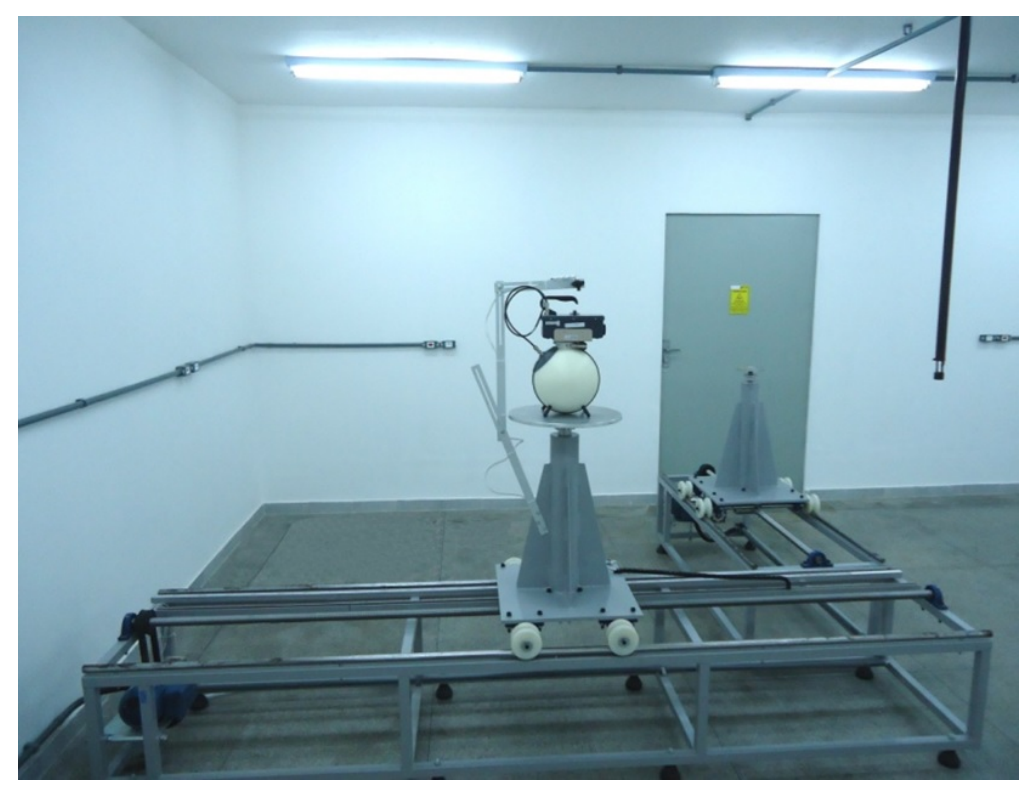

Figura 4.8: Visão lateral do arranjo de irradiação do LTN.

\subsection{Sistema de posicionamento da fonte de nêutrons}

O sistema de posicionamento da fonte do LTN tem o objetivo de minimizar o risco de exposição do operador a doses desnecessárias nos procedimentos de testes dos monitores portáteis de nêutrons. 
A fonte posicionada na parte central da blindagem foi fixada em uma das extremidades de um cabo de aço flexível (cabo guia), movimentada por meio de uma catraca de manivela em uma das pontas, localizada na sala de controle. Quando acionada a manivela, o cabo guia conduz a fonte ao longo de um tubo de PVC (tubo guia) até o ponto de parada, que se encontra no centro geométrico da sala a uma distância de $1,40 \mathrm{~cm}$ em relação ao teto e ao piso.

O diagrama esquemático do sistema de posicionamento da fonte é mostrado na Figura 4.9, e as fotos deste sistema são apresentadas nas Figuras 4.10 e 4.11.

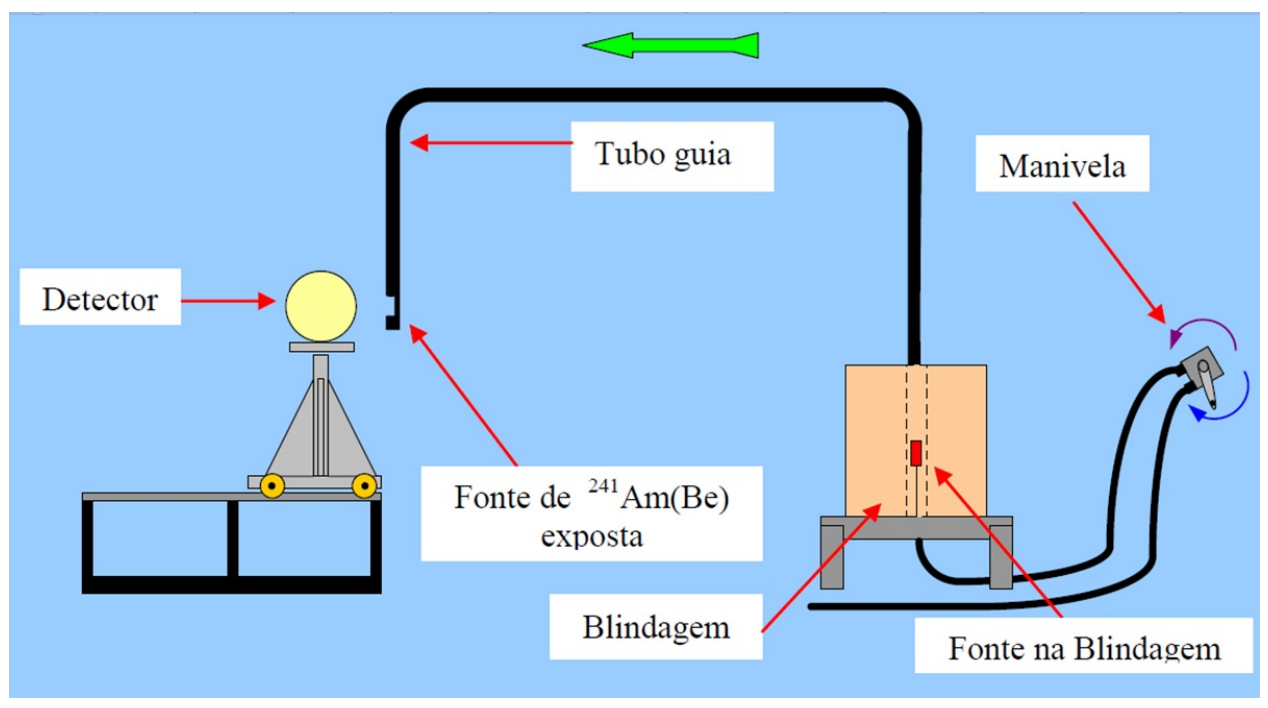

Figura 4.9: Configuração do sistema de posicionamento da fonte do LTN.

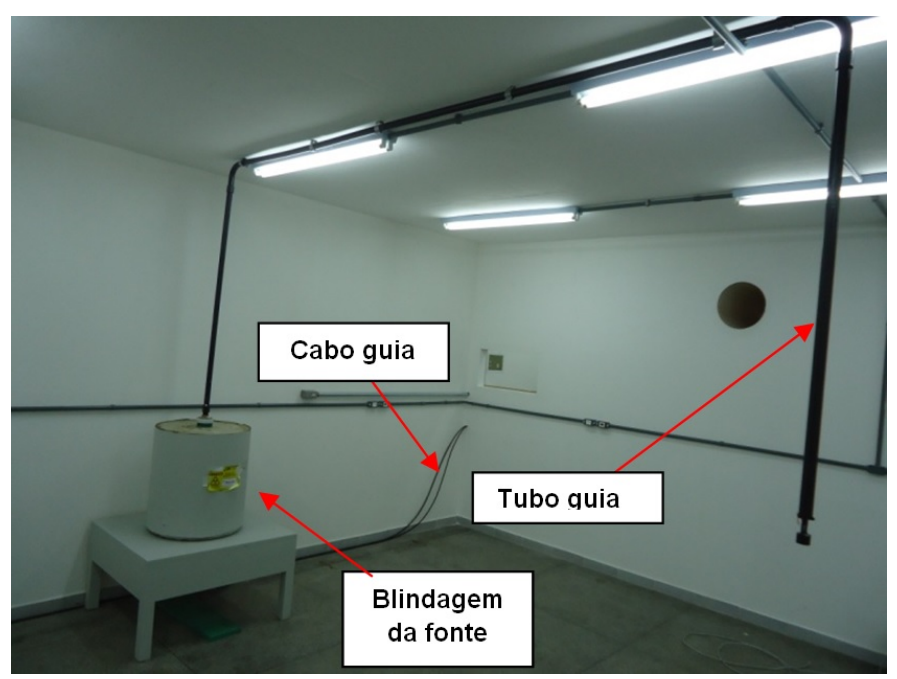

Figura 4.10: Sistema de posicionamento da fonte no LTN. 


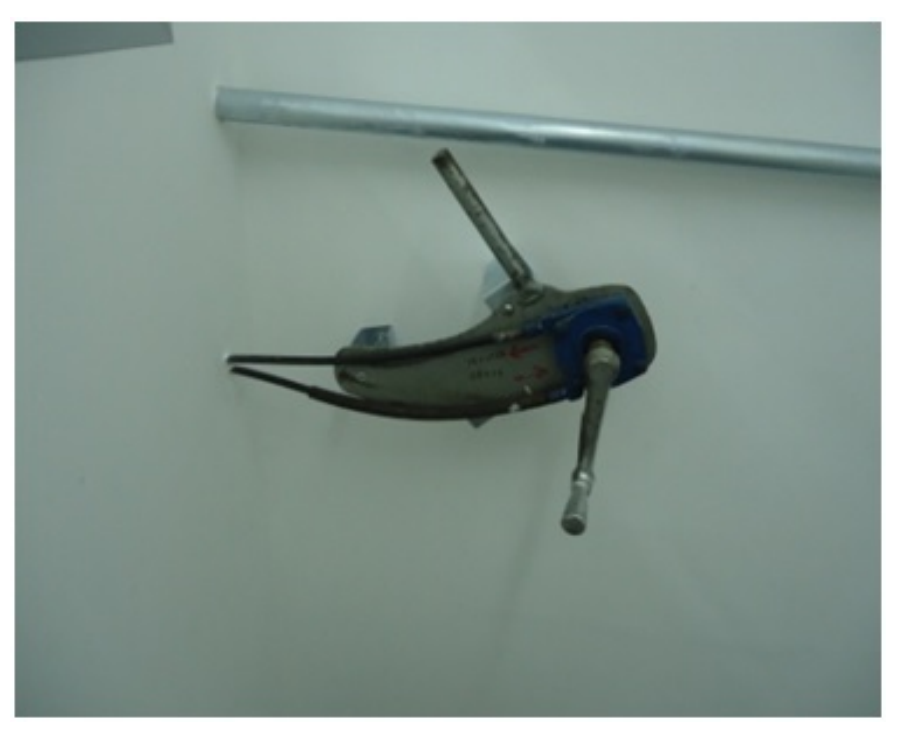

Figura 4.11: Manivela de acionamento para exposição da fonte de ${ }^{241} \mathrm{Am}(\mathrm{Be})$, localizada na sala de controle.

\subsection{Sistema de monitoração da medição e da distância fonte-detector}

Foi implantado no arranjo físico do LTN um sistema de monitoração que permite visualizar a leitura do detector e a distância fonte-detector.

O sistema é composto por duas câmeras de vídeo fixadas na parte superior e na parte inferior da base deslizante, que são utilizadas para visualizar as leituras dos detectores e as distâncias, por meio de um monitor de video localizado na sala de controle.

Uma trena foi fixada numa das bases de alumínio, que utiliza um ponteiro de acrílico para indicação das distâncias fonte-detector. Nas Figuras 4.12 e 4.13 são apresentadas as duas câmeras utilizadas para visualização das leituras dos detectores e das distâncias fonte-detector. 


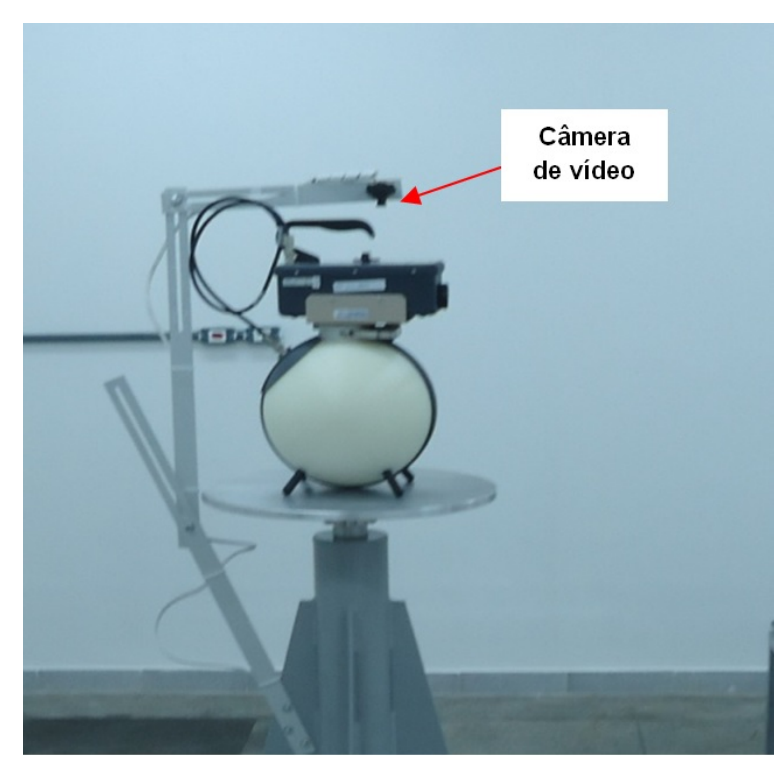

Figura 4.12: Sistema de monitoração das leituras dos detectores, com destaque para a câmera de vídeo.

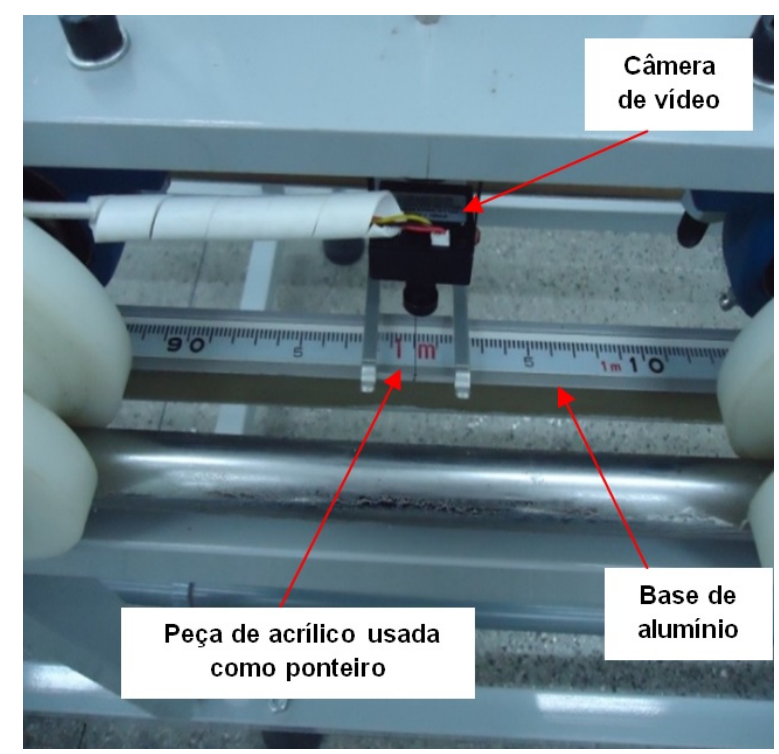

Figura 4.13: Sistema de monitoração das distâncias fonte - detector, com destaque para a câmera de vídeo.

\subsection{Construção do suporte para o cone de sombra}

Para utilização do cone de sombra foi necessário projetar um suporte especial para o seu posicionamento, em conjunto com o setor de projetos do IPEN. A confecção deste suporte demandou uma tarefa mais detalhada em virtude do peso total do cone que é de $30 \mathrm{~kg}$. O material escolhido para construção foi o alumínio, devido à fácil usinagem e ao baixo espalhamento da radiação.

Na Figura 4.14 é mostrada a configuração final do suporte do cone de sombra 
projetado, utilizando o software Solid Edge. A partir deste projeto foi construído o suporte para o cone de sombra, que foi instalado na base metálica, que fica posicionado entre o detector e a fonte, conforme a Figura 4.15.

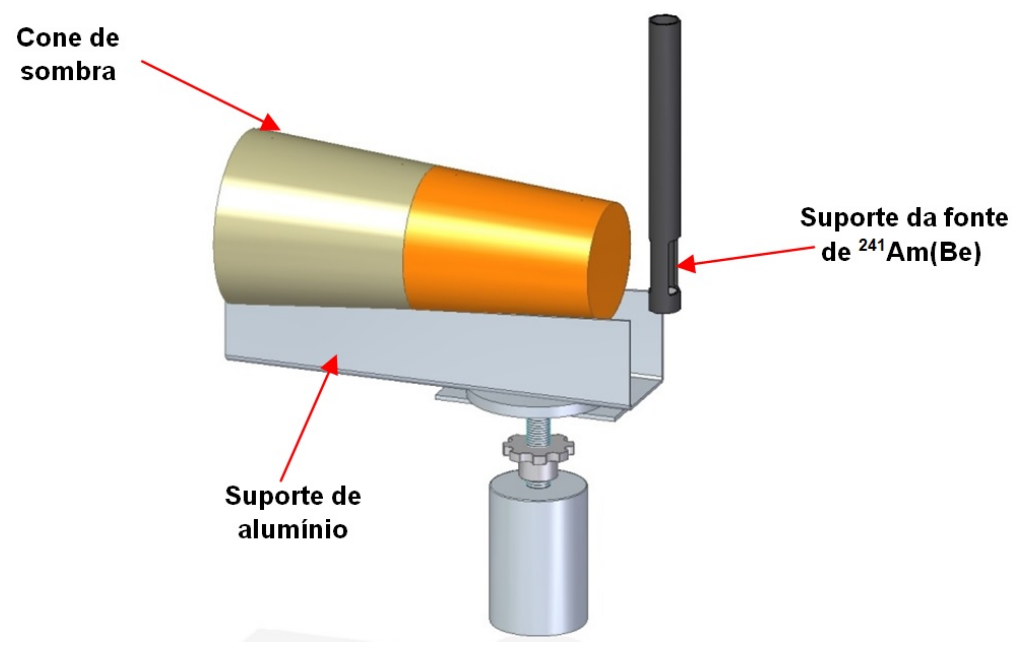

Figura 4.14: Projeto com a utilização do software Solid Edge do suporte para o cone de sombra.

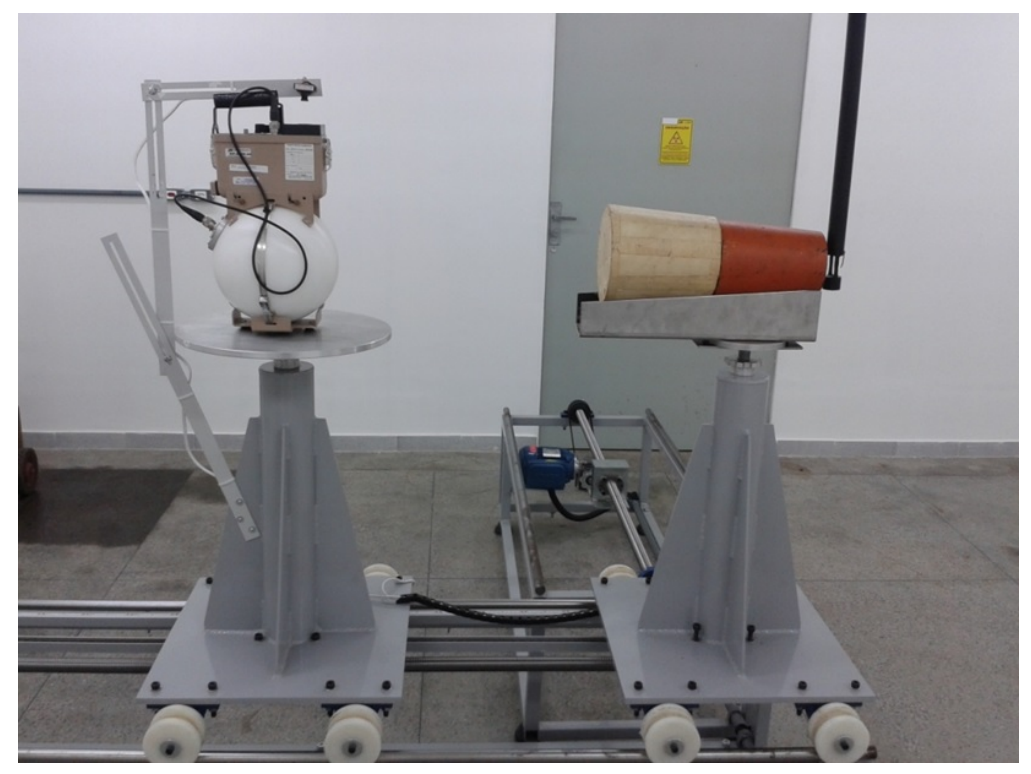

Figura 4.15: Suporte final para o cone de sombra. 


\subsection{Levantamento radiométrico}

Para avaliação das condições existentes no local e para a classificação das áreas do LTN, foi realizado um levantamento radiométrico, avaliando-se os níveis de equivalente de dose aos quais estarão expostos os trabalhadores e o público, e se eles são compatíveis com os limites admissíveis, estipulados nas normas de radioproteção (CNEN, 2011).

Foram selecionadas 15 posições, a distâncias diferentes em relação à fonte, denominadas pontos de medição, indicados na Figura 4.16. As medições foram feitas na área interna do laboratório com a fonte dentro da blindagem, e na sala de controle e no corredor que dá acesso aos laboratórios, com a fonte exposta.

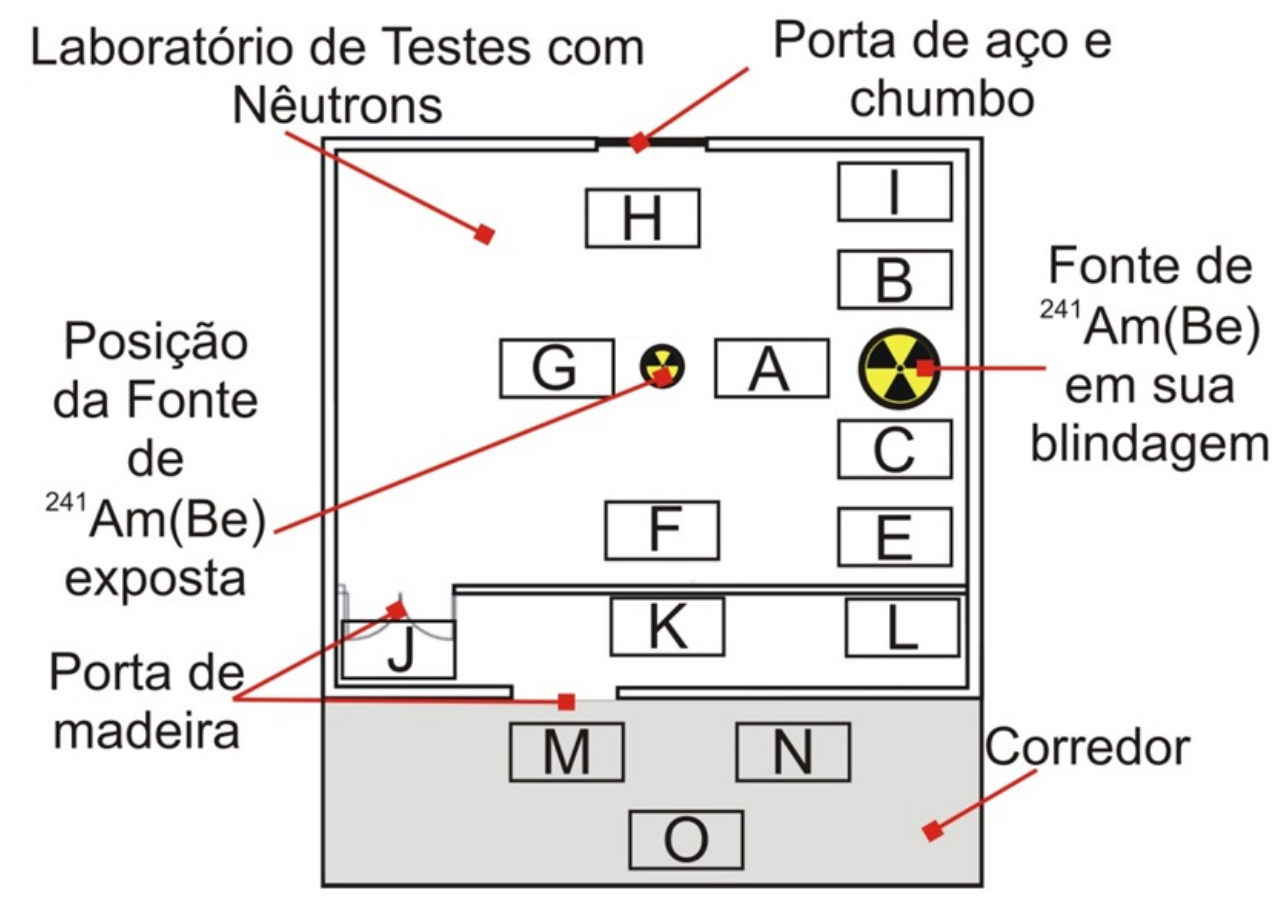

Figura 4.16: Planta baixa do LTN, identificando os pontos de medição onde foi realizado o levantamento radiométrico. O ponto de medição $D$ está localizado na parte superior da blindagem da fonte, e não pode ser visto na figura.

As medições foram realizadas sob a supervisão de um técnico da Gerência de Radioproteção (GRP/IPEN), em 16 de junho de 2013. Foram utilizados os monitores portáteis de radiação Geiger-Müller/Graetz 6150 ADS (série 10739) e Camberra modelo Dineutron (série 361). Na Tabela 4.2 estão representados os resultados obtidos do levantamento radiométrico realizado. 
Tabela 4.2: Níveis de radiação do LTN em 16/07/2013, com a fonte de ${ }^{241} \mathrm{Am}(\mathrm{Be})$ na blindagem e exposta.

\section{Taxa de equivalente de dose}

\begin{tabular}{|c|c|c|c|c|}
\hline \multirow{3}{*}{$\begin{array}{l}\text { Ponto } \\
\text { de } \\
\text { Medição }\end{array}$} & \multicolumn{4}{|c|}{$(\mu \mathrm{Sv} / \mathrm{h})$} \\
\hline & \multicolumn{2}{|c|}{ Radiação gama } & \multicolumn{2}{|c|}{ Radiação de nêutrons } \\
\hline & Valor & $\begin{array}{c}\text { Incerteza } \\
(\%)\end{array}$ & Valor & $\begin{array}{c}\text { Incerteza } \\
(\%)\end{array}$ \\
\hline \multicolumn{5}{|c|}{ Medições realizadas com a fonte na blindagem } \\
\hline A & 7,1 & 3,3 & 0,6 & 2,5 \\
\hline B & 6,0 & 3,0 & 0,7 & 3,0 \\
\hline $\mathrm{C}$ & 6,5 & 4,3 & 0,8 & 2,6 \\
\hline $\mathrm{D}$ & 8,3 & 2,5 & 12,2 & 2,1 \\
\hline $\mathrm{E}$ & 0,6 & 3,0 & 0,5 & 4,1 \\
\hline $\mathrm{F}$ & 0,5 & 2,8 & 0,4 & 3,4 \\
\hline G & 0,3 & 2,7 & 0,4 & 3,3 \\
\hline $\mathrm{H}$ & 0,5 & 2,8 & 0,3 & 2,9 \\
\hline I & 0,8 & 1,3 & 0,4 & 3,0 \\
\hline \multicolumn{5}{|c|}{ Medições realizadas com a fonte exposta } \\
\hline $\mathrm{J}$ & 0,5 & 2,3 & 0,4 & 2,8 \\
\hline $\mathrm{K}$ & 0,8 & 2,6 & 0,4 & 2,6 \\
\hline $\mathrm{L}$ & 0,4 & 2,7 & 0,4 & 2,0 \\
\hline M & 0,2 & 2,4 & 0,1 & 3,2 \\
\hline $\mathrm{N}$ & 0,1 & 3,0 & 0,1 & 3,1 \\
\hline 0 & 0,1 & 3,0 & 0,1 & 4,3 \\
\hline
\end{tabular}

É possível verificar que os pontos com maior taxa de dose, tanto para radiação de nêutrons e como para radiação gama, foram obtidos nos pontos $A$, $\mathrm{B}, \mathrm{C}$ e $\mathrm{D}$ devido à localização dos pontos de medição, próximos (e equidistantes a $10 \mathrm{~cm}$, no caso dos pontos $A, B$ e C) da blindagem. $O$ ponto de medição D, localizado na parte superior da blindagem, foi o ponto com o maior nível de radiação, mas o valor obtido está ainda dentro do limite recomendado pela norma (CNEN, 2011).

Nos pontos E, F, G, H e I, dentro do laboratório, com a fonte recolhida na blindagem, os níveis estão muito abaixo dos limites admissíveis para 
trabalhadores (CNEN, 2011).

Na sala de controle e no corredor, com a fonte exposta na posição de teste, no interior do LTN, os níveis estão dentro dos valores admissíveis em áreas supervisionadas.

\subsection{Determinação de parâmetros do LTN utilizando simulação de Monte Carlo}

Foi realizada uma simulação utilizando o código de Monte Carlo MCNP5 (X-5 Monte Carlo Team, 2008), com o objetivo de desenvolver um estudo detalhado do Laboratório de Testes com Nêutrons (LTN).

Foram simuladas $2 \times 10^{9}$ histórias, com o tally F4, com o objetivo de obter resultados com incertezas menores. A geometria utilizada foi baseada nas plantas baixas do laboratório, disponíveis no IPEN, bem como nas medições no local para garantir que todas as dimensões utilizadas na simulação estivessem em concordância com as do laboratório.

Os materiais levados em consideração na composição do Laboratório de Testes com Nêutrons foram: ar atmosférico, drywall, concreto, madeira, solo e granito. A constituição destes materiais seguiu a descrição da construção do laboratório, e sua inserção no código MCNP5 foi feita com base nos dados do relatório PNNL-1570 (McCONN Jr et al., 2011).

O espectro da fonte radioativa, utilizada durante as simulações, foi obtido da Norma ISO 8529-Parte 1 (ISO, 2001). A descrição da instalação encontra-se na Figura 4.16.

Com o propósito de obter uma simulação mais realista, as áreas adjacentes ao laboratório também foram incorporadas ao arranjo geométrico da simulação, visto que os nêutrons podem sofrer espalhamento nestas áreas, causando alterações no espectro.

As avaliações do LTN utilizando o método de Monte Carlo foram divididas em duas etapas: avaliação das doses de radiação em pontos específicos do 
laboratório e avaliação da radiação espalhada em diversas posições de testes. Os resultados destas análises são apresentados a seguir.

\subsubsection{Avaliação das doses de radiação em pontos específicos do LTN}

A geometria utilizada durante as simulações é mostrada na Figura 4.17. Os pontos de medição foram escolhidos para se avaliar as taxas de equivalente de dose provenientes da fonte de ${ }^{241} \mathrm{Am}(\mathrm{Be})$ em diversas posições: num laboratório adjacente (Ponto 1); na sala da fonte (Ponto 2); num laboratório localizado no piso superior (Ponto 3); numa rua localizada no nível do piso superior (Ponto 4), na sala de controle (Ponto 5) e no corredor de acesso ao laboratório LTN (Ponto 6). Nas Figuras 4.18 e 4.19 são mostrados estes pontos de medição de forma detalhada.

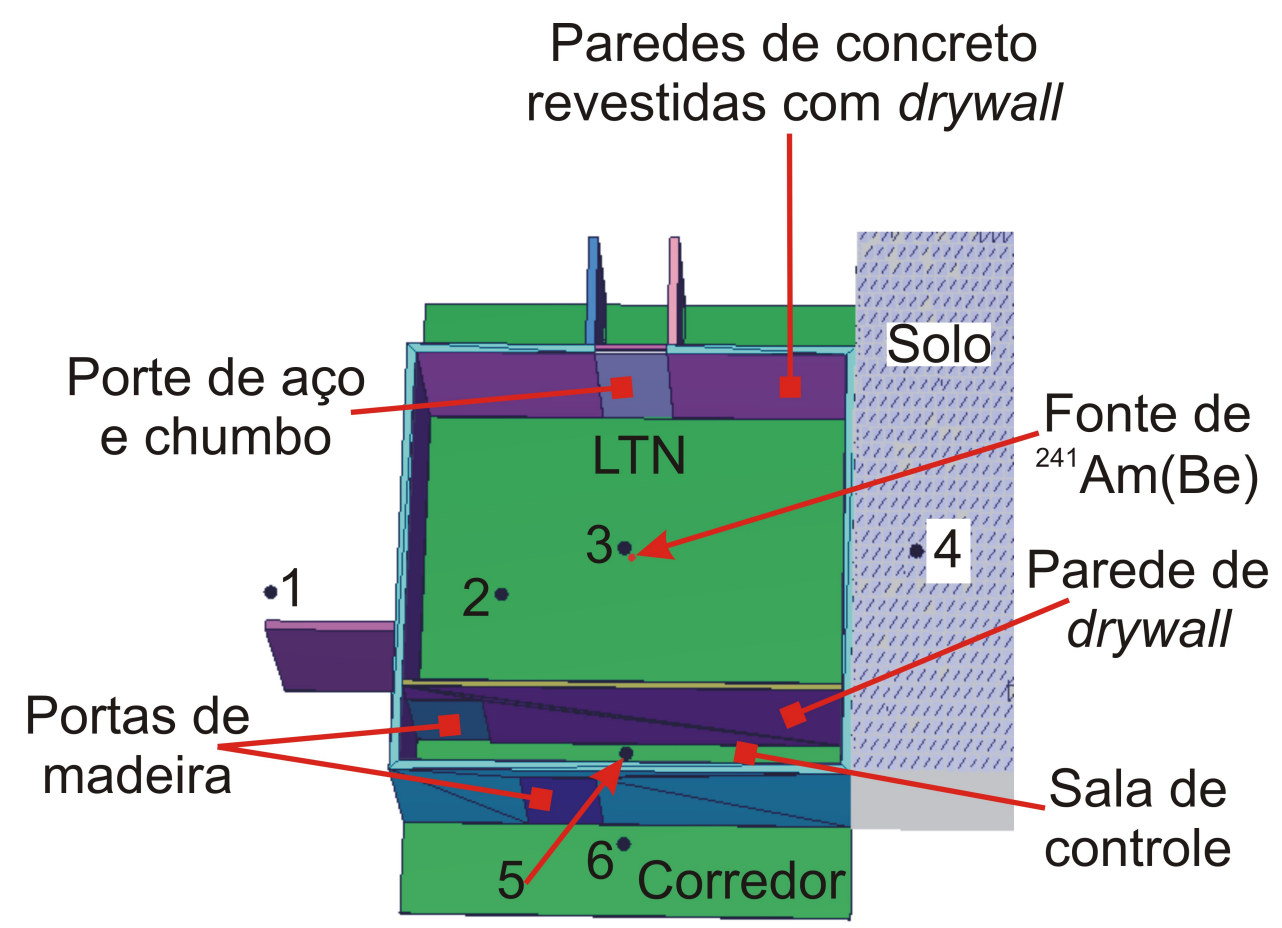

Figura 4.17: Geometria do LTN utilizada na simulação com o código de Monte Carlo MCNP5. Os pontos de medição são mostrados na figura: 1 a 6 . 


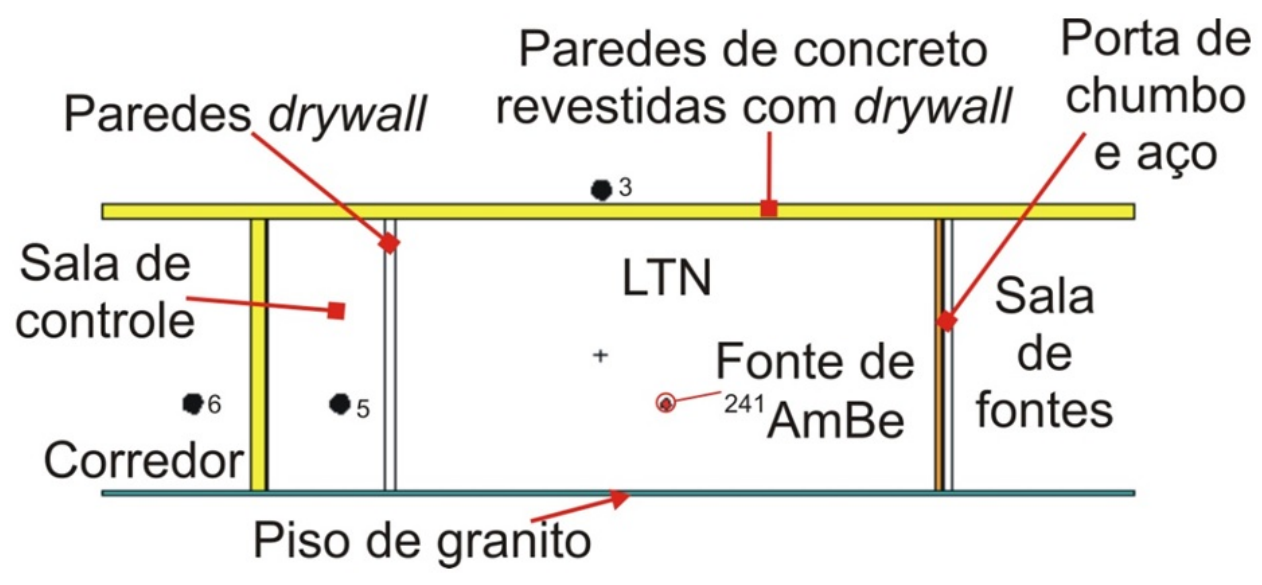

Figura 4.18: Corte lateral da geometria do LTN utilizada na simulação com o código de Monte Carlo MCNP5.

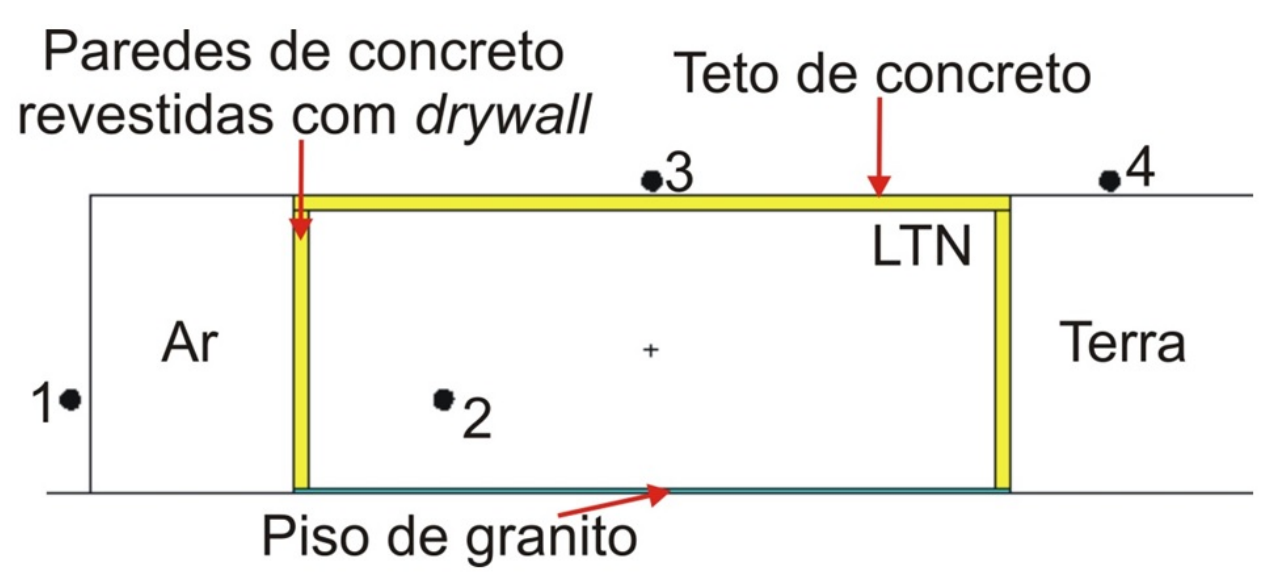

Figura 4.19: Corte axial da geometria do LTN utilizado na simulação com o código de Monte Carlo MCNP5.

Os resultados das simulações do transporte de nêutrons emitidos pela fonte de ${ }^{241} \mathrm{Am}(\mathrm{Be})$ no LTN são mostrados na Tabela 4.3. Para obter estes valores da energia depositada no ar nas posições de referência, obtidos com o código MCNP, foram convertidos para taxa de equivalente de dose ambiente utilizando os coeficientes de conversão de fluência para dose da norma ICRP (ICRP, 1996). Os valores foram calculados empregando um fator de conversão, que leva em consideração a medição experimental no Ponto 5. 
Tabela 4.3: Taxas de equivalente de dose $\dot{H}^{\star}(10)$, simulados (para nêutrons) obtidos em diversos pontos no LTN.

\begin{tabular}{ccc}
\hline Ponto de medição & Localização & $\dot{\boldsymbol{H}}^{\star}(\mathbf{1 0})(\boldsymbol{\mu S v} / \mathbf{h})$ \\
\hline 1 & Laboratório adjacente & $0,0004 \pm 0,0001$ \\
2 & Sala de irradiação & $0,4825 \pm 0,0001$ \\
4 & Teto & $0,1677 \pm 0,0001$ \\
5 & Solo, na parte externa & $0,0025 \pm 0,0001$ \\
6 & Sala de controle & $0,2000 \pm 0,0001$ \\
\hline
\end{tabular}

De acordo com as normas do órgão regulamentador brasileiro (CNEN, 2011), as áreas devem ser classificadas para público em geral e trabalhadores. Se uma determinada área for classificada para uso público, o limite de dose anual é de $1 \mathrm{mSv}$ e se for para trabalhadores, o limite é de $20 \mathrm{mSv}$. É importante ressaltar que estas doses devem ser otimizadas, de acordo com o princípio ALARA (CNEN, 2011).

Para este novo laboratório, as áreas dos pontos de medição 1, 3 e 6 fazem parte da área controlada, mas com níveis de doses admissíveis para indivíduos do público, de acordo com as restrições estabelecidas na legislação.

Considerando uma ocupação plena dos laboratórios adjacentes, pontos 1 e 3 , as doses para $8 \mathrm{~h} /$ dia de carga de trabalho serão de até $0,8 \mathrm{mSv}$ por ano e de 0,3 mSv por ano, respectivamente, que estão dentro dos limites admissíveis. Estes valores são muito mais baixos para as áreas dos pontos 4 e 6 , onde a ocupação é de cerca de 1/16 do laboratório.

Os pontos 2 e 5 estão em áreas de trabalho. Neste cenário, considerando uma carga de trabalho irreal de $8 \mathrm{~h} / \mathrm{dia}$, as doses seriam de até 0,4 mSv por ano, e portanto dentro do limite admissível de $20 \mathrm{mSv} / \mathrm{ano}$. O ponto 2 não será acessado com a fonte exposta, o que poderia ocorrer apenas no caso de uma falha no sistema de exposição da fonte.

Considerando todos esses fatos, os resultados da Tabela 4.3 mostram que a blindagem do laboratório é adequada para a fonte de ${ }^{241} \mathrm{Am}(\mathrm{Be})$, 
que será utilizada para calibrar os dosímetros e detectores de radiação. Portanto, os trabalhadores poderão permanecer na sala de controle durante os procedimentos de testes dos detectores de nêutrons.

Além disso, o espaço escolhido para abrigar o Laboratório de Testes com Nêutrons não precisa de nenhuma melhoria na blindagem, o que poderia resultar no aumento do custo na sua implantação.

\subsubsection{Avaliação da radiação espalhada nos pontos utilizados para testes de instrumentos}

A radiação espalhada pelos elementos estruturais do laboratório pode contribuir significativamente para o campo de radiação num certo ponto e, portanto, influenciar a leitura de um instrumento a ser testado. Como o processo de teste/calibração será pelo método de substituição (ISO, 2001), a radiação espalhada irá influenciar o dosímetro padrão e o dosímetro a ser testado da mesma forma; é necessário o conhecimento da intensidade desta componente, a fim de montar o sistema de teste/calibração na posição em que a radiação espalhada tenha a menor influência e para a obtenção de curvas de calibração de dosímetros, por exemplo do estado sólido.

O estudo proposto tem como objetivo caracterizar a contribuição da radiação de nêutrons espalhados da fonte de ${ }^{241} \mathrm{Am}(\mathrm{Be})$ em diferentes posições de teste/calibração dos detectores. Para isto, foi empregada a simulação de Monte Carlo, para a avaliação do laboratório antes de sua montagem final. Os pontos de medição, bem como a geometria do LTN, utilizadas com o código MCNP5, são mostrados na Figura 4.20. 


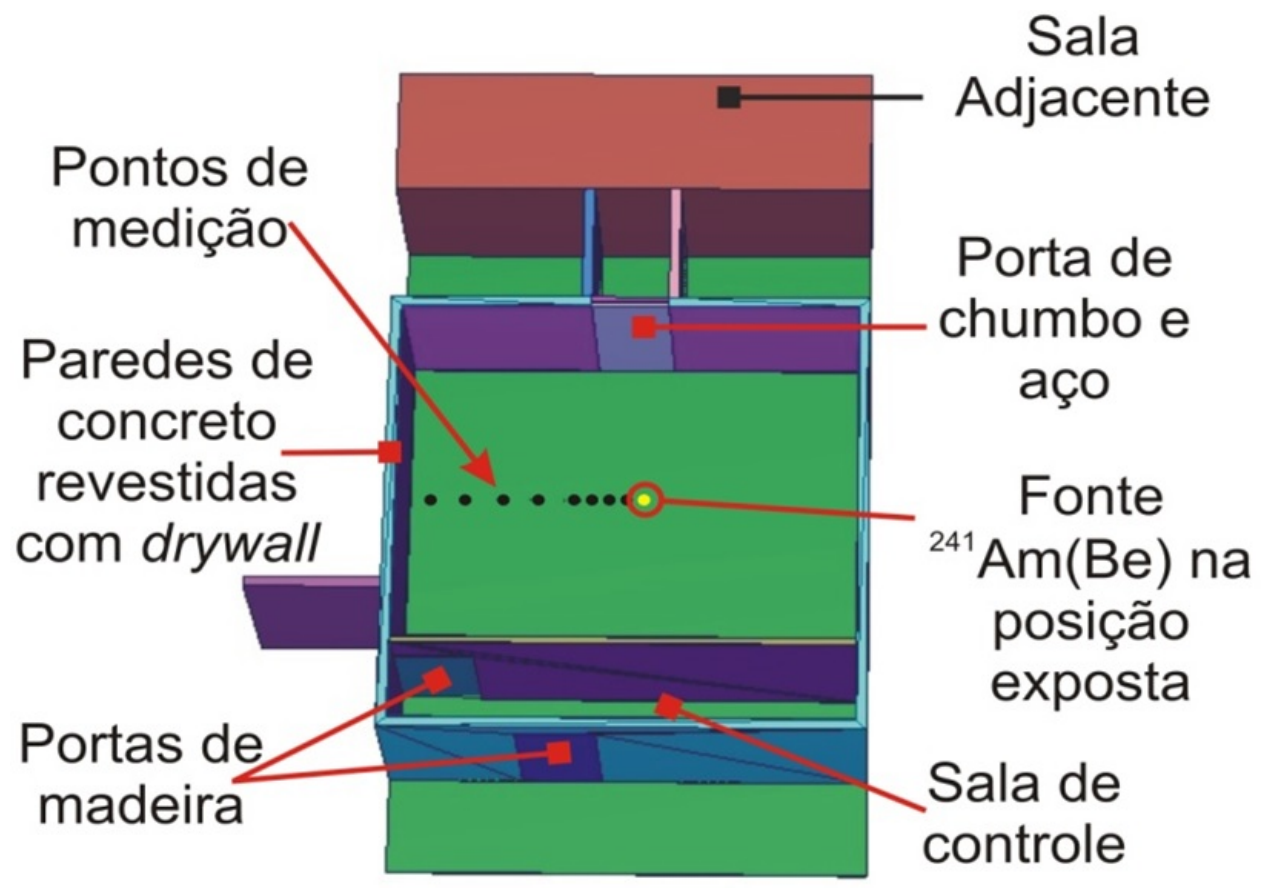

Figura 4.20: Geometria do LTN utilizada na simulação com o código de Monte Carlo MCNP5. Os oitos pontos de medição são mostrados na figura.

Em cada um dos oito pontos de medição foi determinado o espectro de nêutrons no LTN com todos os seus componentes estruturais. Para evitar as incertezas advindas da mudança da geometria no código de Monte Carlo, todas as superfícies e as células foram mantidas, mas a densidade dos materiais foi considerada nula, no caso do laboratório sem os componentes estruturais.

O espectro determinado nos pontos de medição foi convertido em taxa de equivalente de dose ambiente, $\dot{H}^{*}(10)$, utilizando os coeficientes de conversão da norma ICRP 74 (ICRP, 1996). Os valores do fluxo de nêutrons foram obtidos diretamente do código MCNP5 (X-5 Monte Carlo Team, 2008).

A influência da radiação espalhada determinada como sendo a razão entre os valores de $\dot{H}^{\star}(10)$ do laboratório sem os componentes estruturais e os valores de $\dot{H}^{\star}(10)$ do laboratório completo. O mesmo procedimento foi adotado para a avaliação da influência sobre o fluxo de nêutrons. Os resultados da influência da radiação espalhada nos valores de $\dot{H}^{\star}(10)$ e do fluxo de nêutrons dos oito pontos de medição são mostrados na Tabela 4.4. 
Tabela 4.4: Influência da radiação espalhada na determinação da $\dot{H}^{\star}(10)$ e do fluxo de nêutrons nos oito Pontos de medição.

\begin{tabular}{cccc}
\hline & $\begin{array}{c}\text { Distância da } \\
\text { fonte de }\end{array}$ & \multicolumn{2}{c}{$\begin{array}{c}\text { Influência } \\
\text { (\%) }\end{array}$} \\
\cline { 3 - 4 } medição & $\begin{array}{c}\text { 241 Am(Be) } \\
\text { (cm) }\end{array}$ & $\begin{array}{c}\text { Taxa de equivalente } \\
\text { de dose ambiente }\end{array}$ & Fluxo de nêutrons \\
\hline 1 & 25 & 0 & 0 \\
2 & 50 & 6,7 & 14,9 \\
3 & 75 & 13,3 & 28,2 \\
4 & 100 & 19,4 & 40,3 \\
5 & 150 & 36,5 & 59,0 \\
6 & 200 & 47,6 & 70,5 \\
7 & 250 & 56,8 & 78,9 \\
8 & 300 & 61,8 & 83,3 \\
\hline
\end{tabular}

Pode-se verificar que as posições de testes entre 25,0 cm e $100 \mathrm{~cm}$ apresentam uma influência da radiação espalhada de até 19,4\% nos valores de taxa de equivalente de dose ambiente $\dot{H}^{\star}(10)$ e de $40,3 \%$ nos valores de fluxo. Esta influência é devida à degradação do espectro de nêutrons por causa do espalhamento ocasionado pelos componentes estruturais do laboratório, principalmente o piso e as paredes. Para distâncias maiores do que $100 \mathrm{~cm}$, a influência torna-se muito maior, chegando a $61,8 \%$ para $300 \mathrm{~cm}$ de distância em relação à fonte e de 2,4 cm da parede de drywall e $30 \mathrm{~cm}$ da parede de concreto.

Os testes dos dosímetros em campos de nêutrons serão realizados a distâncias de até $100 \mathrm{~cm}$ da fonte radioativa, tanto para os valores de $\dot{H}^{\star}(10)$ quanto para o fluxo de nêutrons.

Com base em resultados obtidos na literatura, como os Laboratórios de Calibração Monju e OEC no Japão (TAKADA et al., 2011), que possuem laboratórios e fontes radioativas compatíveis com a estrutura do LTN do IPEN, observa-se que a influência da radiação espalhada a $100 \mathrm{~cm}$ da fonte de radiação é de aproximadamente 40,0\%. Este valor só é consideravelmente menor para 
laboratórios considerados "sem espalhamento", como o Laboratório de Tokai (TAKADA et al., 2011). Neste caso, o piso é revestido com placas dopadas com boro e paredes de concreto especial. Além disso, este laboratório possui dimensões de $13,0 \mathrm{~m} \times 12,5 \mathrm{~m}$.

\subsection{Determinação preliminar da radiação espalhada com o método de cone de sombra}

A avaliação do espalhamento pode ser feita por meio do método do cone de sombra. Foram comparadas as leituras de um dos detectores de referência, da marca Thermo, modelo ASP-2, série 02514 para medições sem o cone (feixe direto) e com o cone (feixe espalhado).

O detector foi posicionado às distâncias fonte-detector de 100, 110, 120, $130,140 \mathrm{~cm}$ e foram realizadas 10 medições cada vez e determinado o desvio padrão de cada série de medições, ou seja, a incerteza do tipo A. A influência da radiação espalhada foi determinada como sendo a razão entre valores das medições com o cone e sem o cone.

A Tabela 4.5 mostra os resultados da influência da radiação espalhada nas leituras do detector obtidas sem o cone e com o cone nos cinco pontos de medição. Estes resultados concordam com os obtidos pelo Método de Monte Carlo para a distância fonte-detector de $100 \mathrm{~cm}$. O método do cone de sombra deveria ter sido realizado com um espectrômetro para se ter resultados mais confiáveis. Esta experiência não pôde ser realizada neste trabalho. 
Tabela 4.5: Influência da radiação espalhada nas leituras do detector nos cinco pontos de medição.

\begin{tabular}{|c|c|c|c|c|}
\hline \multirow{2}{*}{$\begin{array}{l}\text { Distância } \\
\text { fonte- } \\
\text { detector } \\
\text { (cm) }\end{array}$} & \multicolumn{3}{|c|}{$\begin{array}{l}\text { Taxa de equivalente de dose } \\
\text { (mrem/h) }\end{array}$} & \multirow{2}{*}{$\begin{array}{l}\text { Influência da } \\
\text { radiação } \\
\text { espalhada } \\
(\%)\end{array}$} \\
\hline & $\begin{array}{l}\text { Sem cone } \\
\text { (A) }\end{array}$ & $\begin{array}{l}\text { Com cone } \\
\text { (B) }\end{array}$ & $(A-B)$ & \\
\hline 100 & $2,78 \pm 0,04$ & $0,616 \pm 0,053$ & $2,17 \pm 0,06$ & 22 \\
\hline 110 & $2,46 \pm 0,06$ & $0,439 \pm 0,079$ & $2,03 \pm 0,10$ & 17,5 \\
\hline 120 & $2,29 \pm 0,03$ & $0,424 \pm 0,040$ & $1,87 \pm 0,05$ & 18,4 \\
\hline 130 & $2,17 \pm 0,05$ & $0,381 \pm 0,010$ & $1,79 \pm 0,05$ & 17,3 \\
\hline 140 & $2,07 \pm 0,04$ & $0,323 \pm 0,012$ & $1,74 \pm 0,04$ & 15,3 \\
\hline
\end{tabular}

Na Figura 4.21 pode-se observar o comportamento da resposta do detector em questão: curva obtida sem o uso do cone de sombra e outra curva obtida tendo se subtraído os valores obtidos com o uso do cone de sombra. Os ajustes das curvas foram realizados com o uso do software OriginPro 8. As unidades das escalas dos equipamentos foram conservados mesmo não fazendo parte do Sistema Internacional de Unidades. As incertezas são todas estatísticas (tipo A). 


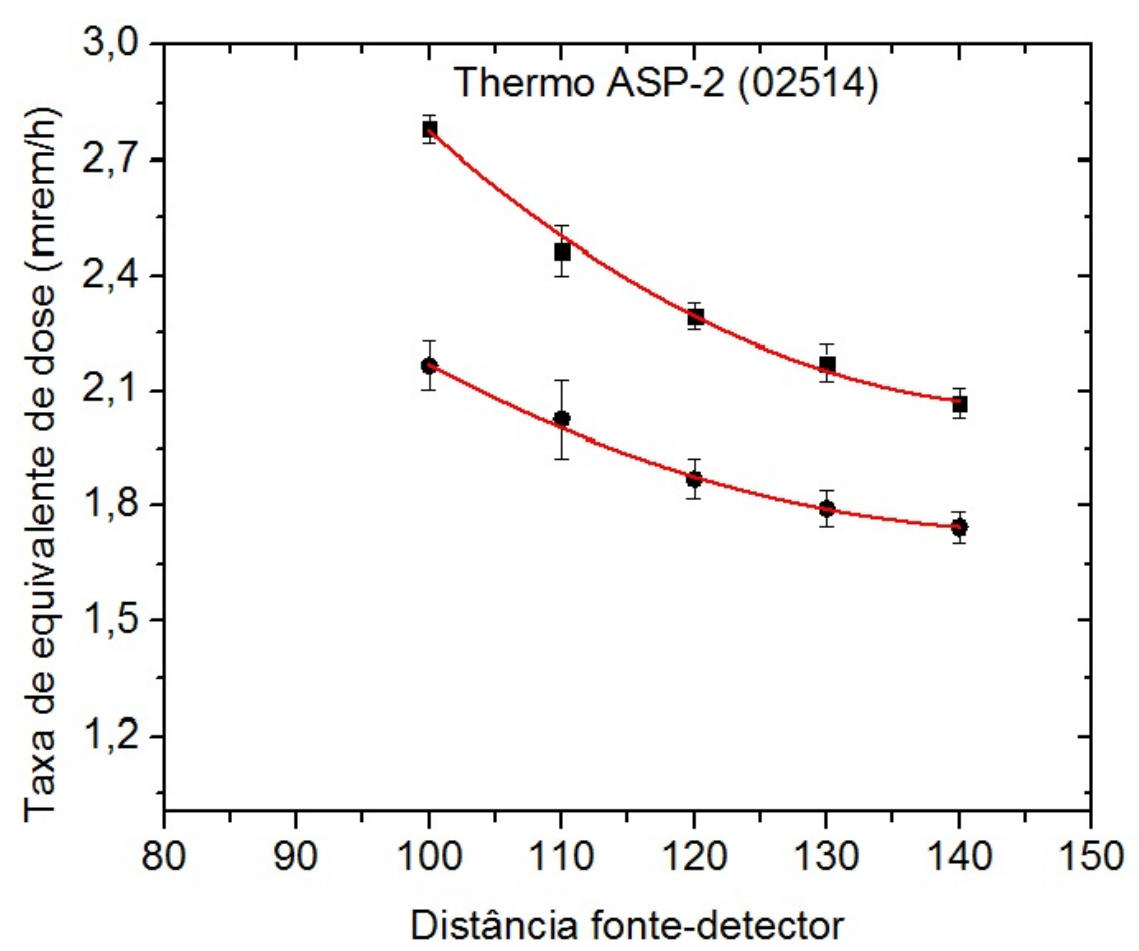

Figura 4.21: Influência da radiação espalhada na resposta do detector Thermo, modelo ASP-2 (02514). (ロ) Medições sem o cone de sombra e $(\bullet)$ medições com o cone de sombra com subtração das medições sem o cone de sombra.

\subsection{Estudo da estabilidade a curto prazo da resposta dos detectores}

Para se verificar a estabilidade a curto prazo (repetitibilidade) da resposta dos detectores de nêutrons, foi analisada a variação das suas respostas em diferentes pontos de medição, sob as mesmas condições.

Neste estudo, cada detector foi submetido a dez medições consecutivas em intervalos de 20 s cada vez, em três distâncias fonte-detector: 50, 75 e $100 \mathrm{~cm}$. As variações máximas na resposta dos detectores em cada distância são dadas pelos valores dos desvios padrões das medições.

Os resultados obtidos de repetitibilidade estão apresentados nas Tabelas 4.6, 4.7 e 4.8, onde é possível observar que o valor máximo do desvio padrão percentual obtido foi de $11,0 \%$, no caso do detector Camberra modelo Dineutron (133) à distância de $100 \mathrm{~cm}$. Portanto, todos os detectores apresentam os resultados dentro do limite recomendado pela norma (IAEA, 2000), que é de 
$30 \%$ para detectores de nêutrons. Neste estudo, as unidades das escalas dos equipamentos foram conservadas mesmo não fazendo parte do Sistema Internacional de Unidades. 
Tabela 4.6: Estabilidade a curto prazo dos detectores de nêutrons a $50 \mathrm{~cm}$ de distância em relação à fonte.

\begin{tabular}{|c|c|c|c|}
\hline Detectores & $\begin{array}{c}\text { Taxa de } \\
\text { equivalente } \\
\text { de dose }\end{array}$ & Desvio padrão & $\begin{array}{c}\text { Desvio } \\
\text { padrão } \\
\text { percentual } \\
(\%)\end{array}$ \\
\hline $\begin{array}{c}\text { Thermo ASP-2 } \\
(02514)\end{array}$ & 7,77 mrem/h & $0,31 \mathrm{mrem} / \mathrm{h}$ & 4,0 \\
\hline $\begin{array}{c}\text { Thermo ASP-2 } \\
(02517)\end{array}$ & $7,19 \mathrm{mrem} / \mathrm{h}$ & $0,46 \mathrm{mrem} / \mathrm{h}$ & 6,3 \\
\hline $\begin{array}{l}\text { Ludlum } 2241-4 \\
\qquad(274063)\end{array}$ & $70,28 \mu \mathrm{Sv} / \mathrm{h}$ & $1,84 \mu \mathrm{Sv} / \mathrm{h}$ & 2,6 \\
\hline $\begin{array}{l}\text { Ludlum 2241-4 } \\
\text { (274065) }\end{array}$ & $68,60 \mu \mathrm{Sv} / \mathrm{h}$ & $0,71 \mu \mathrm{Sv} / \mathrm{h}$ & 1,0 \\
\hline $\begin{array}{l}\text { Ludlum 12-4 } \\
\text { (227914) }\end{array}$ & $6,80 \mathrm{mrem} / \mathrm{h}$ & $0,50 \mathrm{mrem} / \mathrm{h}$ & 7,3 \\
\hline $\begin{array}{l}\text { Ludlum 12-4 } \\
\text { (305363) }\end{array}$ & $81,74 \mu \mathrm{Sv} / \mathrm{h}$ & $0,08 \mu \mathrm{Sv} / \mathrm{h}$ & 10,0 \\
\hline $\begin{array}{c}\text { Camberra } \\
\text { Dineutron } \\
(361)\end{array}$ & 7,12 mrem/h & $0,25 \mathrm{mrem} / \mathrm{h}$ & 3,5 \\
\hline $\begin{array}{c}\text { Camberra } \\
\text { Dineutron } \\
(292)\end{array}$ & $5,47 \mathrm{mrem} / \mathrm{h}$ & $0,21 \mathrm{mrem} / \mathrm{h}$ & 3,9 \\
\hline $\begin{array}{c}\text { Camberra } \\
\text { Dineutron } \\
(293)\end{array}$ & 4,48 mrem/h & $0,26 \mathrm{mrem} / \mathrm{h}$ & 5,8 \\
\hline $\begin{array}{c}\text { Camberra } \\
\text { Dineutron } \\
(133)\end{array}$ & $5,61 \mathrm{mrem} / \mathrm{h}$ & $0,10 \mathrm{mrem} / \mathrm{h}$ & 1,8 \\
\hline $\begin{array}{c}\text { Thermo } \\
\text { Identifinder } \\
(3574-468)\end{array}$ & $35,08 \mu \mathrm{Sv} / \mathrm{h}$ & $0,40 \mu \mathrm{Sv} / \mathrm{h}$ & 1,1 \\
\hline
\end{tabular}


Tabela 4.7: Estabilidade a curto prazo dos detectores de nêutrons a $75 \mathrm{~cm}$ de distância em relação à fonte.

\begin{tabular}{|c|c|c|c|}
\hline Detectores & $\begin{array}{c}\text { Taxa de } \\
\text { equivalente } \\
\text { de dose }\end{array}$ & Desvio padrão & $\begin{array}{c}\text { Desvio } \\
\text { padrão } \\
\text { percentual } \\
(\%)\end{array}$ \\
\hline $\begin{array}{c}\text { Thermo ASP-2 } \\
(02514)\end{array}$ & $4,53 \mathrm{mrem} / \mathrm{h}$ & $0,30 \mathrm{mrem} / \mathrm{h}$ & 6,7 \\
\hline $\begin{array}{c}\text { Thermo ASP-2 } \\
(02517)\end{array}$ & $4,10 \mathrm{mrem} / \mathrm{h}$ & $0,35 \mathrm{mrem} / \mathrm{h}$ & 8,6 \\
\hline $\begin{array}{l}\text { Ludlum } 2241-4 \\
\qquad(274063)\end{array}$ & $38,7 \mu \mathrm{Sv} / \mathrm{h}$ & $1,68 \mu \mathrm{Sv} / \mathrm{h}$ & 4,3 \\
\hline $\begin{array}{l}\text { Ludlum 12-4 } \\
\text { (227914) }\end{array}$ & 4,48 mrem/h & $0,17 \mathrm{mrem} / \mathrm{h}$ & 3,9 \\
\hline $\begin{array}{l}\text { Ludlum 12-4 } \\
\qquad(305363)\end{array}$ & $58,30 \mu \mathrm{Sv} / \mathrm{h}$ & $0,04 \mu \mathrm{Sv} / \mathrm{h}$ & 7,3 \\
\hline $\begin{array}{l}\text { Ludlum 2241-4 } \\
\qquad(274065)\end{array}$ & $40,95 \mu \mathrm{Sv} / \mathrm{h}$ & $1,48 \mu \mathrm{Sv} / \mathrm{h}$ & 3,6 \\
\hline $\begin{array}{c}\text { Camberra } \\
\text { Dineutron } \\
(361)\end{array}$ & $3,39 \mathrm{mrem} / \mathrm{h}$ & $0,33 \mathrm{mrem} / \mathrm{h}$ & 9,7 \\
\hline $\begin{array}{c}\text { Camberra } \\
\text { Dineutron } \\
(292)\end{array}$ & $3,1 \mathrm{mrem} / \mathrm{h}$ & $0,19 \mathrm{mrem} / \mathrm{h}$ & 6,2 \\
\hline $\begin{array}{c}\text { Camberra } \\
\text { Dineutron } \\
(293)\end{array}$ & 2,36 mrem/h & $0,24 \mathrm{mrem} / \mathrm{h}$ & 10,1 \\
\hline $\begin{array}{c}\text { Camberra } \\
\text { Dineutron } \\
(133) \\
\end{array}$ & 2,93 mrem/h & $0,15 \mathrm{mrem} / \mathrm{h}$ & 5,1 \\
\hline $\begin{array}{c}\text { Thermo } \\
\text { Identifinder } \\
(3574-468)\end{array}$ & $19,42 \mu \mathrm{Sv} / \mathrm{h}$ & $0,30 \mu \mathrm{Sv} / \mathrm{h}$ & 1,6 \\
\hline
\end{tabular}


Tabela 4.8: Estabilidade a curto prazo dos detectores de nêutrons a $100 \mathrm{~cm}$ de distância em relação à fonte.

\begin{tabular}{|c|c|c|c|}
\hline Detectores & $\begin{array}{c}\text { Taxa de } \\
\text { equivalente } \\
\text { de dose }\end{array}$ & Desvio padrão & $\begin{array}{c}\text { Desvio } \\
\text { padrão } \\
\text { percentual } \\
(\%)\end{array}$ \\
\hline $\begin{array}{c}\text { Thermo ASP-2 } \\
(02514)\end{array}$ & 2,83 mrem/h & $0,23 \mathrm{mrem} / \mathrm{h}$ & 8,1 \\
\hline $\begin{array}{c}\text { Thermo ASP-2 } \\
(02517)\end{array}$ & $2,72 \mathrm{mrem} / \mathrm{h}$ & $0,18 \mathrm{mrem} / \mathrm{h}$ & 6,6 \\
\hline $\begin{array}{l}\text { Ludlum } 2241-4 \\
\qquad(274063)\end{array}$ & $26,3 \mu \mathrm{Sv} / \mathrm{h}$ & $1,45 \mu \mathrm{Sv} / \mathrm{h}$ & 5,5 \\
\hline $\begin{array}{l}\text { Ludlum 12-4 } \\
\text { (227914) }\end{array}$ & $26,55 \mu \mathrm{Sv} / \mathrm{h}$ & $0,35 \mu \mathrm{Sv} / \mathrm{h}$ & 1,3 \\
\hline $\begin{array}{l}\text { Ludlum 12-4 } \\
\qquad(305363)\end{array}$ & 3,21 $\mathrm{mrem} / \mathrm{h}$ & 0,26 mrem/h & 8,0 \\
\hline $\begin{array}{l}\text { Ludlum } 2241-4 \\
\qquad(274065)\end{array}$ & $35,56 \mu \mathrm{Sv} / \mathrm{h}$ & $0,02 \mu \mathrm{Sv} / \mathrm{h}$ & 4,2 \\
\hline $\begin{array}{c}\text { Camberra } \\
\text { Dineutron } \\
(361)\end{array}$ & 1,95 mrem/h & $0,10 \mathrm{mrem} / \mathrm{h}$ & 5,1 \\
\hline $\begin{array}{c}\text { Camberra } \\
\text { Dineutron } \\
(292)\end{array}$ & $1,49 \mathrm{mrem} / \mathrm{h}$ & $0,03 \mathrm{mrem} / \mathrm{h}$ & 2,1 \\
\hline $\begin{array}{c}\text { Camberra } \\
\text { Dineutron } \\
(293)\end{array}$ & 1,44 mrem/h & $0,09 \mathrm{mrem} / \mathrm{h}$ & 6,2 \\
\hline $\begin{array}{c}\text { Camberra } \\
\text { Dineutron } \\
(133)\end{array}$ & 1,93 mrem/h & $0,21 \mathrm{mrem} / \mathrm{h}$ & 11,0 \\
\hline $\begin{array}{c}\text { Thermo } \\
\text { Identifinder } \\
(3574-468)\end{array}$ & $12,5 \mu \mathrm{Sv} / \mathrm{h}$ & $0,20 \mu \mathrm{Sv} / \mathrm{h}$ & 1,4 \\
\hline
\end{tabular}


Nas Figuras 4.22, 4.23, 4.24, 4.25, 4.26, 4.27, 4.28, 4.29, 4.30, 4.31 e 4.32 pode-se observar o comportamento da resposta dos detectores de nêutrons em função da distância fonte-detector entre 50, 75 e $100 \mathrm{~cm}$. Apesar de apenas três distâncias diferentes, tem-se uma noção do comportamento destes detectores.

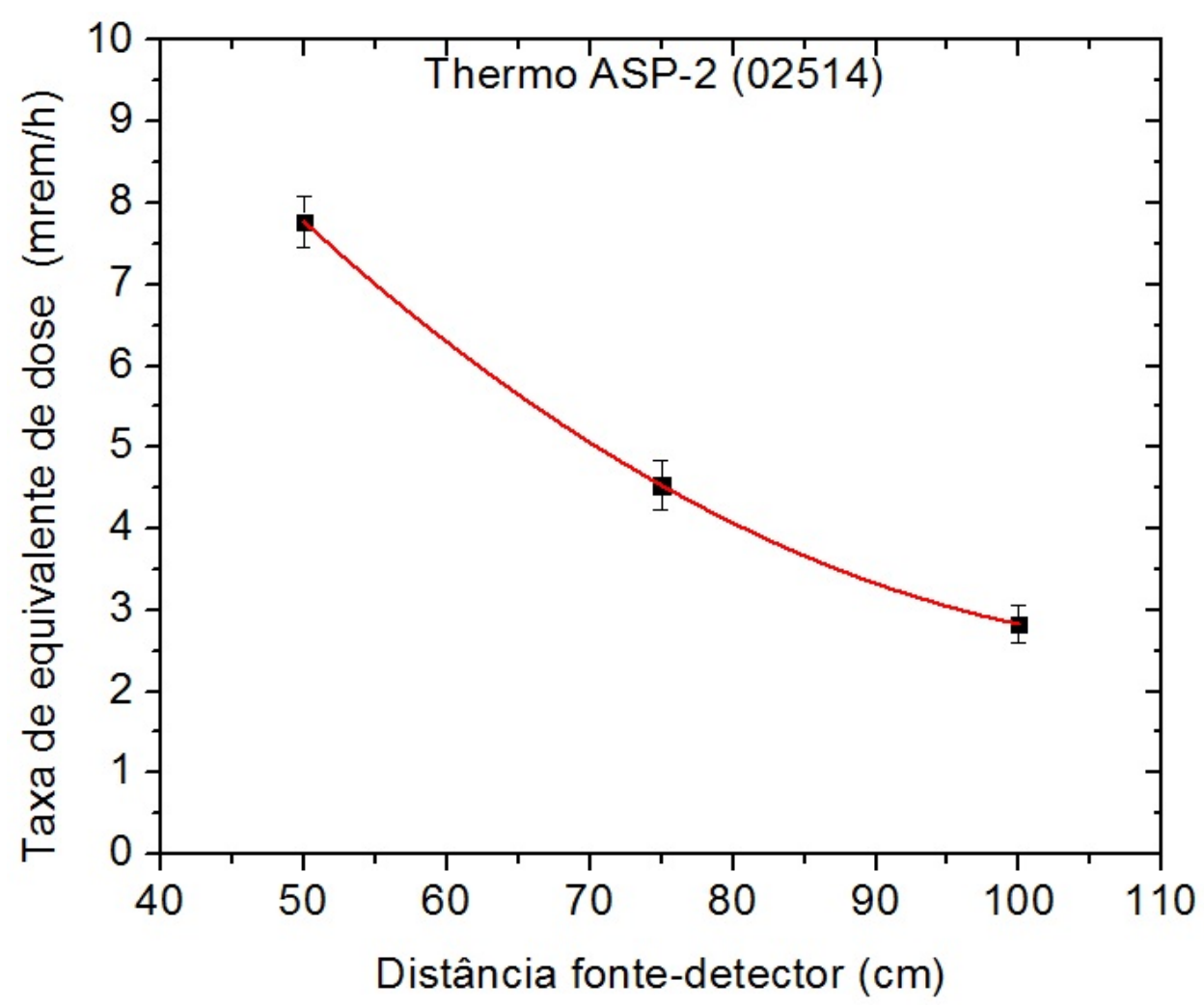

Figura 4.22: Resposta do detector de nêutrons Thermo ASP-2 (02514) em função da distância fonte - detector. 


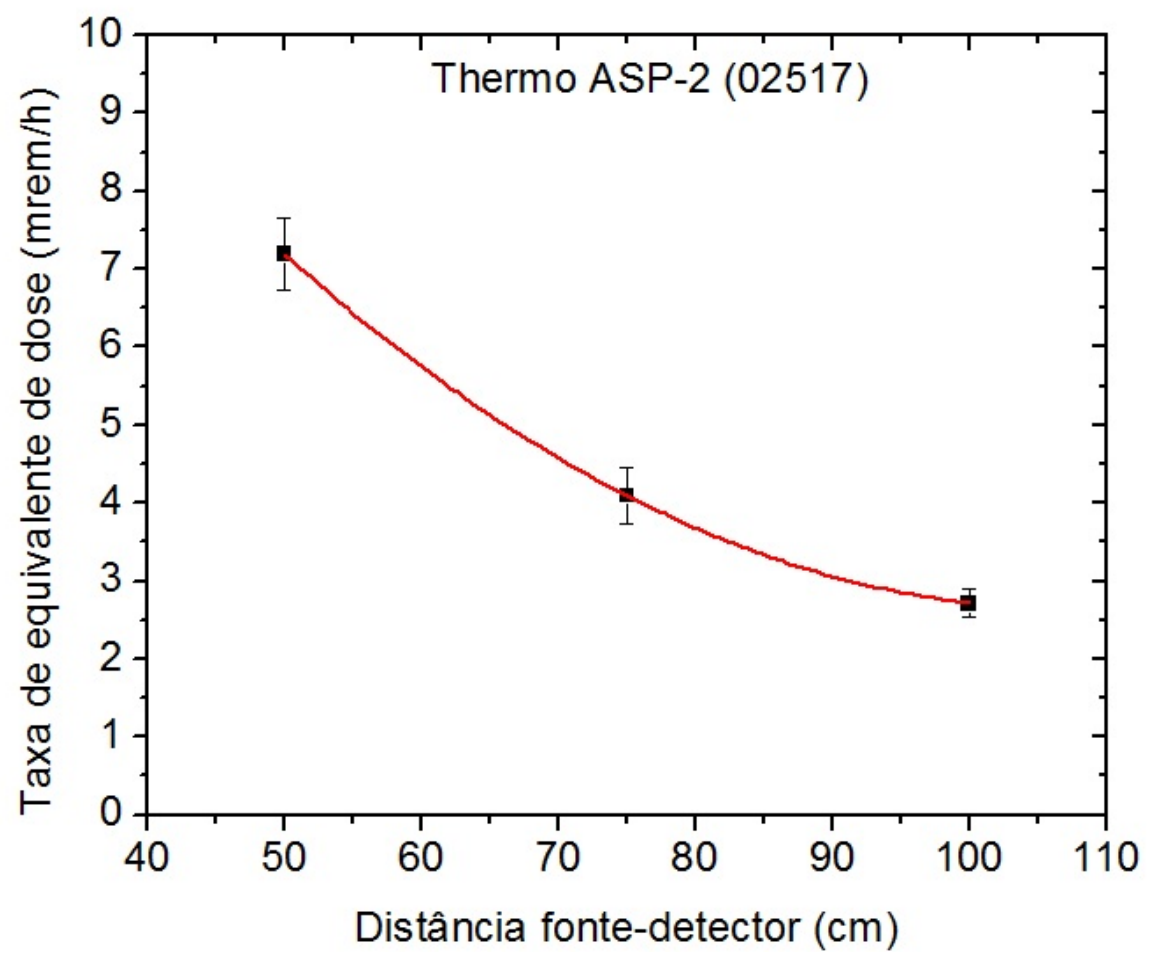

Figura 4.23: Resposta do detector de nêutrons Thermo ASP-2 (02517) em função da distância fonte - detector.

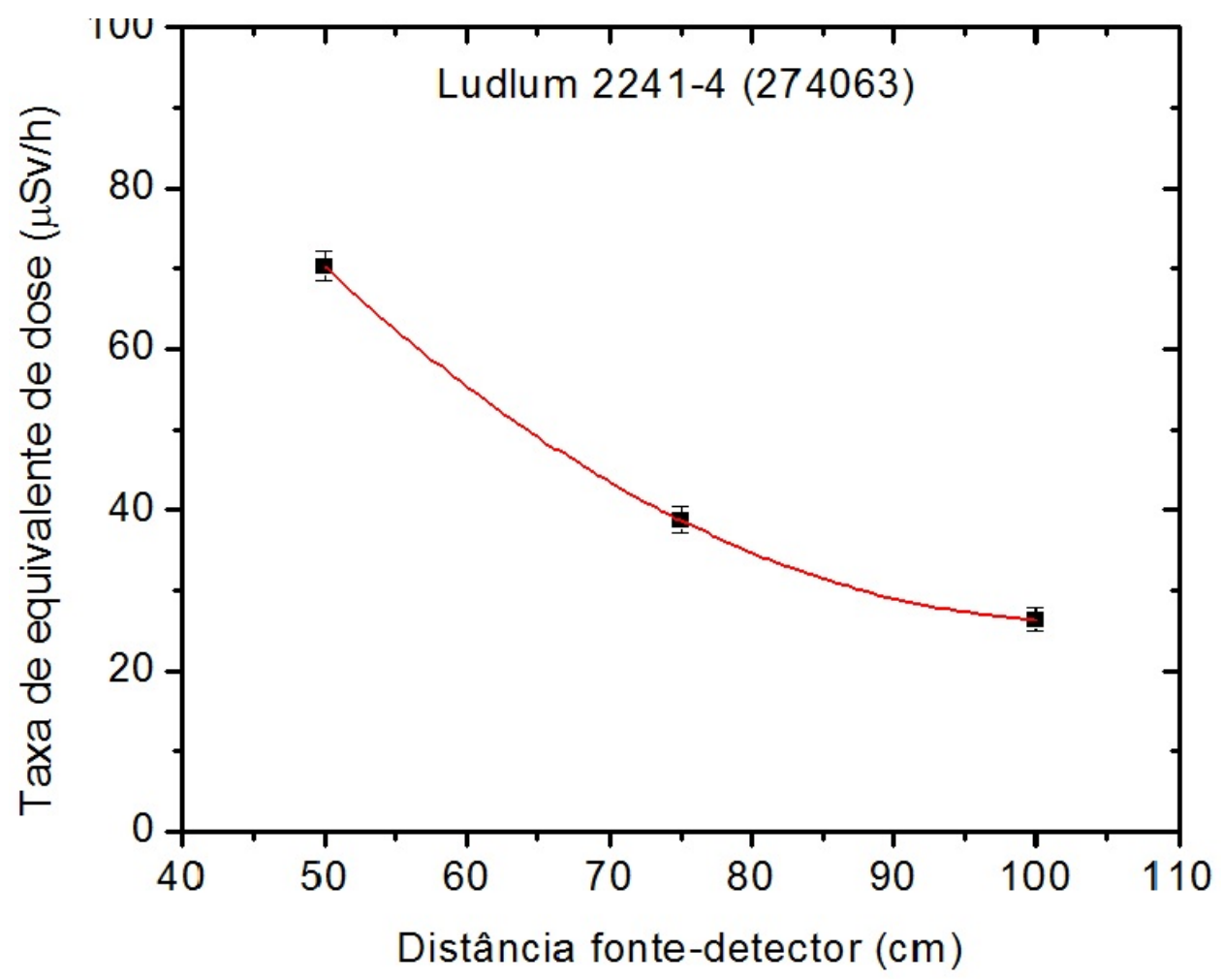

Figura 4.24: Resposta do detector de nêutrons Ludlum 2241-4 (274063) em função da distância fonte - detector. 


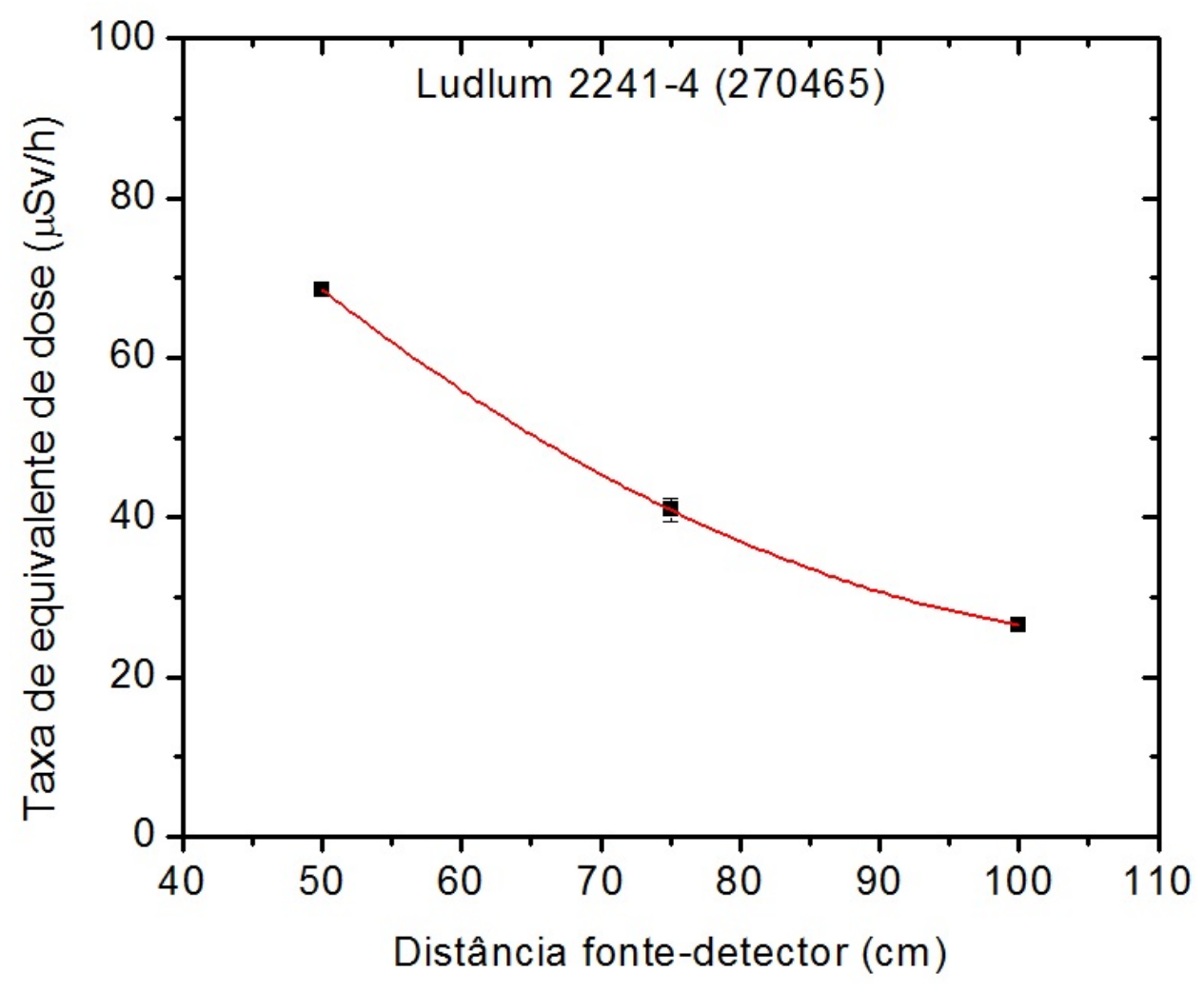

Figura 4.25: Resposta do detector de nêutrons Ludlum 2241-4 (270465) em função da distância fonte - detector.

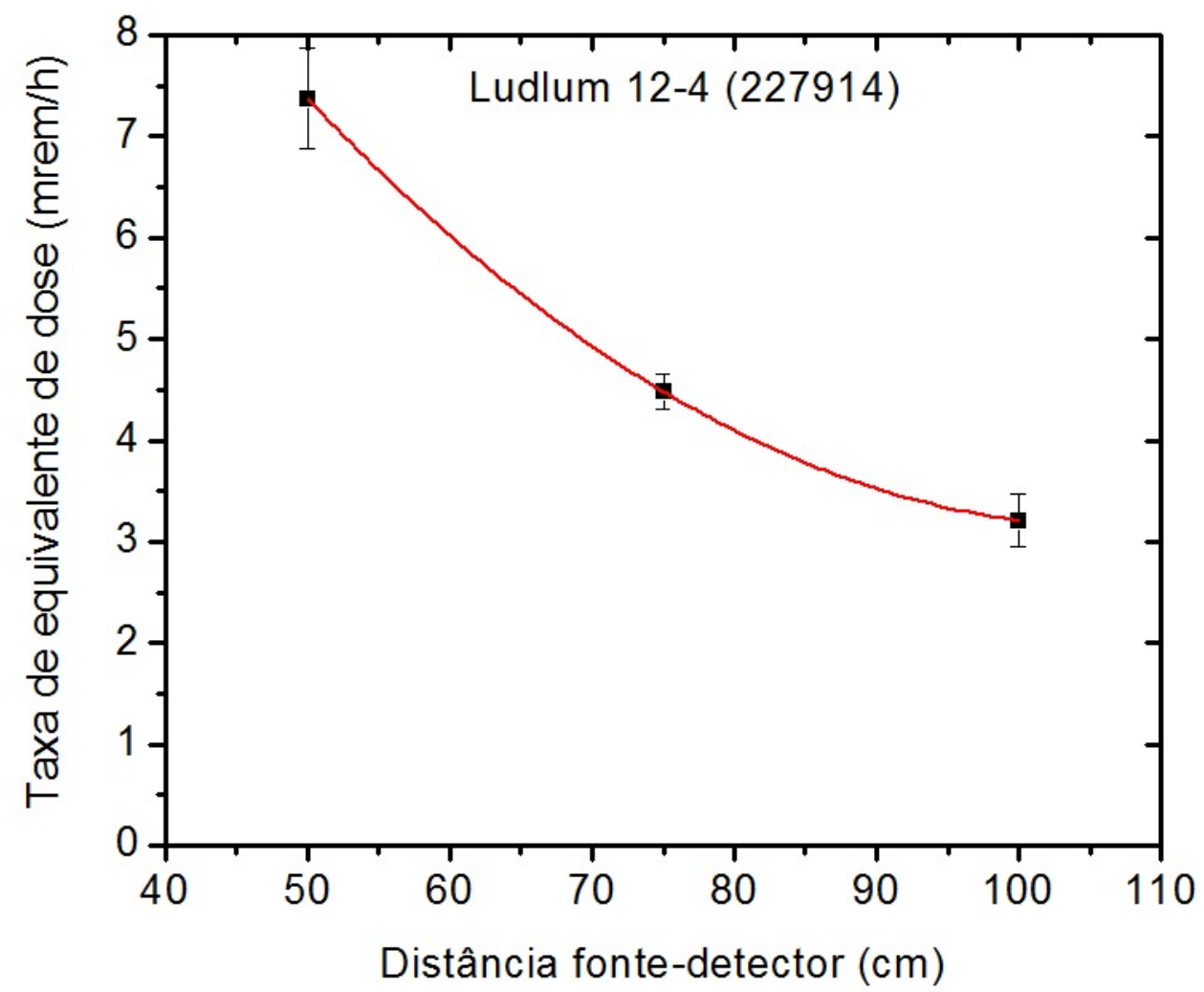

Figura 4.26: Resposta do detector de nêutrons Ludlum 12-4 (227914) em função da distância fonte - detector. 


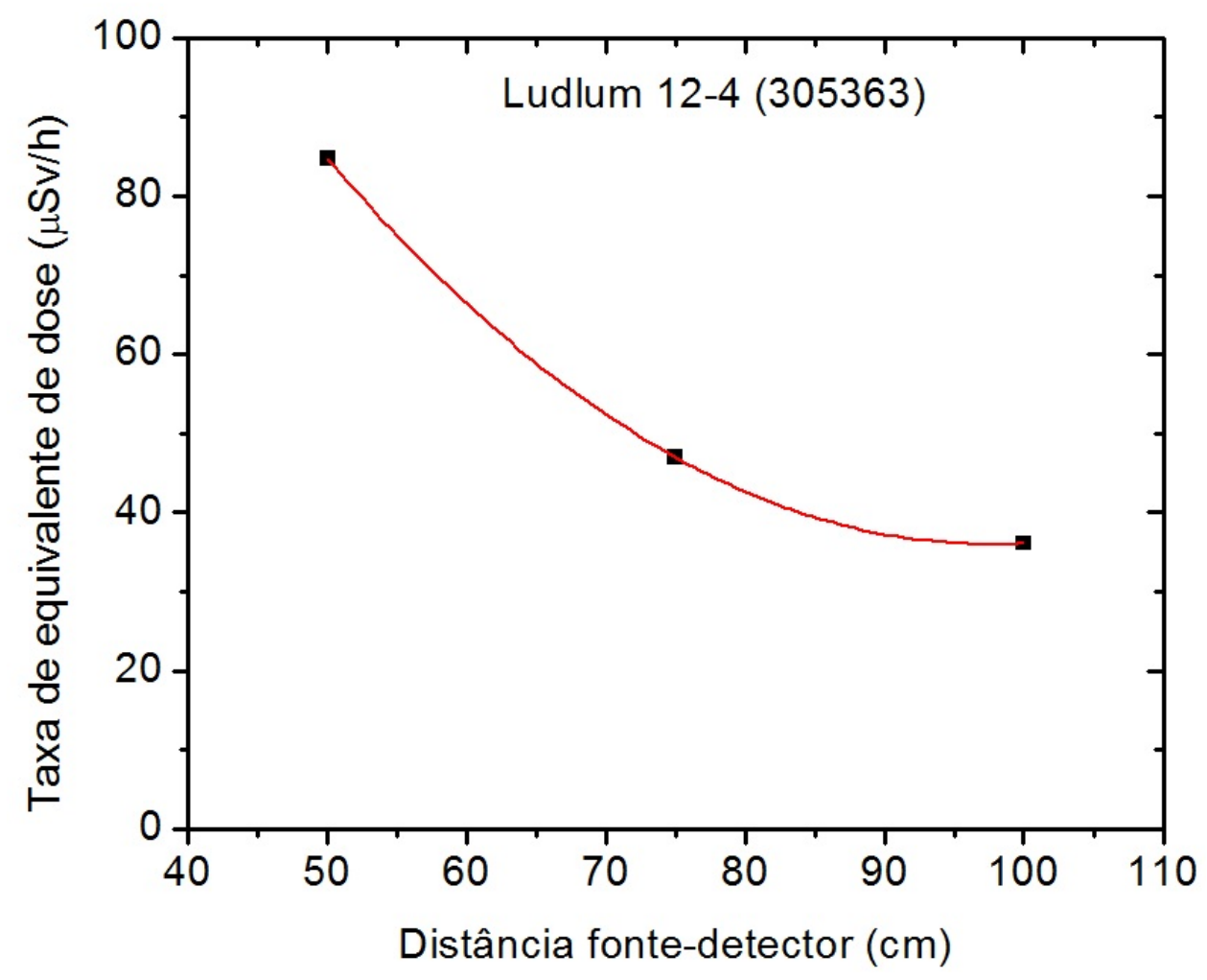

Figura 4.27: Resposta do detector de nêutrons Ludlum 12-4 (305363) em função da distância fonte - detector. $A$ incerteza máxima foi de $0,7 \%$, não visível na curva.

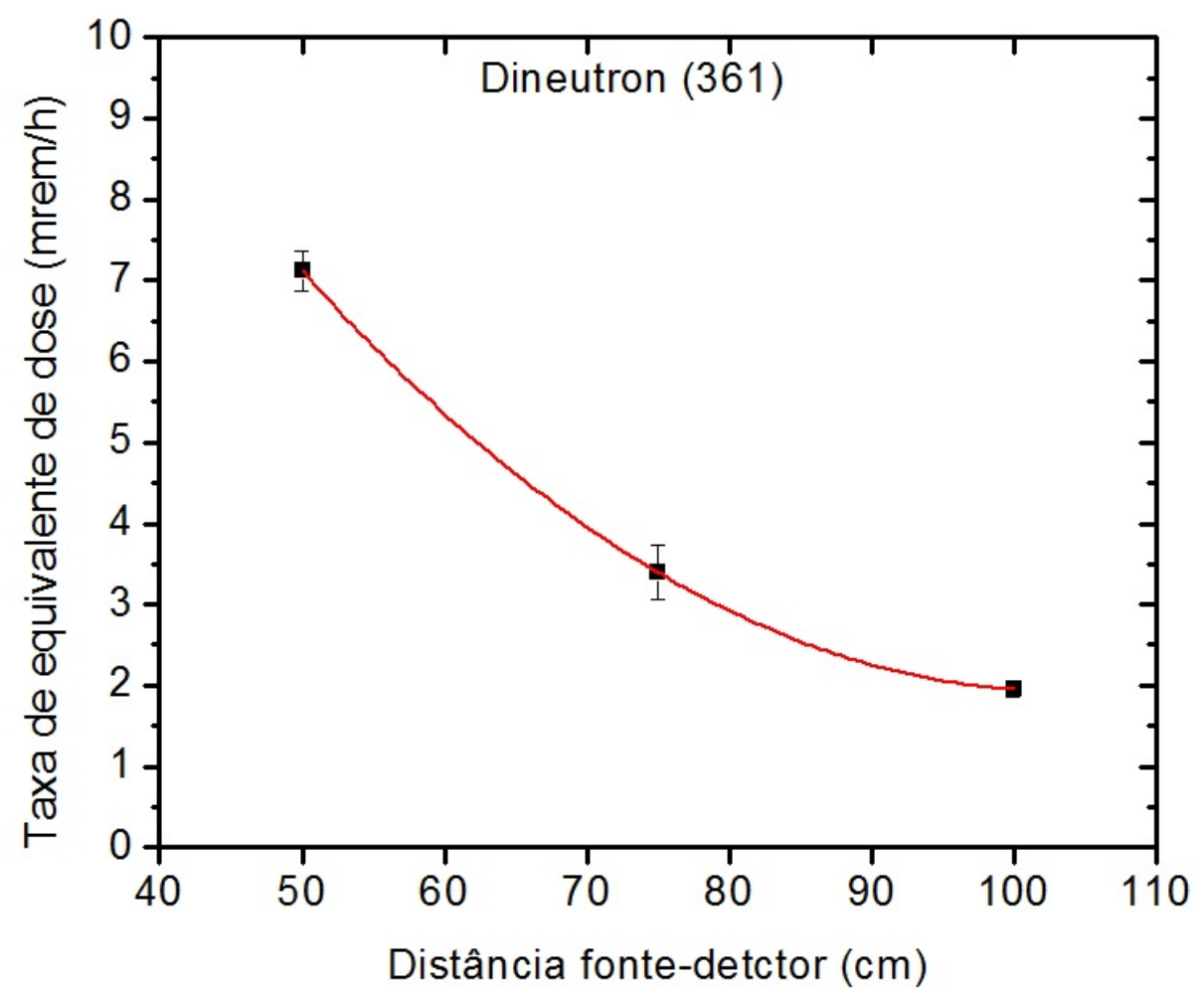

Figura 4.28: Resposta do detector de nêutrons Camberra Dineutron (361) em função da distância fonte - detector. 


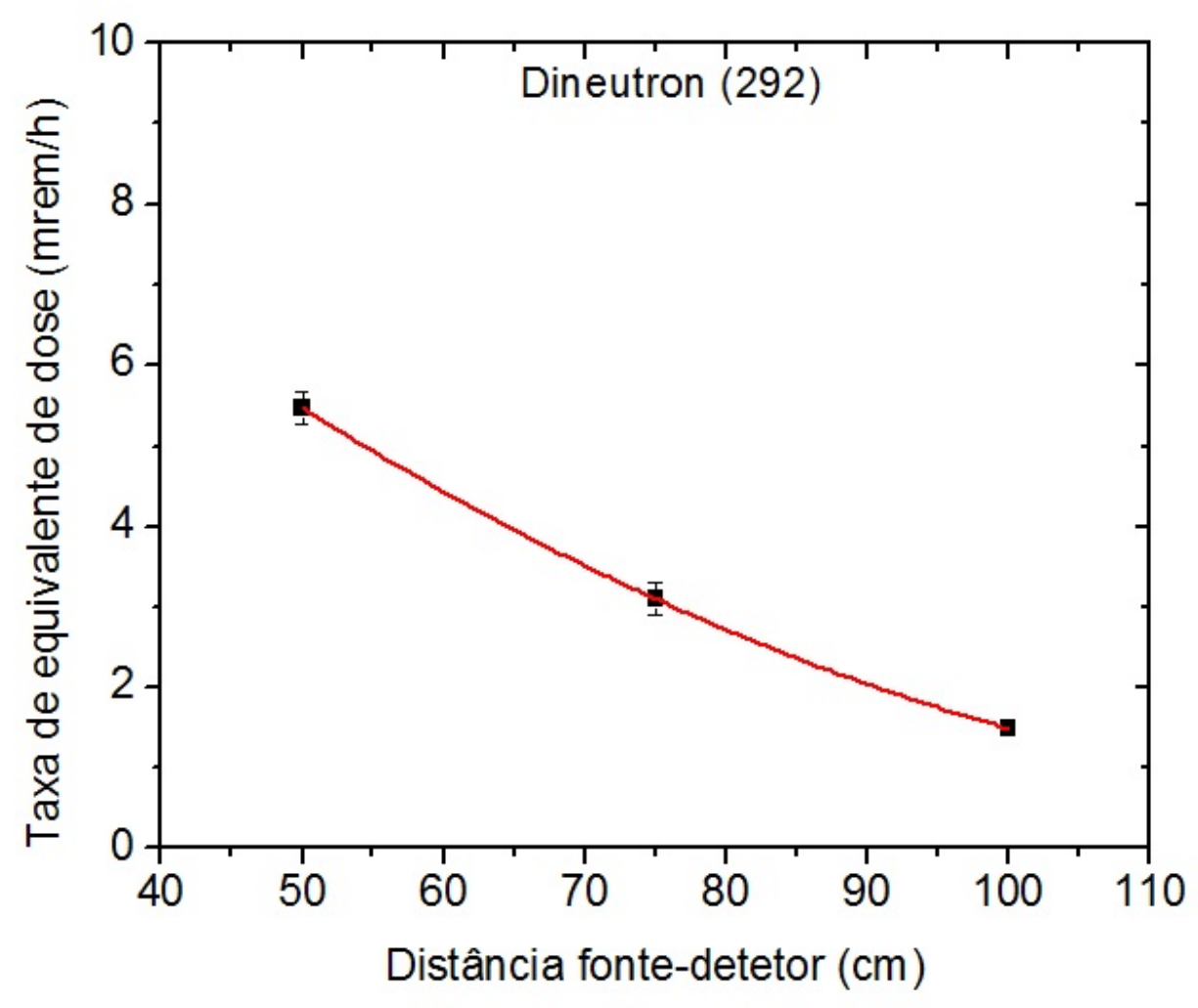

Figura 4.29: Resposta do detector de nêutrons Camberra Dineutron (292) em função da distância fonte - detector.

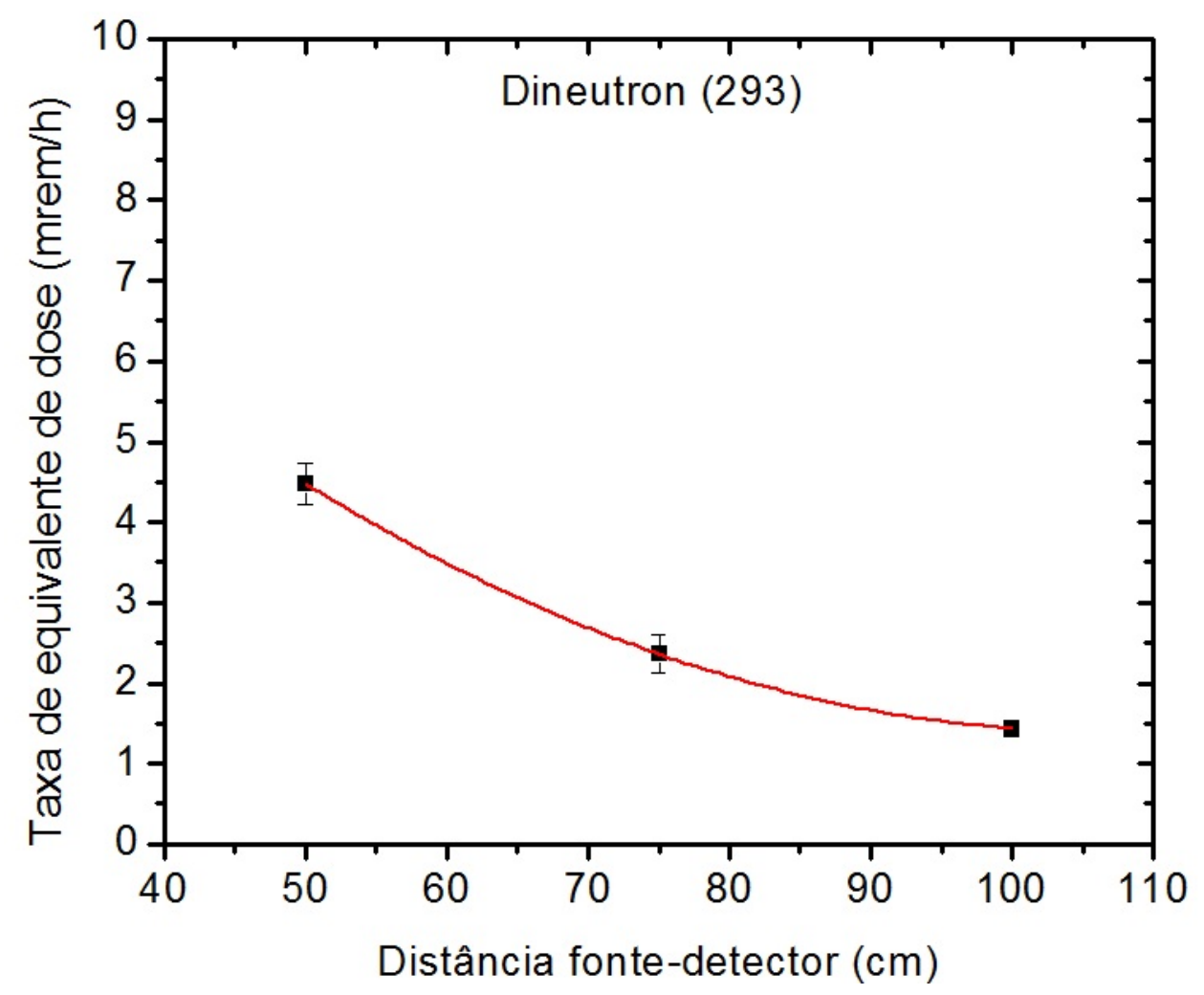

Figura 4.30: Resposta do detector de nêutrons Camberra Dineutron (293) em função da distância fonte - detector. 


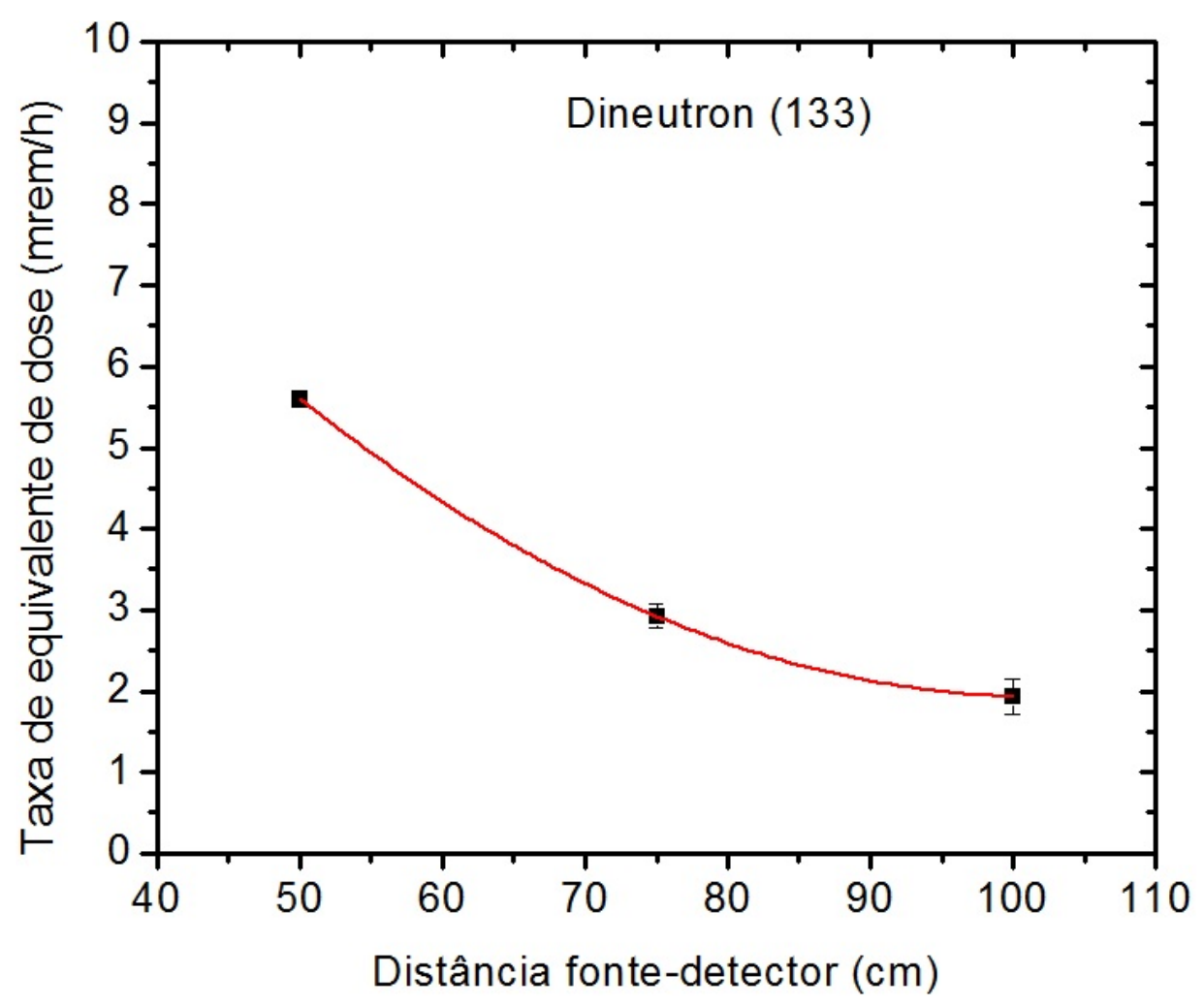

Figura 4.31: Resposta do detector de nêutrons Camberra Dineutron (133) em função da distância fonte - detector.

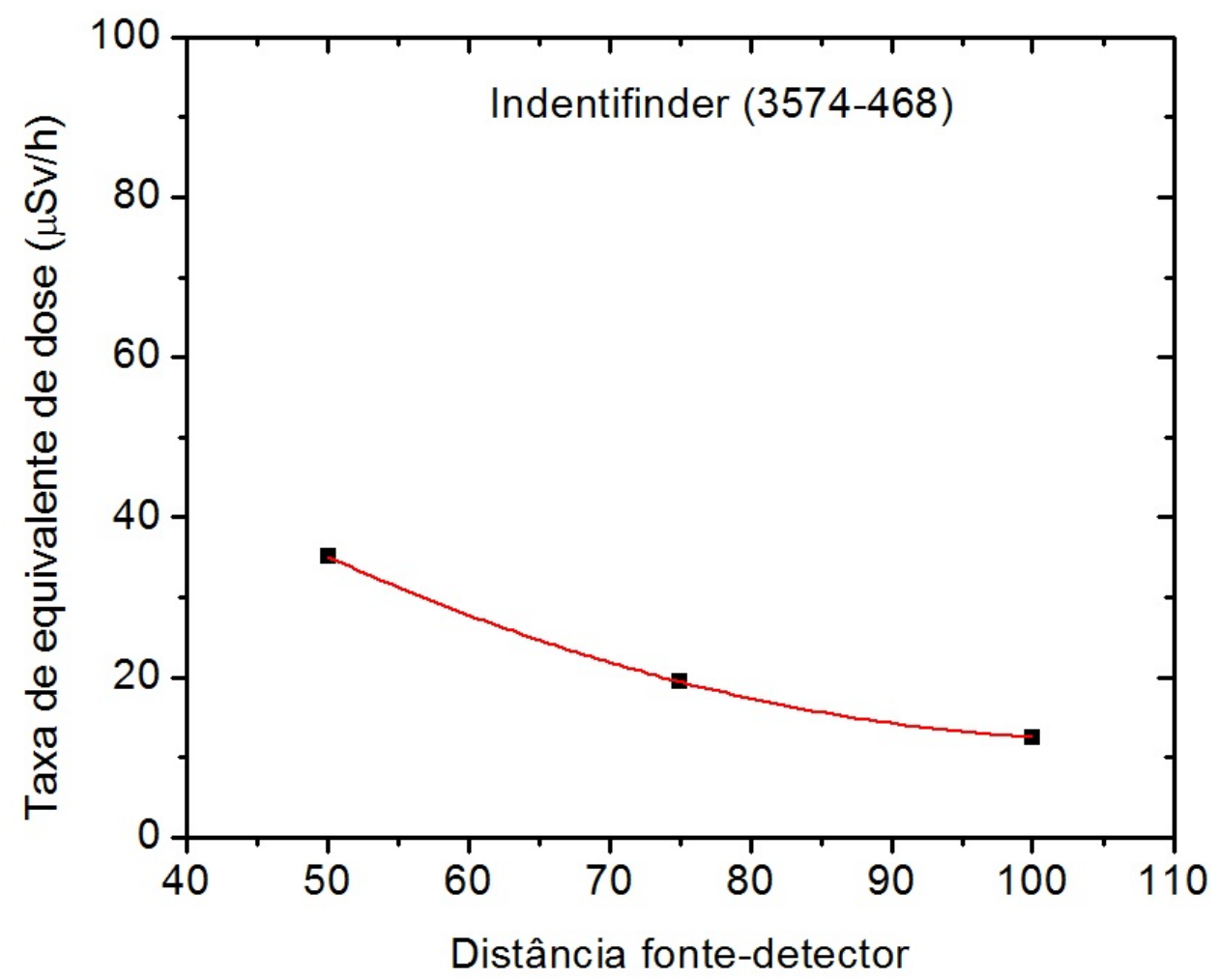

Figura 4.32: Resposta do detector nêutrons-gama Thermo Identifinder (3574-468) em função da distância fonte - detector. A incerteza máxima foi de 1,6\%, não visível na curva. 


\subsection{Estudo da estabilidade a médio prazo da resposta dos detectores}

Para a realização do teste de estabilidade a médio prazo da resposta de 5 detectores (teste de reprodutibilidade), foram tomadas 20 medições da taxa de equivalente de dose ambiente à distância fonte-detector de $100 \mathrm{~cm}$, em intervalos de $10 \mathrm{~s}$, sendo este teste repetido 10 vezes para cada detector. Para cada série de medições realizadas no teste de estabilidade a médio prazo, foi calculado um valor médio e a variação destes valores médios e seus desvios padrões da média fornecem a reprodutibilidade da resposta dos detectores. Nas Figuras 4.33, 4.34, 4.35, 4.36 a 4.37 são apresentados os resultados obtidos dos detectores: valor médio das respostas em função do número das medições. As incertezas são todas do tipo A. As linhas tracejadas representam os limites recomendados pela (IAEA, 2000).

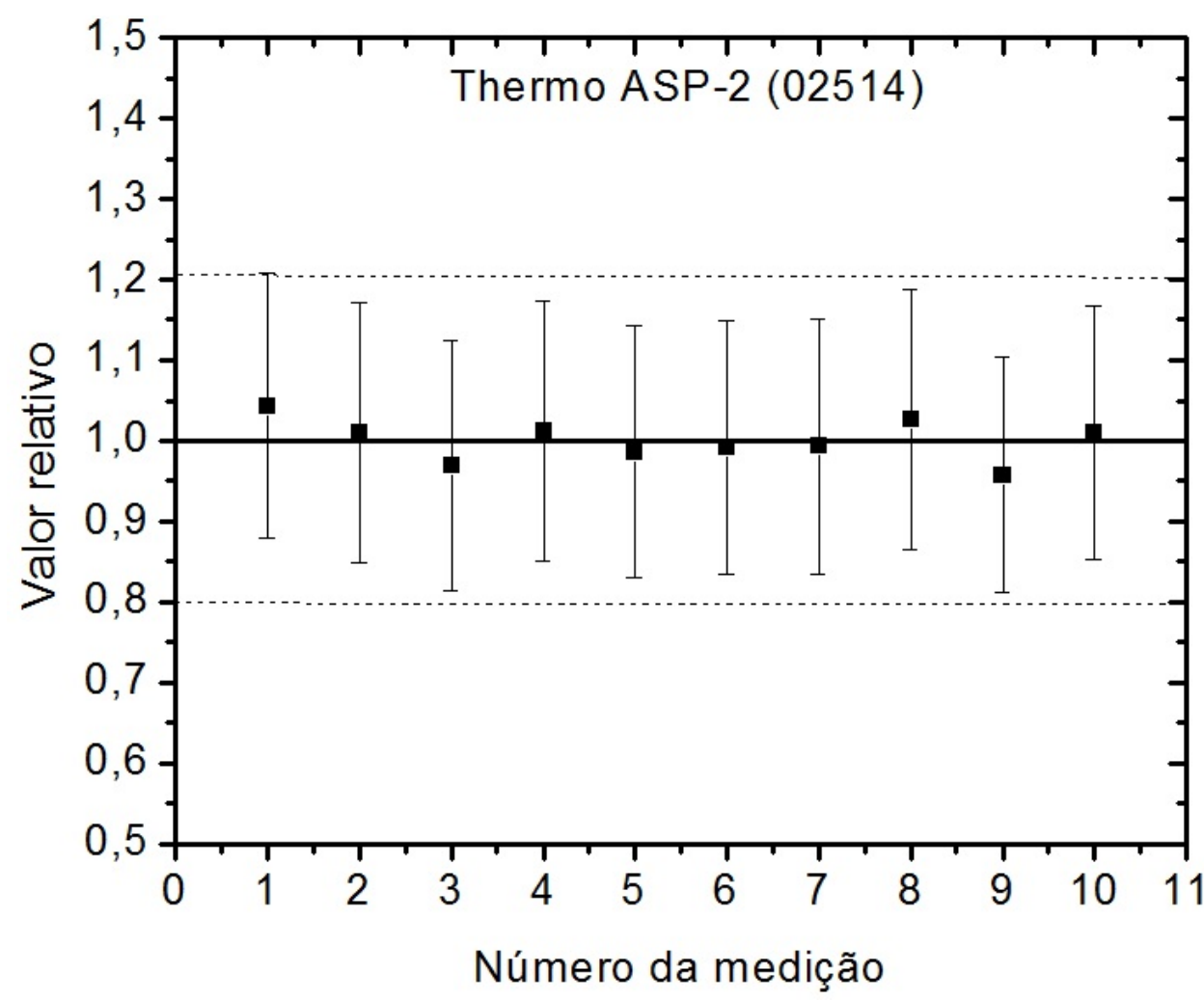

Figura 4.33: Reprodutibilidade da resposta do detector Thermo ASP-2 (02514). 


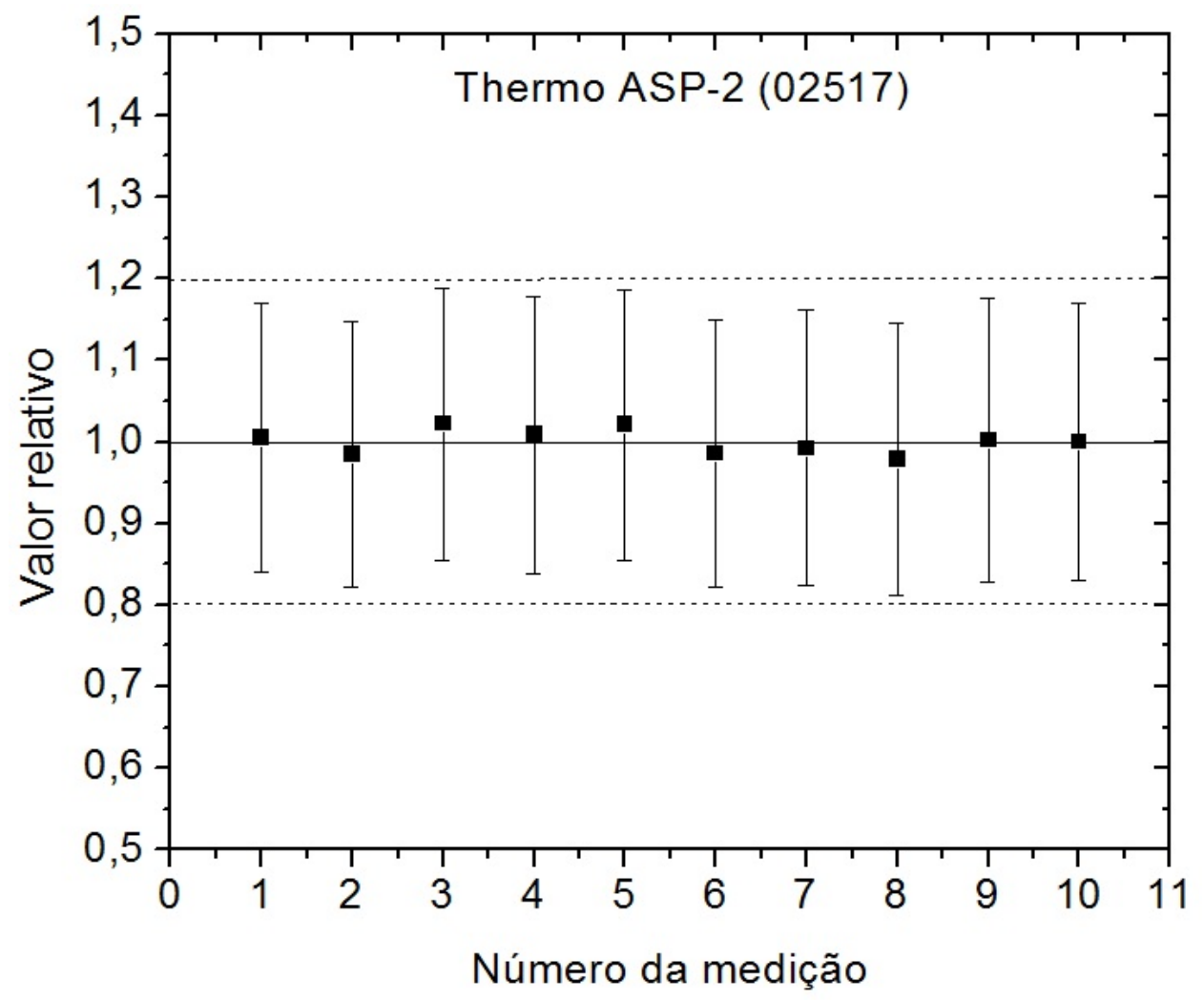

Figura 4.34: Reprodutibilidade da resposta do detector Thermo ASP-2 (02517).

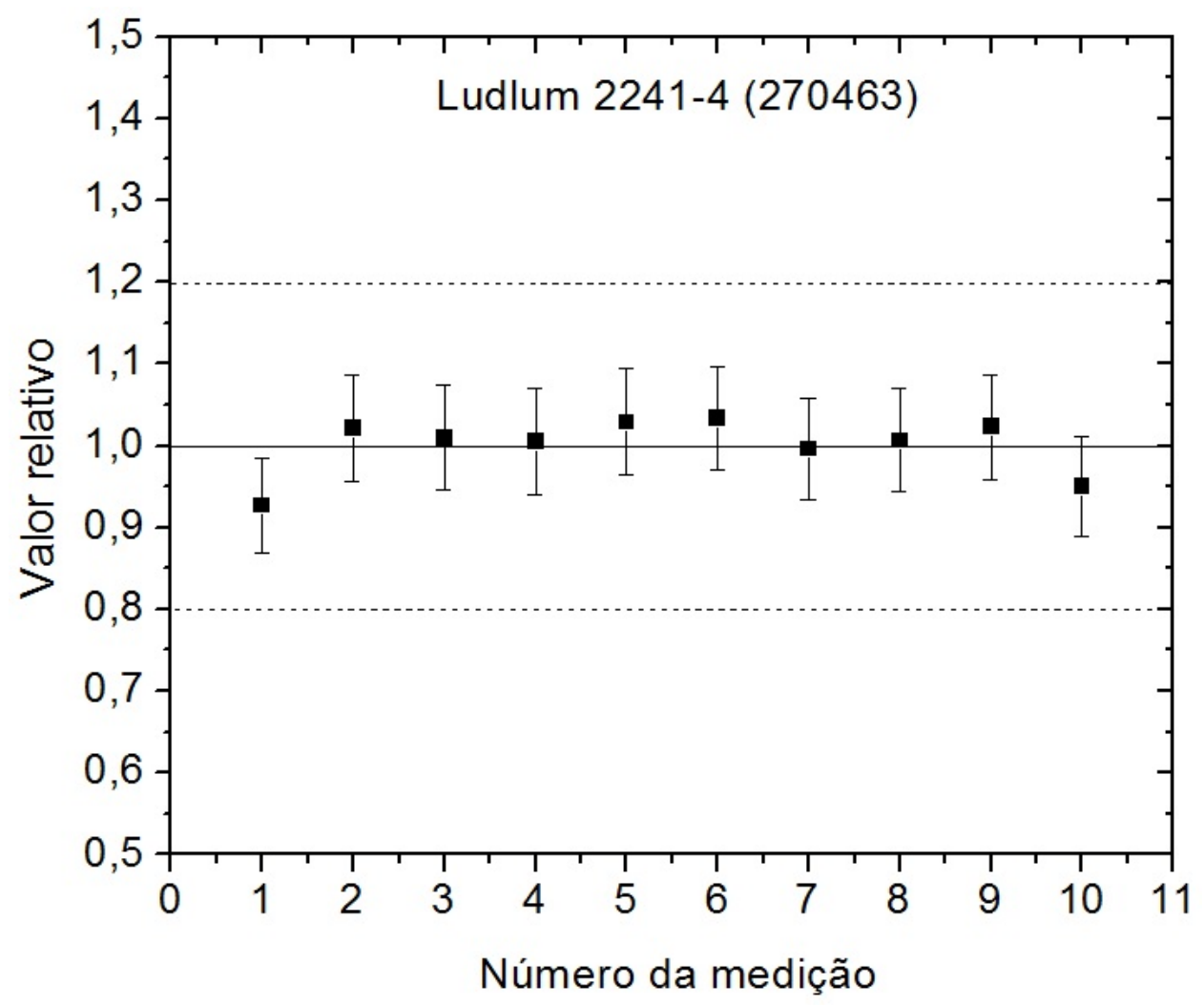

Figura 4.35: Reprodutibilidade da resposta do detector Ludlum 2241-4 (270463). 


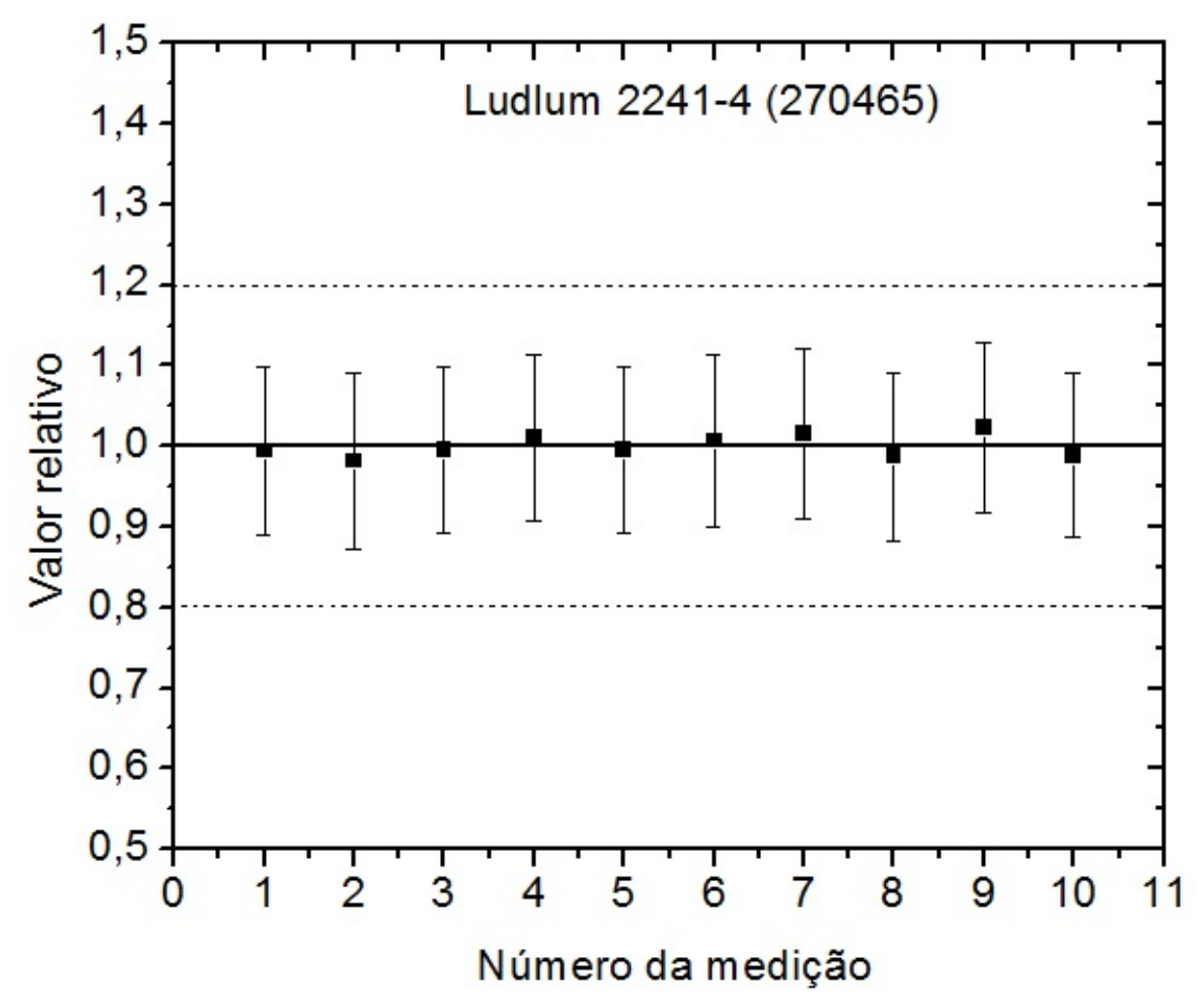

Figura 4.36: Reprodutibilidade da resposta do detector Ludlum 2241-4 (270465).

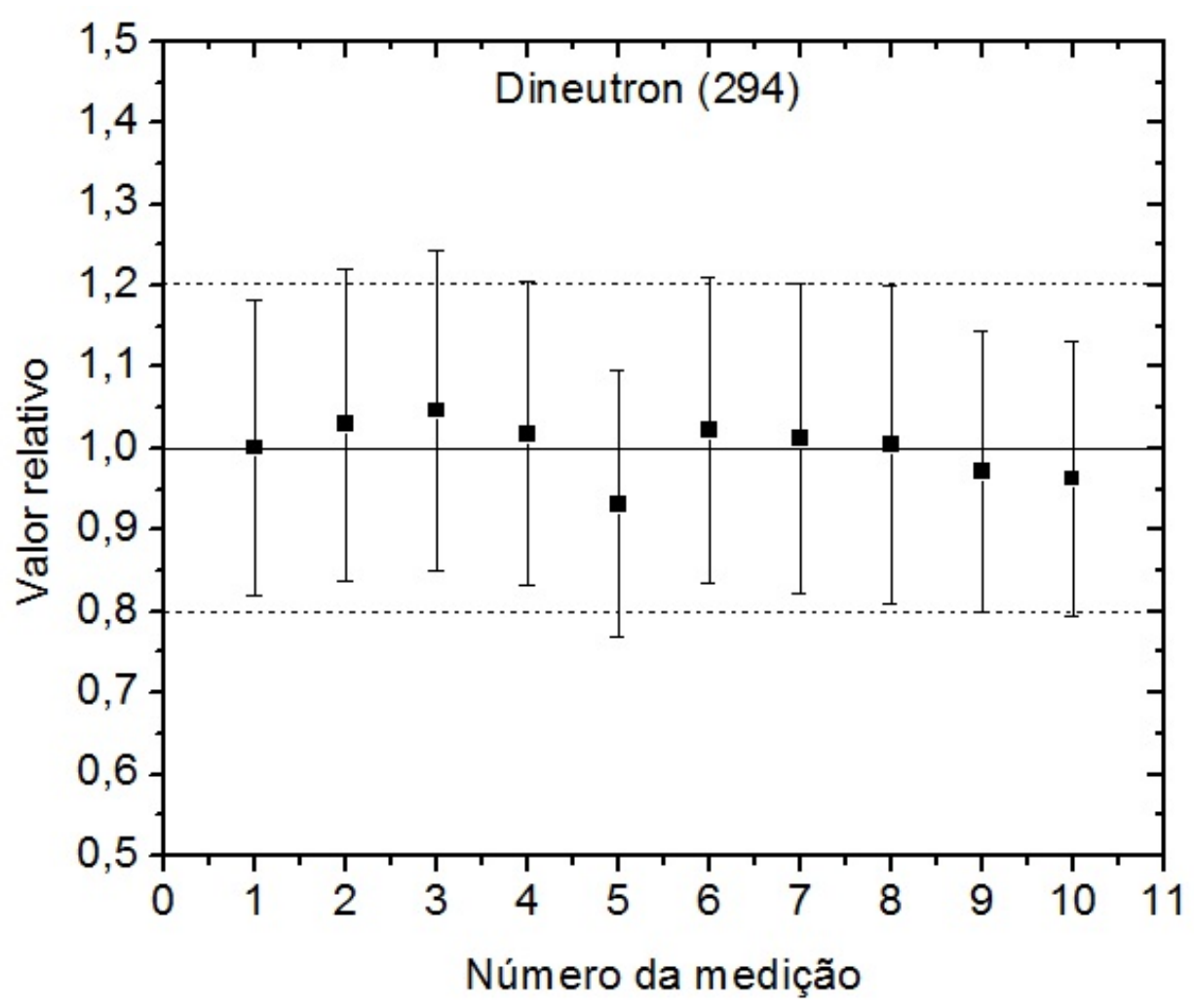

Figura 4.37: Reprodutibilidade da resposta do detector Cambera Dineutron (294). 
É possível observar que a variação máxima obtida para o teste de reprodutibilidade de resposta foi de $20 \%$ do detector Dineutron (294). Os valores obtidos dos detectores estão dentro do limite máximo recomendado de $20 \%$ (IAEA, 2000).

\subsection{Mapeamento do campo de radiação}

Para a definição dos pontos de medição no procedimento de testes de detectores de nêutrons no LTN, foi realizado o mapeamento do campo de radiação. Para isto, inicialmente foi estudada a resposta de dez detectores: Camberra Dineutron (133), (294) e (361), Ludlum 12-4 (305363) e (227914), Ludlum 2241-4 (214063), (214065), Thermo Identifinder (3574-468) e Thermo ASP-2 (02514) e (02517).

Os dois últimos detectores são os sistemas de referência por terem sido calibrados recentemente no LNMRI. Cada detector foi posicionado às distâncias fonte-detector de 7, 10, 20, 25, 35, 40, 50, 60, 70, 75, 80, 100, 110 e $120 \mathrm{~cm}$, e foram realizadas 10 medições com cada detector e determinado o desvio padrão de cada medição, ou seja, a incerteza do tipo A. Os ajustes de todas as curvas foram realizados com o uso do software OriginPro 8, e verificou-se que a resposta dos detectores não segue a lei do inverso do quadrado da distância, muito provavelmente porque se optou por não levar ainda em conta a influência da radiação espalhada, já que este estudo não foi conclusivo, sem o espectrômetro.

A resposta destes detectores estão representadas nas Figuras 4.38, 4.39, $4.40,4.41,4.42,4.43,4.44,4.45,4.46$ e 4.47. Todos apresentam um comportamento similar. 


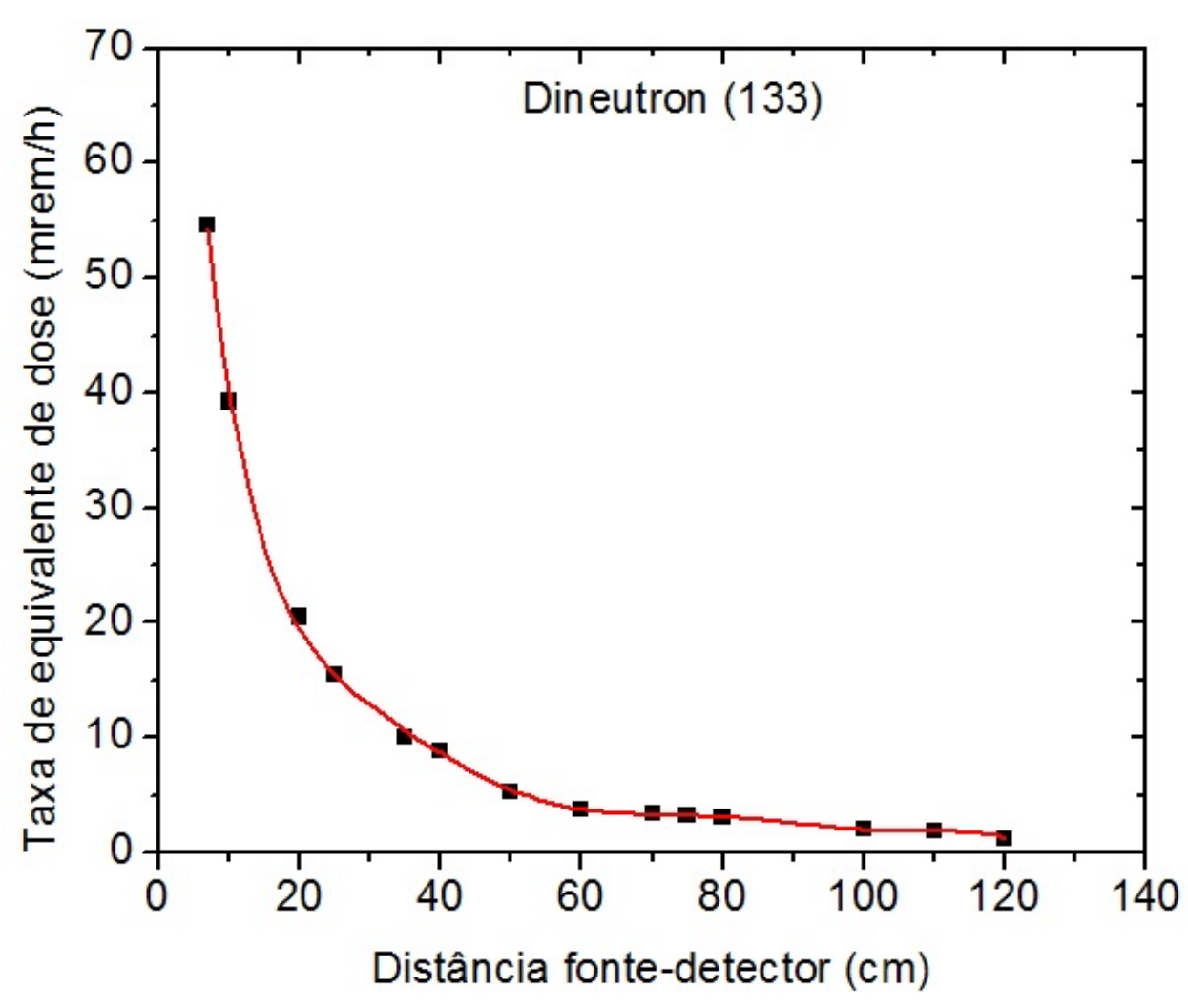

Figura 4.38: Resposta do detector Camberra Dineutron (133) em função da distância fonte-detector. A incerteza máxima foi de 5,0\%, não visível na curva.

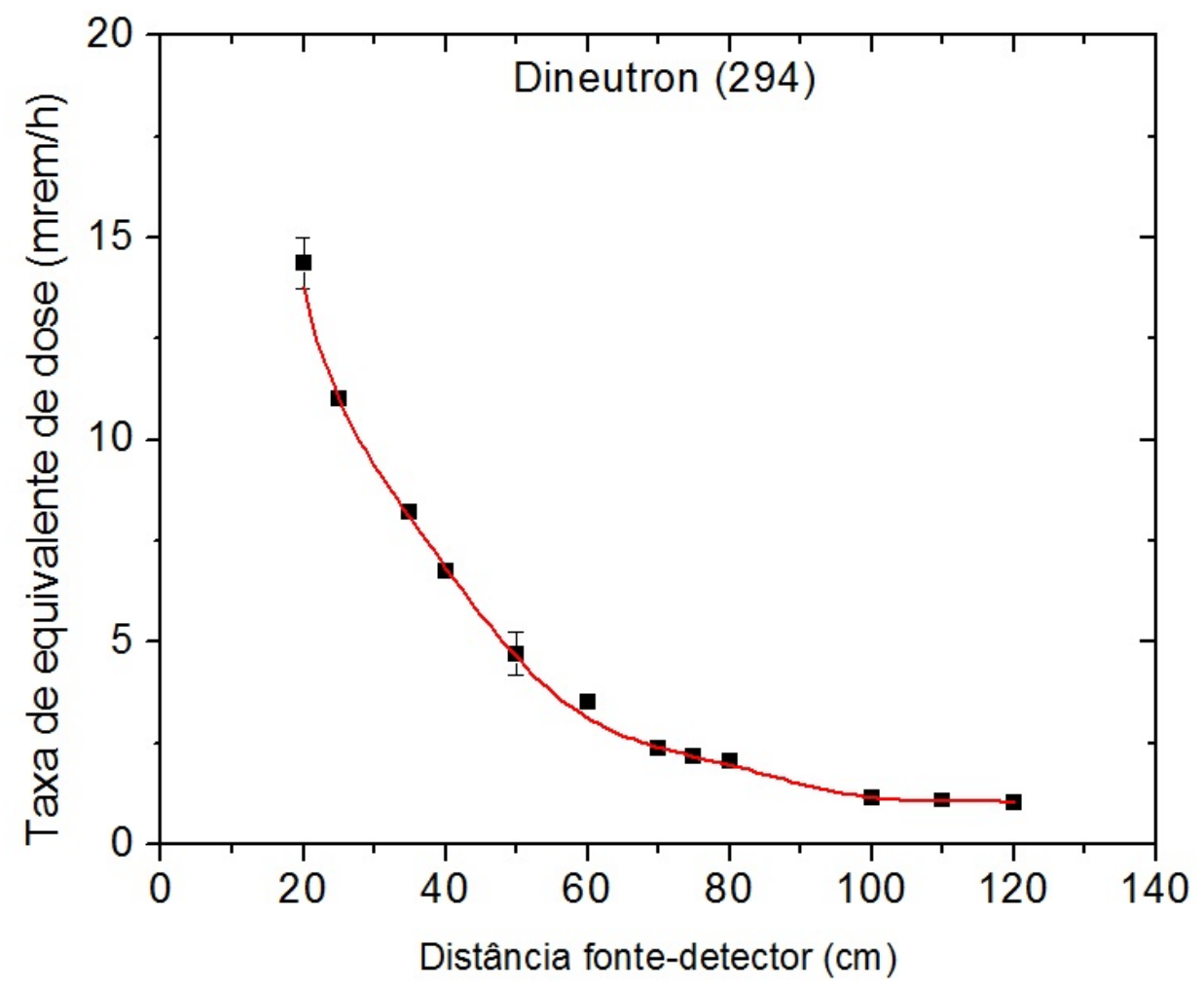

Figura 4.39: Resposta do detector Camberra Dineutron (294) em função da distância fonte-detector. 


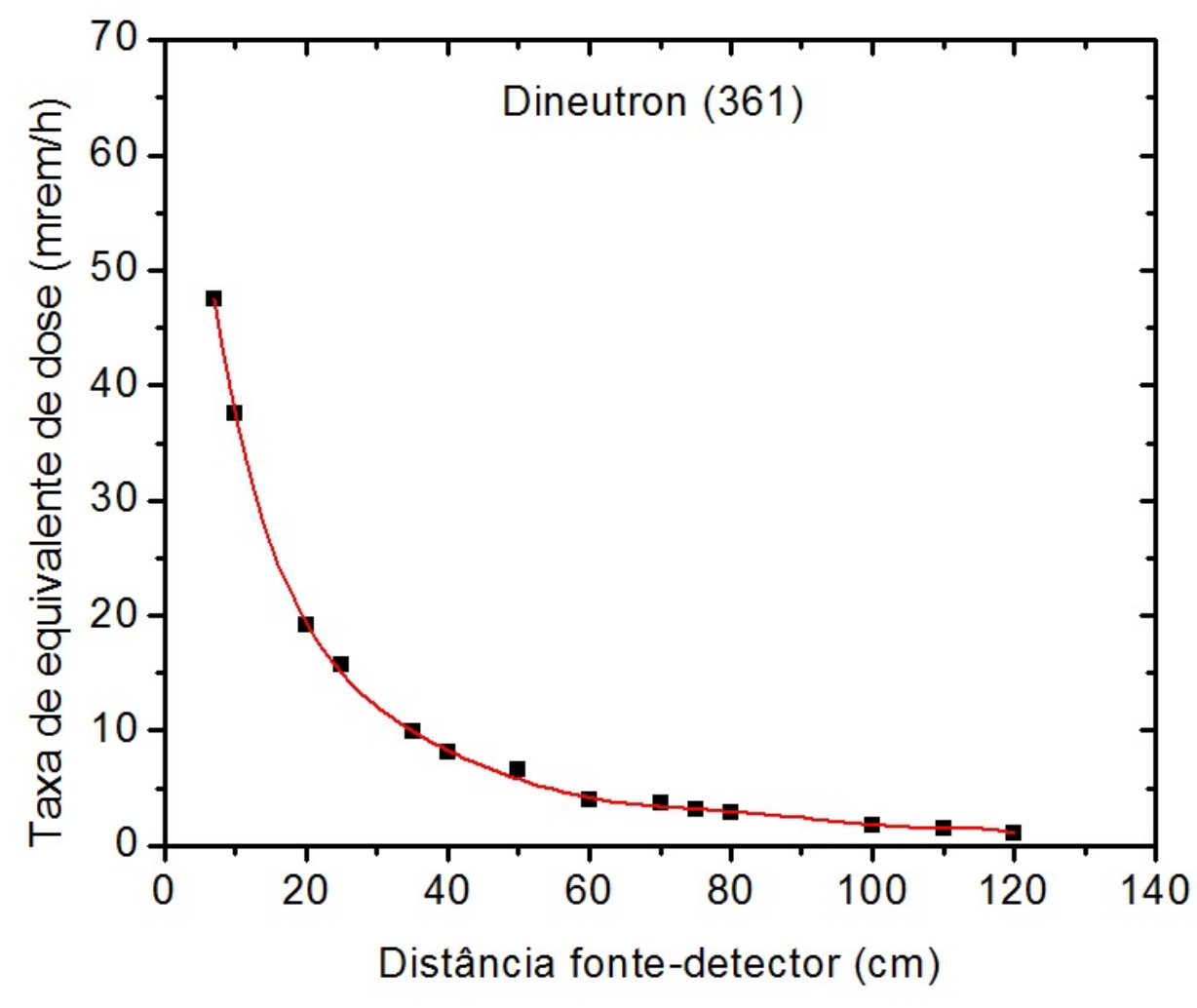

Figura 4.40: Resposta do detector Camberra Dineutron (361) em função da distância fonte-detector. A incerteza máxima foi de $2,8 \%$, não visível na curva.

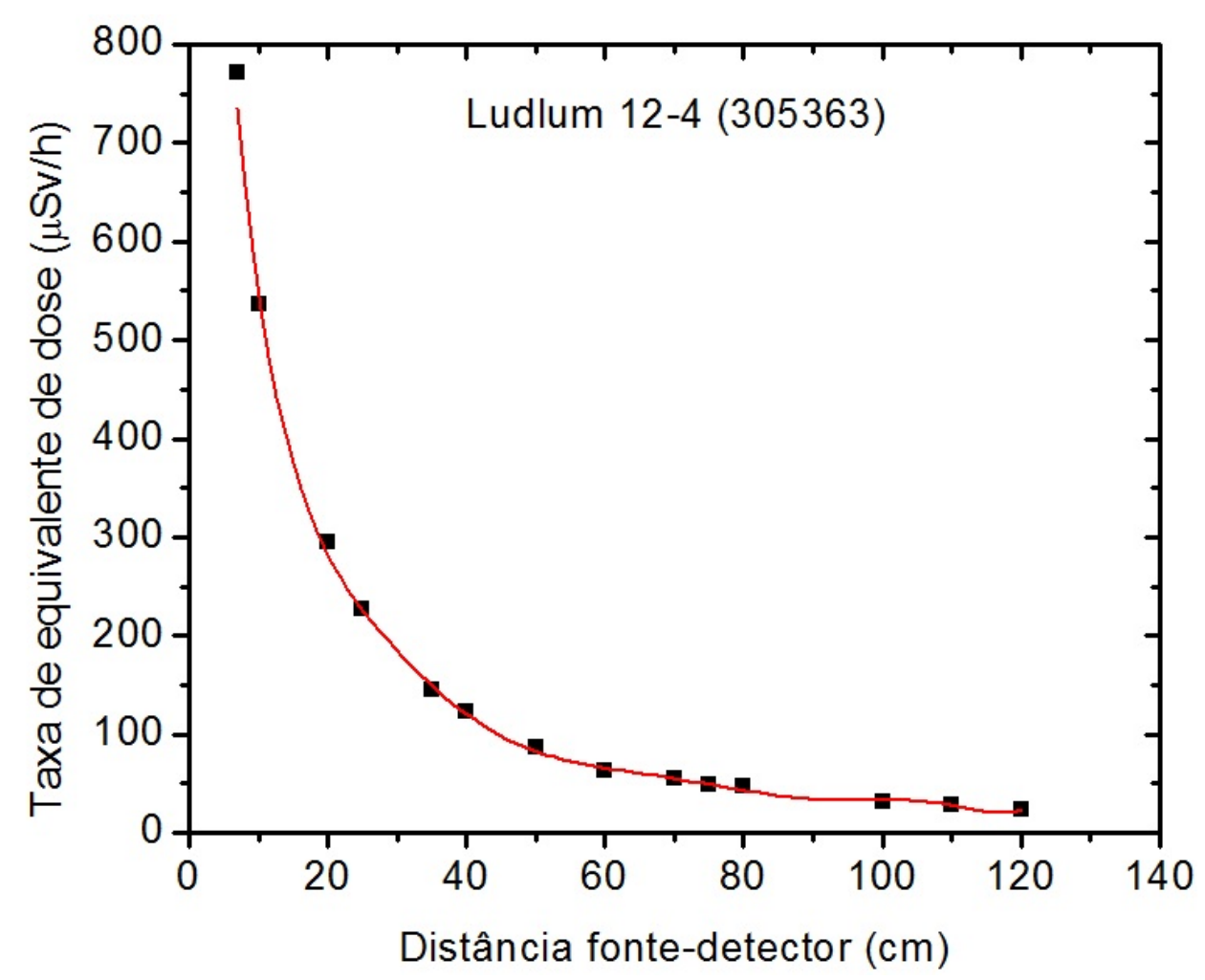

Figura 4.41: Resposta do detector Ludlum12-4(305363) em função da distância fonte-detector. A incerteza máxima foi de 7,8\%, não visível na curva. 


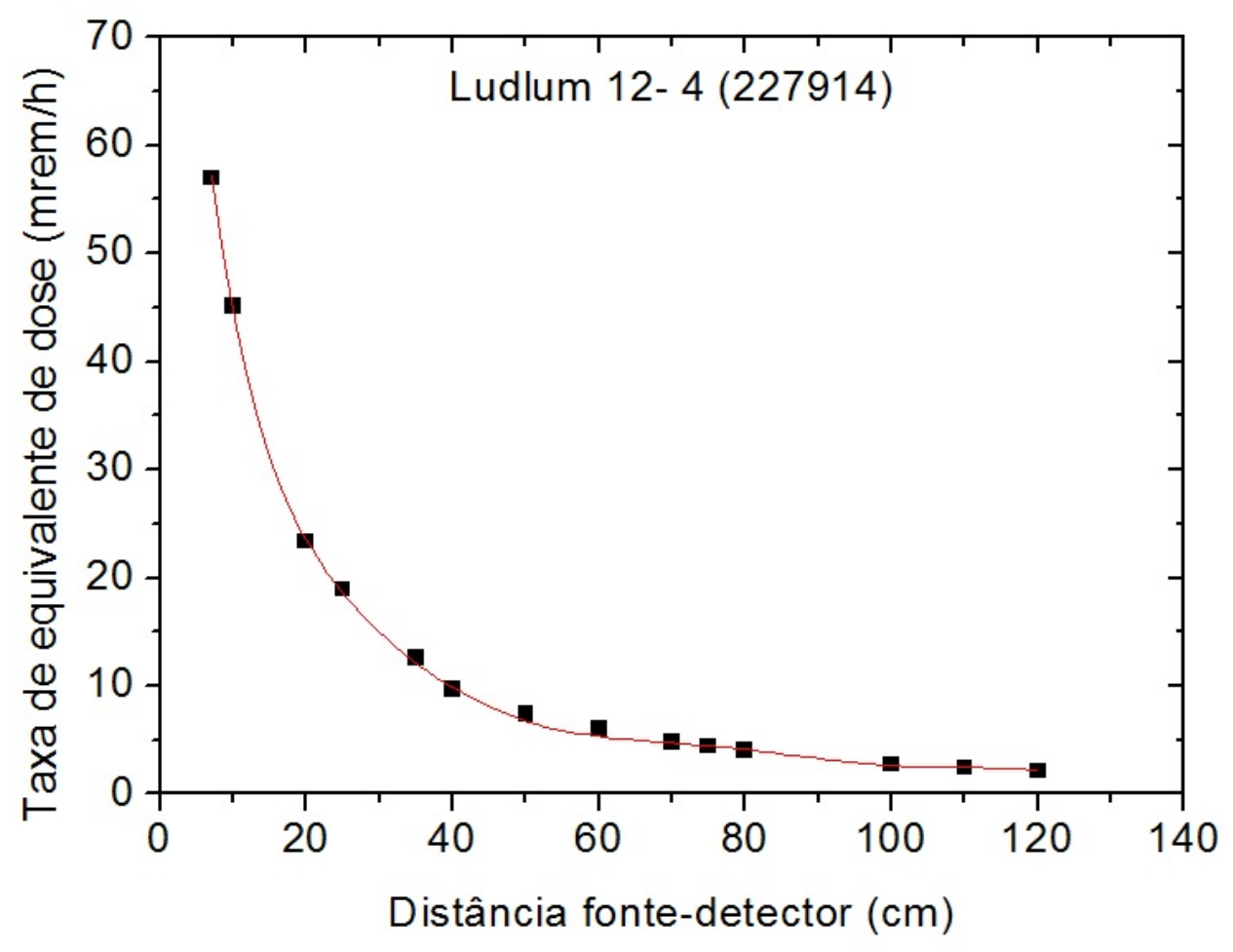

Figura 4.42: Resposta do detector Ludlum12-4 (227914) em função da distância fonte-detector. A incerteza máxima foi de 7,8\%, não visível na curva.

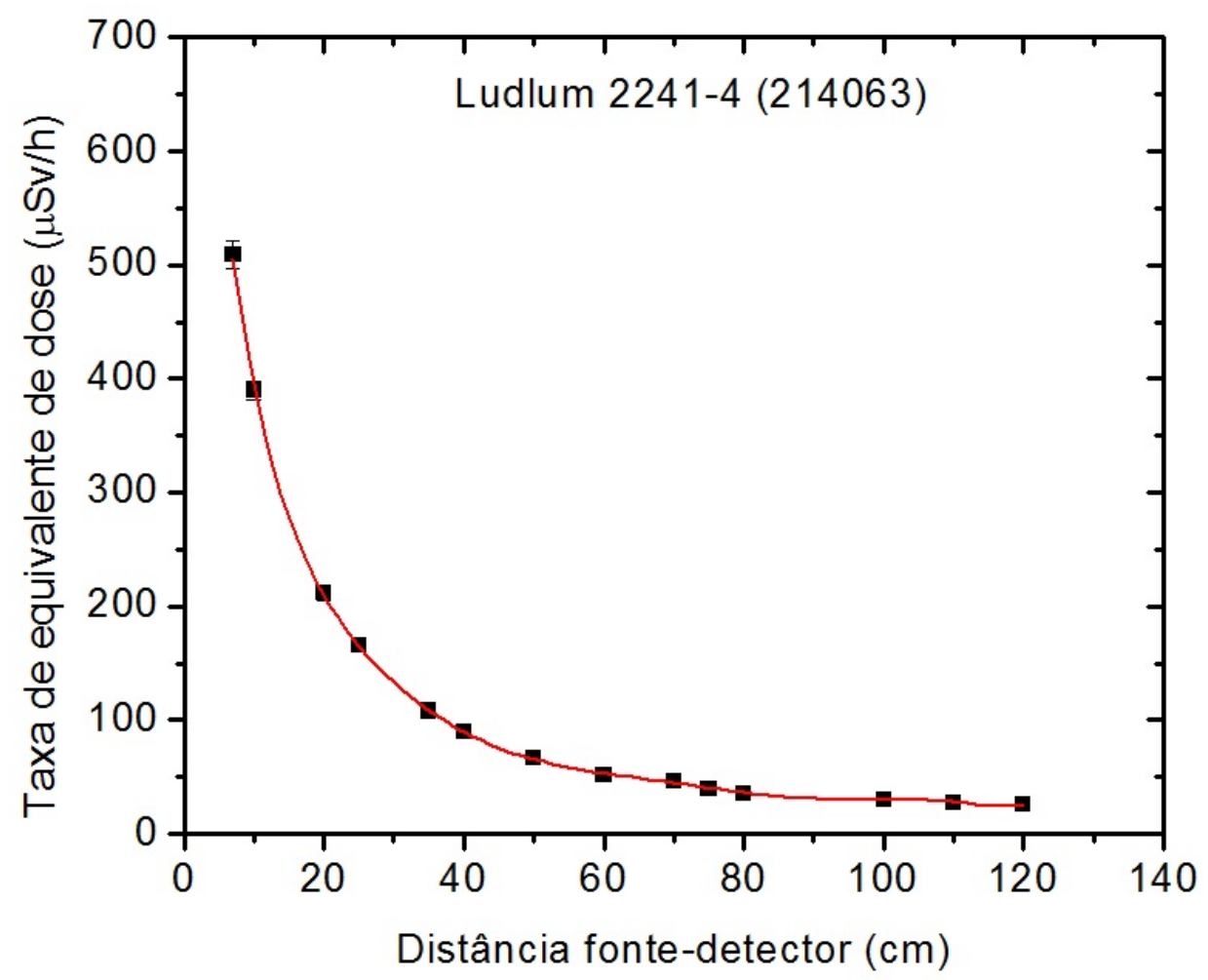

Figura 4.43: Resposta do detector Camberra Ludlum 2241-4 (214063) em função da distância fonte-detector. A incerteza máxima foi de 3,5\%, não visível na curva. 


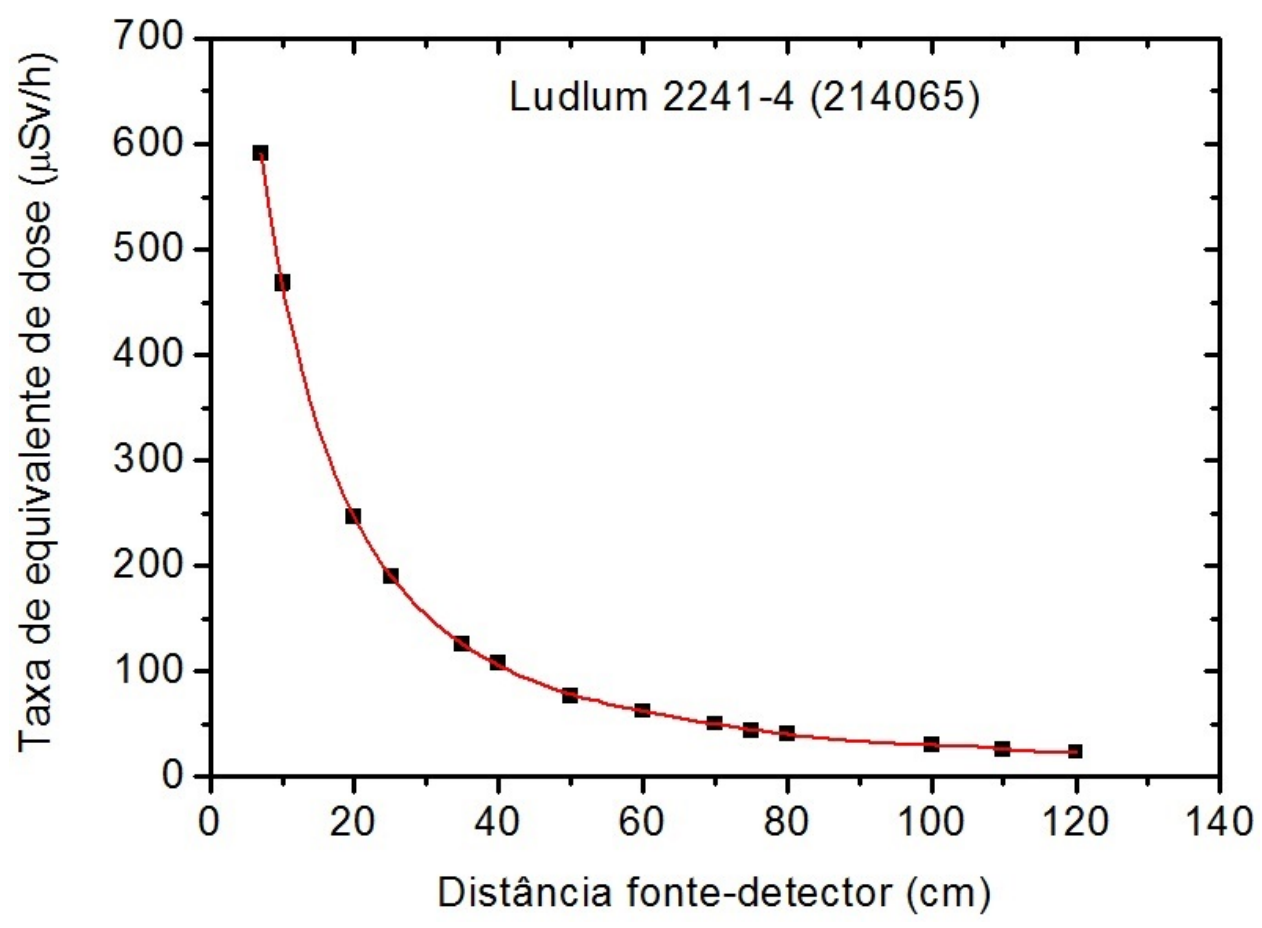

Figura 4.44: Resposta do detector Camberra Ludlum 2241-4 (214065) em função da distância fonte-detector. A incerteza máxima foi de 3,2\%, não visível na curva.

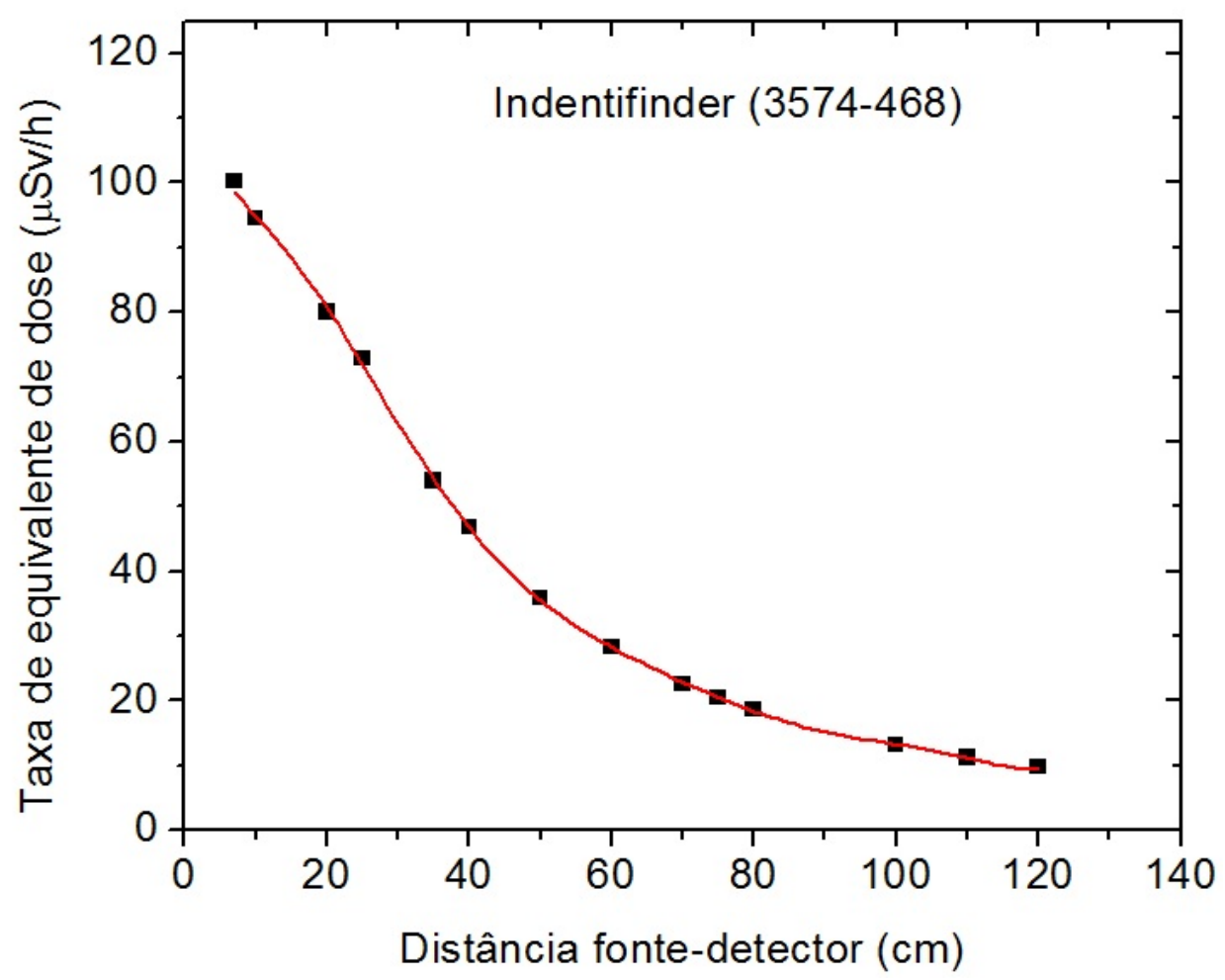

Figura 4.45: Resposta do detector Thermo Identifinder (3574-468) em função da distância fonte-detector. A incerteza máxima foi de $0,5 \%$, não visível na curva. 


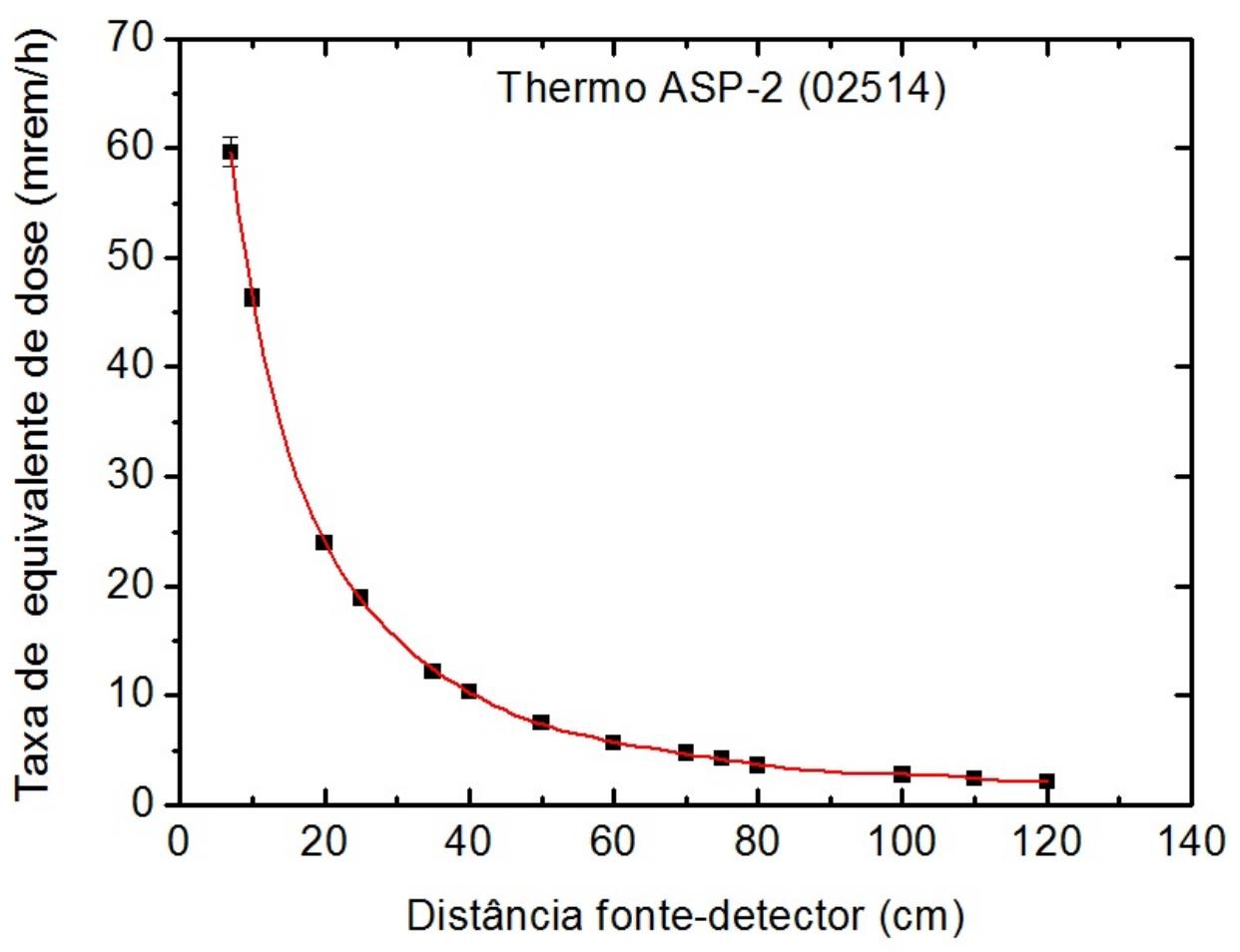

Figura 4.46: Mapeamento do campo de radiação com o detector de referência Thermo ASP-2( 02514).

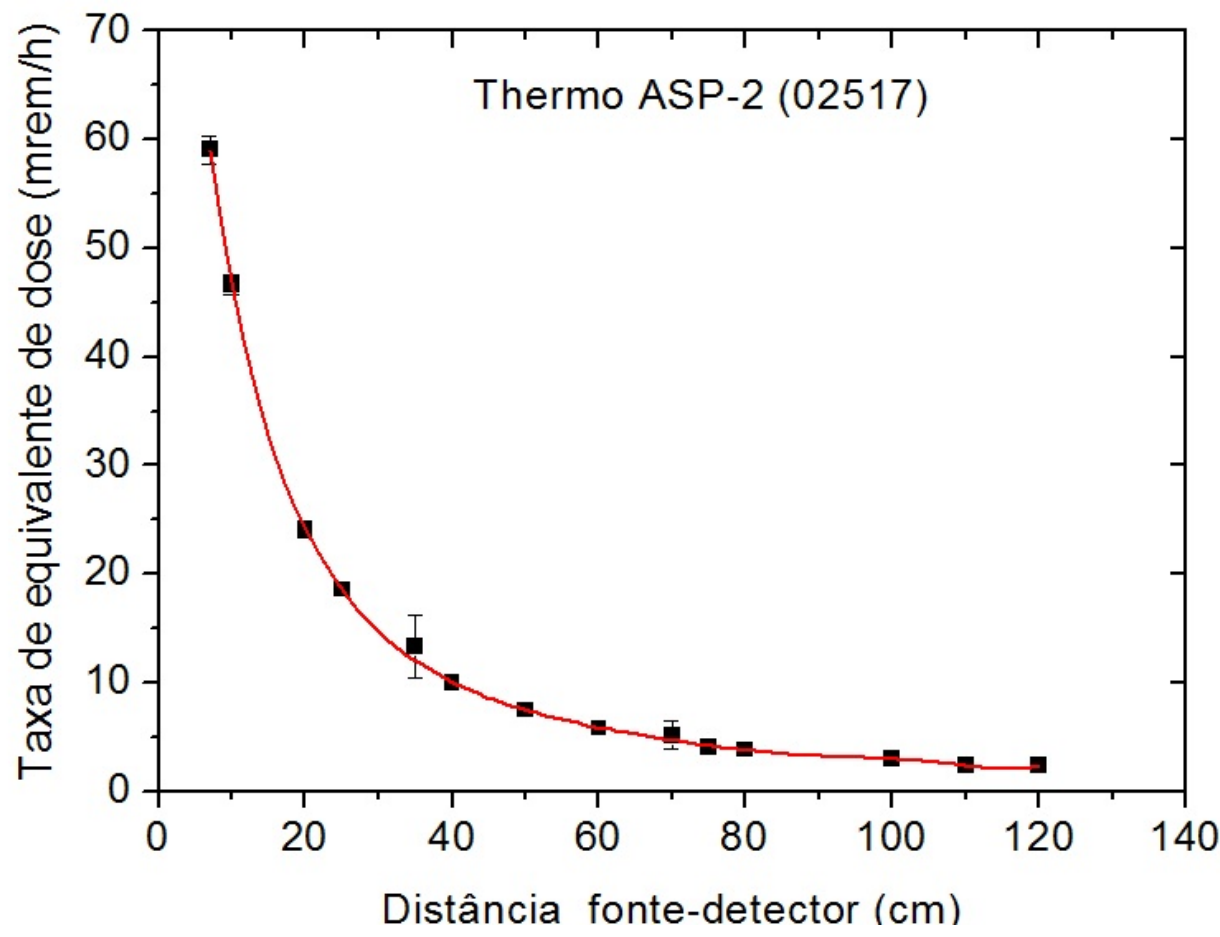

Figura 4.47: Mapeamento do campo de radiação com o detector de referência Thermo ASP-2 (02517). 
Na Tabela 4.9 pode-se verificar os valores dos coeficientes de correlação dos ajustes realizados, que variaram entre 0,9919 e 0,9999.

Tabela 4.9: Coeficientes de correlação obtidos das curvas de resposta dos detectores de nêutrons em função da distância fonte-detector.

\begin{tabular}{cccc}
\hline Marca & $\begin{array}{c}\text { Detector } \\
\text { modelo }\end{array}$ & Número de série & $\begin{array}{c}\text { Coeficiente de } \\
\text { correlação }\end{array}$ \\
\hline Camberra & Dineutron & 133 & 0,9966 \\
Camberra & Dineutron & 294 & 0,9992 \\
Camberra & Dineutron & 361 & 0,9919 \\
Ludlum & $12-4$ & 227914 & 0,9990 \\
Ludlum & $12-4$ & 305363 & 0,9948 \\
Ludlum & $2241-4$ & 274063 & 0,9980 \\
Ludlum & $2241-4$ & 274065 & 0,9999 \\
Thermo & Identifinder & $3574-468$ & 0,9997 \\
Thermo & ASP-2e/NRD & 02514 & 0,9997 \\
Thermo & ASP-2e/NRD & 02517 & 0,9998 \\
\hline
\end{tabular}

Os resultados obtidos nas medições utilizando os detectores de referência podem ser observados nas Figuras 4.46 e 4.47 e na Tabela 4.10 em detalhe. Pode-se notar que os comportamentos dos detectores de referência são semelhantes, com uma diferença percentual máxima de 6,9\% para a distância fonte-detector de $100 \mathrm{~cm}$. Na Figura 4.48 está representado o mapeamento do campo de radiação de nêutrons, utilizando o valor médio obtido dos dois sistemas de referência Thermo ASP-2 (02514) e (02517). 
Tabela 4.10: Mapeamento do campo de radiação utilizando os detectores de referência Thermo ASP-2.

\begin{tabular}{|c|c|c|c|c|}
\hline \multirow{2}{*}{$\begin{array}{l}\text { Distância } \\
\text { fonte- } \\
\text { detector } \\
\text { (cm) }\end{array}$} & $\begin{array}{c}\text { Thermo } \\
\text { ASP-2 } \\
(02514) \\
\text { (A) }\end{array}$ & $\begin{array}{c}\text { Thermo } \\
\text { ASP-2 } \\
\text { (02517) } \\
\text { (B) }\end{array}$ & $\begin{array}{l}\text { Valor } \\
\text { médio }\end{array}$ & \multirow[t]{2}{*}{$\begin{array}{c}\text { Diferença } \\
\text { percentual } \\
\frac{A-B}{A} \times 100 \\
(\%)\end{array}$} \\
\hline & \multicolumn{3}{|c|}{ Taxa de equivalente de dose (mrem/h) } & \\
\hline 7 & $59,7 \pm 1,4$ & $59,1 \pm 1,3$ & $59,4 \pm 1,9$ & 1,0 \\
\hline 10 & $46,3 \pm 0,8$ & $46,6 \pm 1,0$ & $46,5 \pm 1,3$ & 0,6 \\
\hline 20 & $24,0 \pm 0,4$ & $24,2 \pm 0,8$ & $24,1 \pm 0,9$ & 0,8 \\
\hline 25 & $18,9_{ \pm 0,4}$ & $18,6 \pm 0,4$ & $18,7 \pm 0,6$ & 1,6 \\
\hline 35 & $12,2 \pm 0,5$ & $12,4 \pm 0,5$ & $12,3 \pm 0,7$ & 1,6 \\
\hline 40 & $10,3 \pm 0,6$ & $10,0 \pm 0,3$ & $10,2 \pm 0,5$ & 2,9 \\
\hline 50 & $7,5 \pm v 0,3$ & $7,5 \pm 0,2$ & $7,5 \pm 0,4$ & 0,0 \\
\hline 60 & $5,7 \pm 0,2$ & $5,8 \pm 0,4$ & $5,7 \pm 0,4$ & 1,7 \\
\hline 70 & $4,7 \pm 0,3$ & $4,7 \pm 0,1$ & $4,7 \pm 0,3$ & 0,0 \\
\hline 75 & $4,3 \pm 0,3$ & $4,1 \pm 0,4$ & $4,2 \pm 0,5$ & 4,7 \\
\hline 80 & $3,5 \pm 0,3$ & $3,7 \pm 0,2$ & $3,6 \pm 0,4$ & 5,7 \\
\hline 100 & $2,7 \pm 0,2$ & $2,9 \pm 0,2$ & $2,8 \pm 0,3$ & 6,9 \\
\hline 110 & $2,4 \pm 0,1$ & $2,4 \pm 0,2$ & $2,4 \pm 0,2$ & 0,0 \\
\hline 120 & $2,2 \pm 0,1$ & $2,2 \pm 0,1$ & $2,2 \pm 0,1$ & 0,0 \\
\hline
\end{tabular}

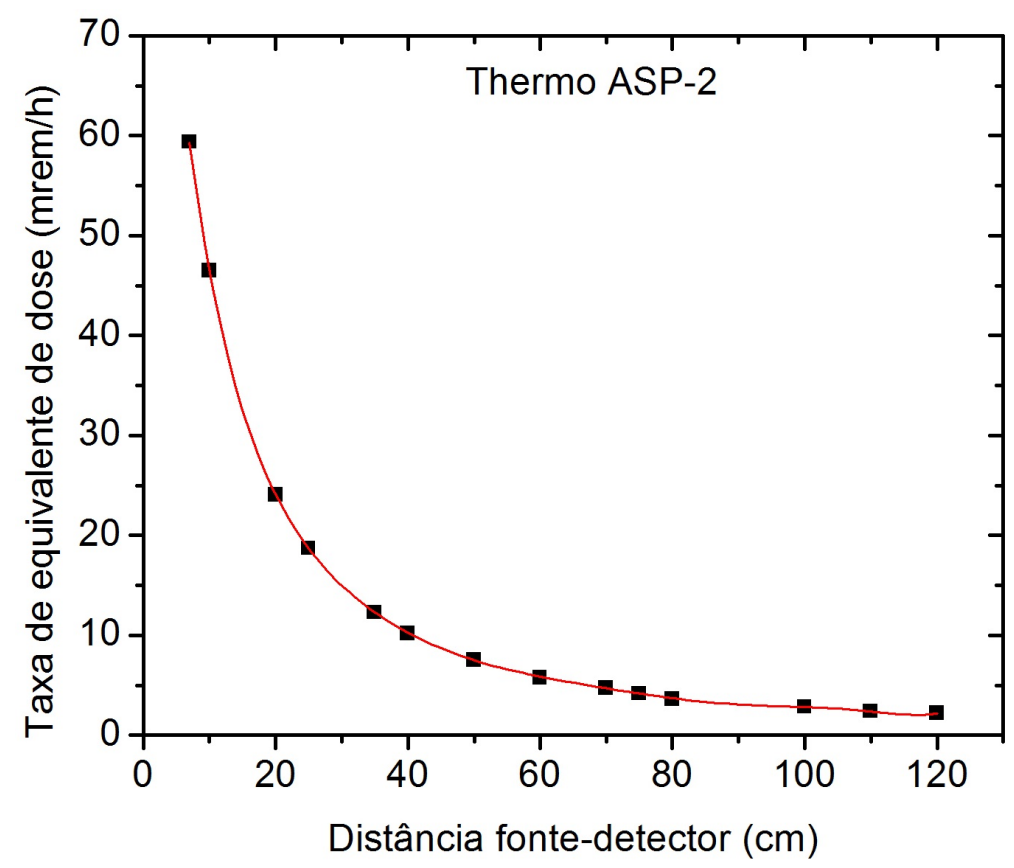

Figura 4.48: Mapeamento do campo de radiação de nêutrons, utilizando os dois sistemas de referência Thermo ASP-2 (02514) e (02517). 
A partir destes dados foram calculados os valores das distâncias a serem utilizados nos testes de detectores de nêutrons, que são apresentados na Tabela 4.11.

Tabela 4.11: Condições de testes dos detectores de radiação de nêutrons.

\begin{tabular}{|c|c|c|}
\hline \multicolumn{2}{|c|}{ Taxa de equivalente de dose ambiente } & \multirow{2}{*}{$\begin{array}{c}\text { Distância } \\
\text { fonte-detector } \\
\text { (cm) }\end{array}$} \\
\hline$(\mu \mathbf{S v} / \mathbf{h})$ & (mrem/h) & \\
\hline 25 & 2,5 & 116,0 \\
\hline 50 & 5 & 67,1 \\
\hline 100 & 10 & 40,7 \\
\hline 200 & 20 & 23,4 \\
\hline 300 & 30 & 16,2 \\
\hline 350 & 35 & 13,9 \\
\hline 400 & 40 & 12,0 \\
\hline 500 & 50 & 9,0 \\
\hline 600 & 60 & 6,7 \\
\hline
\end{tabular}

\subsection{Testes dos detectores de radiação de nêutrons}

Três detectores de radiação de nêutrons: Ludlum 12-4 (227914), Ludlum 2241-4 (274065) e Thorn EMI Mk7 (246), sendo que os dois últimos não foram estudados no presente trabalho, foram testados nos feixes de nêutrons mapeados com os sistemas de referência.

Cada um dos detectores foi posicionado às distâncias padrões para as taxas de equivalente de dose ambiente de $25 \mu \mathrm{Sv} / \mathrm{h}$ a $600 \mu \mathrm{Sv} / \mathrm{h}$ e foram obtidos os resultados apresentados na Tabela 4.12. 
Tabela 4.12: Testes dos detectores de nêutrons.

\begin{tabular}{|c|c|c|c|c|c|}
\hline \multicolumn{2}{|c|}{$\begin{array}{c}\text { Taxa de equivalente de } \\
\text { dose ambiente }\end{array}$} & \multirow{2}{*}{$\begin{array}{l}\text { Distância } \\
\text { fonte- } \\
\text { detector } \\
\text { (cm) }\end{array}$} & \multirow{2}{*}{$\begin{array}{c}\text { Ludlum } \\
12-4 \\
(227914) \\
\text { (mrem/h) }\end{array}$} & \multirow{2}{*}{$\begin{array}{c}\text { Ludlum } \\
2241-4 \\
(274065) \\
(\mu \mathrm{Sv} / \mathrm{h})\end{array}$} & \multirow{2}{*}{$\begin{array}{c}\text { Thorn emi } \\
\text { Mk } 7 \\
(246) \\
\text { (mrem/h) }\end{array}$} \\
\hline ( $\mu \mathbf{S v} / \mathbf{h})$ & (mrem/h) & & & & \\
\hline 25 & 2,5 & 116,0 & $2,5 \pm 0,1$ & $24,5 \pm 0,4$ & $2,1 \pm 0,1$ \\
\hline 50 & 5 & 67,1 & $4,9 \pm 0,0$ & $48,7 \pm 0,5$ & $4,6 \pm 0,2$ \\
\hline 100 & 10 & 40,7 & $9,9 \pm 0,0$ & $98,8 \pm 1,5$ & $8,0 \pm 0,2$ \\
\hline 200 & 20 & 23,4 & $19,2 \pm 0,1$ & $195,2 \pm 1,3$ & $18,5 \pm 0,2$ \\
\hline 300 & 30 & 16,2 & $29,5 \pm 0,1$ & $294,3 \pm 0,9$ & $27,9 \pm 0,4$ \\
\hline 350 & 35 & 13,9 & $34,5 \pm 0,0$ & $343,9_{ \pm} 4,3$ & $33,5 \pm 1,2$ \\
\hline 400 & 40 & 12,0 & $39,7 \pm 0,2$ & $396,2 \pm 5,7$ & $38,0 \pm 0,3$ \\
\hline 500 & 50 & 9,0 & $49,5 \pm 0,0$ & $497,1 \pm 0,2$ & $47,3 \pm 0,4$ \\
\hline 600 & 60 & 6,7 & $59,7 \pm 0,0$ & $593,6 \pm 6,8$ & $56,7 \pm 0,5$ \\
\hline
\end{tabular}

Pode-se observar que, dos três detectores submetidos aos testes, somente o detector Thorn EMI Mk7 (246) apresentou a resposta com diferença máxima de $20 \%$ em relação aos valores nominais de taxa de equivalente de dose no caso da distância fonte-detector de 40,7 cm. Isto significa que não há necessidade de uma calibração extra, pois as respostas dos detectores apresentaram resultados dentro dos limites recomendados pela norma. 


\section{Capítulo 5}

\section{Conclusões}

$\mathrm{Na}$ ala dos laboratórios de calibração de detectores com radiação gama (Bunker), localizada no andar inferior do Laboratório de Calibração de Instrumentos do IPEN, uma sala foi reformada e adaptada para ser o Laboratório de Testes com Nêutrons (LTN). Para isto, as paredes foram forradas com material adequado (drywall) para diminuir a ocorrência de radiação espalhada da fonte de nêutrons, e foi criada uma sala de controle do sistema de exposição e posicionamento da fonte e para o operador responsável pelos procedimentos de testes/calibração dos instrumentos.

Foi desenvolvida uma blindagem adequada para a fonte de ${ }^{241} \mathrm{Am}(\mathrm{Be})$, previamente calibrada no Laboratório Nacional de Metrologia das Radiações lonizantes (LNMRI), num sistema padrão primário.

Um arranjo de irradiação automatizado foi implantado, possibilitando a variação da distância fonte-detector por meio de um comando à distância por um painel eletrônico localizado na sala de controle. Um sistema de monitoração possibilita a visualização da indicação do detector e a distância fonte-detector, durante os procedimentos de testes dos monitores portáteis.

Por meio do levantamento radiométrico foi possível avaliar as condições existentes no LTN e a sua classificação. Os resultados mostraram que os níveis de radiação estão perfeitamente dentro dos limites recomendados pelas normas.

A estabilidade a curto e a médio prazo da resposta de diversos tipos 
de detectores de radiação de nêutrons foi estudada e verificou-se que todos apresentaram resultados dentro do limite recomendado pelas normas.

A influência da radiação espalhada foi determinada por duas técnicas: Método de Monte Carlo e método experimental, com a utilização de um cone de sombra e um detector de radiação de nêutrons portátil calibrado no LNMRI. O procedimento recomendado neste caso é utilizar um espectrômetro com o cone de sombra, de modo que o resultado não foi conclusivo, apesar de ser comparável com o obtido com o método de simulação.

Como os procedimentos dos testes são realizados pela técnica da substituição, a radiação espalhada não foi levada neste caso em consideração. Entretanto, para irradiação de dosímetros, por exemplo de estado sólido, é imprescindível o conhecimento da influência da radiação espalhada no feixe de radiação.

A modelagem computacional do LTN foi realizada de acordo com as dimensões baseadas nas plantas baixas do laboratório; foram levados em consideração todos os materiais que compõem o laboratório com o propósito de obter uma simulação realista. Desta forma, com os resultados das simulações foi possível concluir que a estrutura do LTN está em concordância com os resultados obtidos em outros laboratórios que oferecem o mesmo serviço.

Foi realizado o mapeamento do campo de radiação com dois sistemas de referência, calibrados no LNMRI, e assim foram determinadas as distâncias de testes dos instrumentos.

Finalmente, foram testados alguns detectores portáteis nas condições estabelecidas, obtendo-se valores aceitáveis em relação às normas internacionais.

O objetivo proposto inicialmente do trabalho foi cumprido de modo adequado.

Os resultados obtidos dos ensaios foram muitos bons, de modo que permitem a avaliação dos equipamentos testados, fornecendo parâmetros consistentes para futuros ensaios de equipamentos. 


\section{Referências Bibliográficas}

ALBERTS, W., DIETZ, E., e GULDBAKKE, S., 1996. Aspects of combining Albedo and etched track techniques for use in individual neutron monitoring. Radiation Protection Dosimetry, 46(1):31-36. Citado na pág. 1

AMERSHAM, 1986. AMERSHAM Products Catalog. UK. Citado na pág. xi, 24

BAILEY, S., 2000. Air crew radiation exposure - An overview. Nuclear News, 4(3):32-40. Citado na pág. 1

BRIESMEISTER, J., 1993. MCNP - A general Monte Carlo N-particle transport code. Los Alamos National Laboratory Report LA-12625-M (Los Alamos, NM). Citado na pág. 19

BYRNE, J., 2011. Neutrons, Nuclei, and Matter: An Exploration of the Physics of Slow Neutrons. Dover Publications, $2^{a}$ edition. Citado na pág. 4

CNEN, 2011. Diretrizes Básicas de Proteção Radiológica. Technical Report NN-3.02/004, COMISSÃO NACIONAL DE ENERGIA NUCLEAR, Rio de Janeiro. Citado na pág. 2, 31, 42, 43, 44, 47

DANTAS, M., 2013. Estudo do Espalhamento e da Atenuação do Ar em Função da Distância para Irradiações com Fonte de ${ }^{241} \mathrm{Am}(\mathrm{Be})$ no Salão de baixo Espalhamento do Laboratório de Nêutrons. PhD thesis, Instituto de Radioproteção e Dosimetria, Comissão Nacional de Energia Nuclear, Rio de Janeiro. Citado na pág. 8

FRATIN, L., 1993. Dosimetria de Nêutrons. PhD thesis, Instituto de Física, Universidade de São Paulo. Citado na pág. 17

GRESSIER, V., LACOSTE, V., LeBRETON, L., MULLER, H., PELCOT, G., BAKALI, M., FERNÁNDEZ, F., TÓMAS, M., ROBERTS, N., THOMAS, D., REGINATTO, M., WIEGEL, B., e WITTSTOCK, J., 2004. Characterization of the IRSN Canel/T400 facility producing realistic neutron fields for calibration and test purposes. Radiation Protection Dosimetry, 110(1-4):523-527. Citado na pág. 2

IAEA, 2000. INTERNATIONAL ATOMIC ENERGY AGENCY. Calibration of radiation protection monitoring instruments. Technical Report IAEA SRS 16, IAEA, Vienna. Citado na pág. xi, 2, 20, 21, 53, 64, 67

ICRP, 1991. INTERNATIONAL COMMISSION ON RADIATION UNITS AND MEASUREMENTS. 1990 Recommendations of the International 
Commission on Radiological Protection. Technical Report ICRP 60, ICRP, New York. Citado na pág. xvi, 16

ICRP, 1996. INTERNATIONAL COMMISSION ON RADIATION UNITS AND MEASUREMENTS. Conversion Coefficients for Use in Radiological Protection against External Radiation. Technical Report ICRP 74, ICRP, Oxford. Citado na pág. xvi, 14, 46, 49

ICRP, 1998. INTERNATIONAL COMMISSION ON RADIATION UNITS AND MEASUREMENTS. Fundamental Quantities and Units for Ionizing Radiation. Technical Report ICRU Report 60, ICRP, Bethesda. Citado na pág. 11, 12

ICRP, 2001. INTERNATIONAL COMMISSION ON RADIATION UNITS AND MEASUREMENTS. Determination of Operational Dose Equivalent Quantities for Neutrons. Technical Report ICRU 66, ICRP, England. Citado na pág. 11

ICRP, 2007. INTERNATIONAL COMMISSION ON RADIATION UNITS AND MEASUREMENTS. The 2007 Recommendations of the International Commission on Radiological Protection. Technical Report ICRP 37, ICRP, New York. Citado na pág. xvi, 15

INMETRO, 2012. INSTITUTO NACIONAL DE METROLOGIA, QUALIDADE e TECNOLOGIA: Vocabulário Internacional de Metrologia: Conceitos Fundamentais e Gerais e Termos Associados (VIM 2012). INMETRO, $1^{a}$ luso-brasileira edition. Citado na pág. 20, 22

ISO, 1996. INTERNATIONAL ORGANIZATION FOR STANDARDIZATION. Procedures for Calibrating and Determining the Response of Neutron Protection Purposes. Technical Report ISO 10647, ISO, Geneva. Citado na pág. 18,19

ISO, 2000. INTERNATIONAL ORGANIZATION FOR STANDARDIZATION. Neutron Radiations. Calibration Fundamentals of Radiation Protection Devices related to the Basic Quantities characterizing the Radiation Field. Technical Report ISO 8529, Part 2, ISO, Geneva. Citado na pág. 2, 3, 16, 17, 18

ISO, 2001. INTERNATIONAL ORGANIZATION FOR STANDARDIZATION. Reference Neutron Radiations. Calibration Fundamentals of Radiation Protection Devices related to the Basic Quantities characterizing the Radiation Field. Technical Report ISO 8529, Part 1, ISO, Geneva. Citado na pág. $3,23,44,48$

KHABAZ, R. e HAKIMABAD, H., 2011. Determination of 241Am-Be Spectra using Bonner Sphere Spectrometer by Applying Shadow Cone Technique in Calibration. Journal of Applied Sciences, 11(15):2849-2854. Citado na pág. xi, 18

KNOLL, G., 2010. Radiation Detection and Measurement. John Wiley \& Sons, New York, $4^{a}$ edition. Citado na pág. 10 
LAMARSH, J., 1983. Nuclear Engineering. Menlo Park, California: Addison-Wesley, $2^{a}$ edition. Citado na pág. 7

MADI FILHO, T., 1999. Desenvolvimento de Detectores de Nêutrons usando Sensor tipo Barreira de Superfície com Conversor $(n, p)$ e Conversor $(n, \alpha)$. $\mathrm{PhD}$ thesis, Instituto de Pesquisas Energéticas e Nucleares, Universidade de São Paulo, Brasil. Citado na pág. 8, 9

McCONN Jr, R., GESH, C., PAGH, R., RUCKER, R., e WILLIAMS, R., 2011. Radiation Portal Monitor Project. Compendium of Material Composition Data for Radiation Transport Modeling. Technical Report PNNL-15870, Rev. 1, Pacific Northwest National Laboratory, Richland. Citado na pág. 44

McDONALD, J., AKABANI, G., e LOESCH, R., 1993. Intercomparison of high-energy neutron personnel dosimeters. Em Proceedings of the Workshop on Measurement Quality Assurance for lonizing Radiation, pgs. 159-164. Citado na pág. 2

MURRAY, R., 2004. Energia Nuclear, (traduzido por A. H. HEFFER DA COSTA). Hermus, São Paulo, $2^{a}$ edition. Citado na pág. 33

NCRP, 1971. Protection against Neutron Radiation. Technical Report NCRP, 38, NATIONAL COUNCIL ON RADIATION PROTECTION AND MEASUREMENTS, Washington D.C. Citado na pág. xvi, 33

OLIVEIRA, K., 2011. Estudo de um Sistema de Imagem para Radiografias com Nêutrons Rápidos. PhD thesis, Instituto Alberto Luiz Coimbra e Universidade Federal do Rio de Janeiro. Citado na pág. 34

TAKADA, C., YOSHIDA, T., SAITOH, K., TSUJIMURA, N., e MIKAMI, S., 2011. Calibration of neutron measuring devices in differently sized rooms with different-structural irradiation apparatuses. Em Proceedings of IRPA 11. International Congress of the International Radiation Protection Association, pgs. 1-9. Citado na pág. 50, 51

TURNER, J., 2007. Atoms, Radiation and Radiation Protection. Wiley-VCH, Weinheim, $3^{a}$ edition. Citado na pág. $x v i, 7$

VILELA, E., 1996. Desenvolvimento e Calibração de um Dosímetro Pessoal para Nêutrons utilizando Detectores Sólidos de Traços Nucleares. PhD thesis, Instituto de Pesquisas Energéticas e Nucleares, Universidade de São Paulo, Brasil. Citado na pág. 18

X-5 Monte Carlo Team, 2008. MCNP - A General Monte Carlo N-particle Transport Code, Version 5, Volume I: Overview and Theory. LA-UR-03-1987, Los Alamos National Laboratory (revised 2008). Citado na pág. $29,44,49$

ZAMBONI, C., 2007. Fundamentos da Física de Nêutrons. Livraria da Física, São Paulo, $1^{a}$ edition. Citado na pág. xvi, 4, 5, 6, 7, 9, 13, 19 